Implementação de mecanismos tolerantes a falhas em uma arquitetura SOA com QoS

\author{
Edvard Martins de Oliveira
}




\title{
Implementação de mecanismos tolerantes a falhas em uma arquitetura SOA com QoS
}

\author{
Edvard Martins de Oliveira
}

Orientador: Prof. Dr. Júlio Cézar Estrella

Dissertação apresentada ao Instituto de Ciências Matemáticas e de Computação - ICMC-USP, como parte dos requisitos para obtenção do título de Mestre em Ciências - Ciências de Computação e Matemática Computacional. VERSÃO REVISADA 
Ficha catalográfica elaborada pela Biblioteca Prof. Achille Bassi e Seção Técnica de Informática, ICMC/USP, com os dados fornecidos pelo(a) autor(a)

Oliveira, Edvard Martins de

Implementação de mecanismos tolerantes a falhas em uma arquitetura SOA com QoS / Edvard Martins de Oliveira; orientador Júlio Cézar Estrella. -- São Carlos, 2013. $65 \mathrm{p}$.

Dissertação (Mestrado - Programa de Pós-Graduação em Ciências de Computação e Matemática Computacional) -- Instituto de Ciências Matemáticas e de Computação, Universidade de São Paulo, 2013.

1. Web Services. 2. Quality of Service. 3. Service Oriented Architecture. 4. Fault Tolerance. 5. Avaliação de Desempenho. I. Estrella, Júlio Cézar, orient. II. Título. 
We don't need no education.

Pink Floyd 
Dedico este trabalho aos meus pais, irmão, namorada, e amigos. 


\section{Agradecimentos}

Agradeço a Deus. Agradeço a meus pais e irmão pelo apoio desde sempre, à minha namorada Andressa pelo carinho e companheirismo, ao prof. Júlio pela orientação e paciência, aos demais professores, aos meus colegas de laboratório pelas conversas, risadas e troca de conhecimentos, aos meus amigos de república e aos amigos de toda a vida. Muito obrigado. 
Esta dissertação de mestrado tem como objetivo avaliar a integração de políticas de tolerância a falhas em uma arquitetura de Web Services com múltiplos módulos. A arquitetura utilizada é denominada WSARCH, e foi desenvolvida para o estudo das relações e interoperabilidade entre serviços. Os mecanismos de tolerância a falhas foram integrados aos módulos da arquitetura, testados, comparados e avaliados. A avaliação de desempenho mostrou que os mecanismos de tolerância a falhas introduzidos foram eficientes e apresentaram resultados adequados. As técnicas de reputação utilizadas na seleção de serviço atuaram satisfatoriamente e foram consideradas um importante avanço nos mecanismos da arquitetura. 
This master's thesis aims to evaluate the integration of fault tolerance mechanisms in a Web Services architecture with multiple modules. The architecture used is named WSARCH and was developed for the study of interactions and interoperability of services. WSARCH is an architecture conceived to receive tests and experiments involving concepts of Web Services. The fault tolerance tools were integrated in the architecture, tested, evaluated and comparated. The performance evaluation showed that the fault tolerance mechanisms introduced were efficient and presented appropriate results. The reputation techniques utilized in service selection operated successfully and were considered an important advance in the mechanisms of the architecture. 
Resumo i

Abstract $\quad$ ii

Lista de Figuras $\quad$ vi

Lista de Tabelas vii

Lista de Abreviaturas e Siglas viii

1 Introdução 1

1.1 Considerações iniciais . . . . . . . . . . . . . . . . . . . . . . 1

1.2 Contextualização . . . . . . . . . . . . . . . . . . . . . 1

1.3 Motivação . . . . . . . . . . . . . . . . . . . . . 3

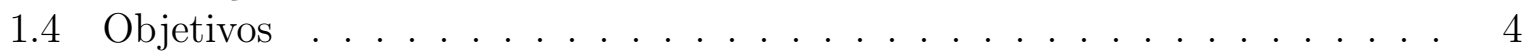

1.5 Organização do texto . . . . . . . . . . . . . . . . 4

2 Fundamentação Teórica 5

2.1 Considerações Iniciais . . . . . . . . . . . . . . . . . . . . . . . . . . . . . . . . . . . . . . . . . . . .

2.2 Web Services . . . . . . . . . . . . . . . . . 5

2.3 Tolerância a Falhas . . . . . . . . . . . . . . . . . . . . . . 8

2.4 Qualidade de Serviço . . . . . . . . . . . . . . . . . . . . . . . . . . . . . . . . . . . . . . . . . . .

2.5 Trabalhos Relacionados . . . . . . . . . . . . . . . . . . 13

2.6 Considerações Finais . . . . . . . . . . . . . . . . . . . . . . . . . . 16

3 A arquitetura WSARCH $\quad 17$

3.1 Considerações Iniciais . . . . . . . . . . . . . . . . . . . . . . . . . . . . . . . . . . . . 17

3.2 Arquitetura WSARCH . . . . . . . . . . . . . . . . 17

3.2.1 Seletor de serviços . . . . . . . . . . . . . . . . . . 20

3.3 Mecanismos Tolerantes a Falhas . . . . . . . . . . . . . . . . . . . . 22

3.3.1 Ferramentas de Injeção de Falhas . . . . . . . . . . . . . . . . . . 23

3.3.2 Ferramentas de Detecção de Falhas . . . . . . . . . . . . . . . . . . 24

3.4 Considerações Finais . . . . . . . . . . . . . . . . . . . . . . . . 27 
4 Desenvolvimento do Projeto 28

4.1 Considerações Iniciais . . . . . . . . . . . . . . . . . . . . . . . . . . . . . 28

4.2 Reputação em Web Services . . . . . . . . . . . . . . . . . 28

4.3 Risk Selector . . . . . . . . . . . . . . . . . . . . 30

4.4 Intelligent Selector . . . . . . . . . . . . . . . . . . . . . 33

4.4 Round Robin Selector . . . . . . . . . . . . . . . . . 37

4.5 Considerações Finais . . . . . . . . . . . . . . . . . . . . . . . 38

5 Avaliação Experimental $\quad 39$

5.1 Considerações Iniciais . . . . . . . . . . . . . . . . . . . . . . . . . 39

5.2 Injeção de Falhas . . . . . . . . . . . . . . . . . . . . . . . . . . . . . . . . . 39

5.3 Configuração do Ambiente . . . . . . . . . . . . . . . . . . . . . . . 40

5.4 Desenho de Experimentos . . . . . . . . . . . . . . . . . . . . . 41

5.5 Análise dos Resultados . . . . . . . . . . . . . . . . . . 43

5.5 .1 Experimento 1 - Teste Inicial . . . . . . . . . . . . . . . . . 44

5.5.2 Experimento 2 - Detalhamento . . . . . . . . . . . . . 45

5.5.3 Experimento 2 - Análise Comparativa . . . . . . . . . . . . 50

5.5 .4 Influência de Fatores . . . . . . . . . . . . . . . . . . . . . 52

5.6 Considerações Finais . . . . . . . . . . . . . . . . . . 54

6 Conclusões $\quad 56$

6.1 Contribuições . . . . . . . . . . . . . . . . . . 56

6.2 Trabalhos Futuros . . . . . . . . . . . . . . . . . 57

$\begin{array}{ll}\text { Referências Bibliográficas } & 65\end{array}$ 


\section{Lista de Figuras}

1.1 Esquema de Web Services. Adaptado de (Livetime, 2009) . . . . . . . . . . 2

2.1 Pilha conceitual dos Web Services. Adaptado de (Brooks, 2002) . . . . . . 7

2.2 Fluxo de execução em Web Services. Adaptado de (W3C, 2011) . . . . . . 7

2.3 Modelo de três universos: falha, erro e defeito (Jalote, 1994) . . . . . . . . 9

2.4 Exemplo de sistema de tolerância a falhas. O switch virtual escolhe entre as máquinas em bom estado para atender a uma solicitação do cliente. Adaptado de (Cline, 2009) . . . . . . . . . . . . . . . . . . . . 10

3.1 A arquitetura WSARCH e seus componentes (Estrella et al., 2011) . . . . 18

3.2 Interrelação entre os componentes da WSARCH (Estrella et al., 2011) . . . 20

3.3 Diagrama de sequência do funcionamento do Default Selector . . . . . . . 21

3.4 Conjuntos FARM (Manfredini, 2001) . . . . . . . . . . . . . . . . 24

3.5 Modelo de injeção de falhas em um sistema. Adaptado de (Touloupis et al., 2007). . . . . . . . . . . . . . . . 25

3.6 Modelo Push (Felber et al., 1999) . . . . . . . . . . . . . 26

3.7 Modelo Pull (Felber et al., 1999) _ . . . . . . . . . . . . . . 26

4.1 Arquitetura WSARCH, com adição do Intelligent Selector e demais seletores no Broker . . . . . . . . . . . . . . . . . . . . . . . 30

4.2 Diagrama de sequência do funcionamento do Risk Selector . . . . . . . . . 33

4.3 Funcionamento básico do Intelligent Selector (Adami e Estrella, 2012) . . . 35

4.4 Diagrama de sequência do funcionamento do Intelligent Selector. . . . . . . 36

5.1 Imagens da estrutura física da WSARCH. . . . . . . . . . . . . . . . . . 42

5.2 Médias dos tempos de resposta dos cenários do primeiro experimento. . . . 44

5.3 Porcentagem de tempo offline. . . . . . . . . . . . . . . . 45

5.4 Gráfico com a diferença de resultados antes e após a configuração correta dos parâmetros do experimento. Tempo médio de resposta para cada seletor. 46

5.5 Resultados com os diferentes parâmetros de monitoração e disparo de requisições. Tempo médio de resposta de cada provedor de acordo com o seletor atuante. . . . . . . . . . . . . . . . . . . . 47

5.6 Taxa de atendimento de cada seletor e taxa de requisições atendidas. . . . 47 
5.7 Comparação dos experimentos antes e depois da configuração dos parâmetros. Médias dos tempos de resposta em cada seletor. . . . . . . . . . . . . 49

5.8 Comparação dos experimentos antes e depois da alteração dos parâmetros. Tempo médio de resposta de cada provedor de acordo com o seletor atuante. 49

5.9 Taxa de atendimento de cada seletor e taxa de requisições atendidas. . . . 50

5.10 Comparação dos tempos de resposta entre os seletores, com 16 clientes e falha estática. . . . . . . . . . . . . . . . . 51

5.11 Comparação dos tempos de resposta para os seletores, com 32 clientes e falha estática. . . . . . . . . . . . . . . . 51

5.12 Comparação dos tempos de resposta entre os seletores, com 16 clientes e falha dinâmica. . . . . . . . . . . . . . . . . . . 52

5.13 Comparação dos tempos de resposta dos seletores, com 32 clientes e falha estática. . . . . . . . . . . . . . . . . 53

5.14 Efeito individual de cada fator . . . . . . . . . . . . . . . . 53

5.15 Interação entre os fatores dos experimentos . . . . . . . . . . . . . . 54 


\section{Lista de Tabelas}

4.1 Default Selector e novos seletores adcionados à WSARCH . . . . . . . . . 30

5.1 Infraestrutura . . . . . . . . . . . . . . . . . . . 41

5.2 Tabela com os fatores, níveis e cenários do $1^{\circ}$ Experimento . . . . . . . . . 42

5.3 Tabela com os fatores, níveis e parâmetros do $2^{\circ}$ Experimento . . . . . . . 43

5.4 Tabela com os cenários do $2^{\circ}$ Experimento . . . . . . . . . . . . . . . . 43

5.5 Tabela com as legendas utilizadas no Experimento 2 . . . . . . . . . . 47

5.6 Tabela com a taxa de atendimento de cada provedor de acordo com os

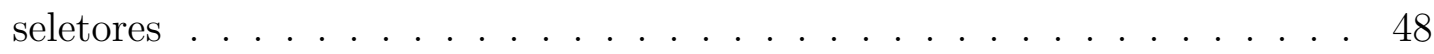

5.7 Tabela com a taxa de atendimento de cada provedor de acordo com os

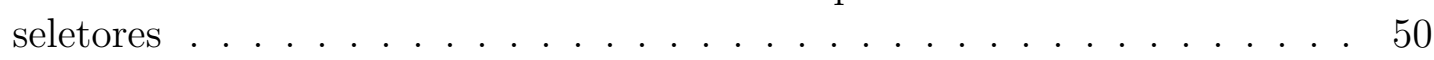

5.8 Tabela com os cenários do $2^{\circ}$ Experimento . . . . . . . . . . 50 


\section{Lista de Abreviaturas e Siglas}

B2B Business to business

FAPESP Fundação de Amparo à Pesquisa do Estado de São Paulo

FM4WS Framework for Web Services

ICSOC Internation Conference on Service Oriented Computing

IP Internet Protocol

KVM Kernel-based Virtual Machine

K-NN K-nearest neighbors

LASDPC Laboratório de Sistemas Distribuídos e Programação Concorrente

MASC Manageable and Adaptive Service Composition

MLP Multilayer Perceptron

P2P Peer-to-peer

QOS Quality of Service

SLA Service Level Agreement

SOA Service Oriented Architecture

SOAP Simple Object Access Protocol

UDDI Universal Description Discovery and Integration

VM Virtual Machine

W3C World Wide Web Consortium

WSARCH Web Service Architecture

WS-BPEL Web Services Business Process Execution Language

WSCAD-SSC Simpósio em Sistemas Computacionais

WSDL Web Service Description Language

XML Extensible Markup Language 


\subsection{Considerações iniciais}

Web Services surgiram para integrar diferentes tecnologias, com o objetivo de oferecer um modelo único para o usuário. Dessa forma, eles são capazes de ignorar as diferenças entre sistemas operacionais, hardwares e linguagens de programação, e trabalhar conjuntamente, para oferecer um mesmo produto final. Uma das características mais importantes dos Web Services é o fraco acoplamento, que permite a módulos independentes comunicarem-se e integrarem um sistema onde cada um cumpre suas tarefas. Além disso, um módulo defeituoso pode ser facilmente substituído, sem prejuízo para o restante da estrutura, assim como novas partes podem ser integradas com esforço relativamente baixo.

\subsection{Contextualização}

Uma vez que a popularização das arquiteturas orientadas a serviço alcançou sistemas críticos, é importante considerar a utilização de aplicações mais robustas e confiáveis, já que os dados e transações não podem ser perdidos. A ligação tardia (late binding) de Web Services em operações business-to-business representa um sério problema para a confiabilidade de um sistema orientado a serviços, por delegar a decisão de confiar um serviço a um agente externo. Apesar das preocupações com a disponibilidade de dados e cuidados com a manutenção dos serviços, é impossível garantir que um sistema seja 100 
\% confiável, uma vez que qualquer programa pode apresentar defeitos de toda ordem durante seu tempo de utilização. A degradação da capacidade de trabalho é causada tanto por falhas de software quanto de hardware, seja individualmente ou combinadas, ainda mais levando-se em conta a natureza totalmente distribuída de arquiteturas orientadas a serviços. O que se observa na Internet é a integração de diversos elementos, os quais possuem diferentes configurações, e operam em linguagens também distintas. Múltiplos hosts estão conectados, oferecendo uma grande diversidade de conteúdo online aos usuários, que recebem os dados em dispositivos cada vez mais inovadores. A diversificação dos meios de acesso é constante, e os provedores precisam acompanhar as tendências para atender satisfatoriamente àqueles que necessitam dos seus serviços. Um esquema simplificado de Web Services pode ser observado na Figura 1.1. O Web Service é publicado e tem suas funcionalidades registradas no UDDI (Universal Description and Discovery Integration), repositório que disponibilizará sua localização e características, e onde também estão armazenadas as informações do perfil do cliente. Por sua vez, o cliente busca através da aplicação um serviço, e a partir deste momento tem início o processo de descoberta. Uma vez encontrado o serviço correspondente no repositório, os provedores de serviços estão aptos a atender as requisições do usuário.

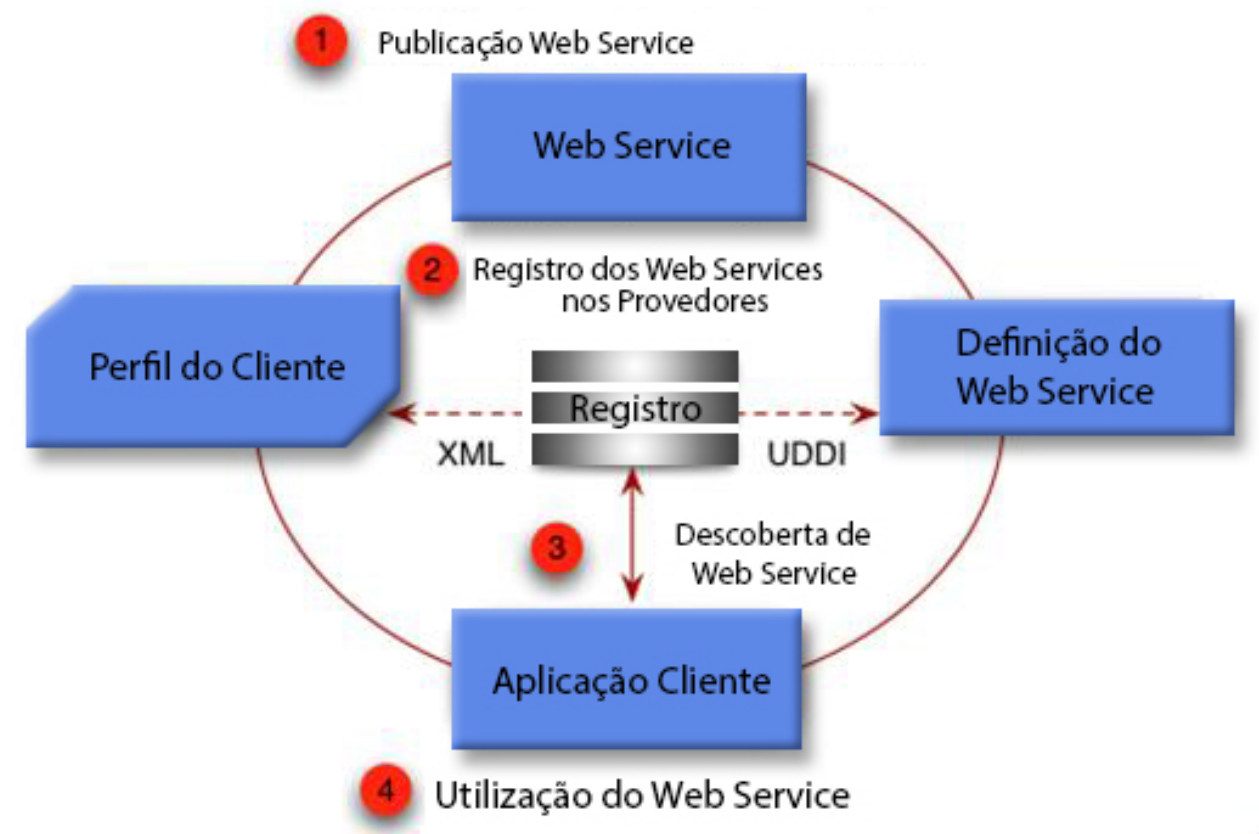

Figura 1.1: Esquema de Web Services. Adaptado de (Livetime, 2009)

Os Web Services são adequados para a Internet devido ao modelo distribuído da rede, pois lidam bem com a heterogeneidade do ambiente. O foco dos Web Services é de fato a interoperabilidade, mas a crescente utilização dos mesmos em ambientes que 
necessitam de confiabilidade, faz perceber que as preocupações com a qualidade do serviço são importantes para garantir um atendimento adequado ao usuário (Estrella, 2010). Em relação à disponibilidade desses serviços, algumas preocupações são necessárias e precisam ser consideradas, tais como:

- Falhas em provedores de serviços que possuem aplicações que não podem ficar inoperantes, como sistemas de monitoramento médico;

- Aplicações que dependem de outras para terminarem um determinado fluxo de execução (ex: composição de serviços);

- Replicação de mecanismos de roteamento de mensagens SOAP (Simple Object Access Protocol) bem como mecanismos para prover qualidade de serviço no acesso às informações funcionais e não funcionais de Web Services em um registro de serviços tal como o UDDI;

- Sobrecarga de provedores de serviços que não implementam mecanismos de controle de admissão, cache de serviços, replicação de dados, etc.

Dessa forma, deve-se atentar para as situações-problema acima listadas, e avaliar o grau de impacto das mesmas na degradação da qualidade dos serviços oferecidos por uma arquitetura SOA (Service Oriented Architecture). Por isso é importante propor soluções para minimizar as limitações de atendimento aos clientes, gerando uma melhora na arquitetura como um todo, e proporcionando melhores condições para o utilizador.

\subsection{Motivação}

Uma vez que os Web Services se tornaram amplamente difundidos e passaram a operar em esferas onde são necessárias garantias de confiabilidade nos serviços, mecanismos de tolerância a falhas surgem como uma parte muito importante do sistema geral. Os mecanismos tolerantes a falhas permitem que as falhas em um sistema sejam ocultadas, recuperadas ou contornadas até a resolução do problema. Dessa forma, uma queda em um servidor ou um conjunto de servidores não pode deixar uma empresa inoperante, uma vez que isso poderia ocasionar grandes prejuízos financeiros ou estratégicos. As estratégias para amenizar problemas podem incluir replicação, registro de requisições ou desvios de fluxo, e se implantadas em conjunto podem prover a robustez necessária para tarefas de alto risco. 


\subsection{Objetivos}

Esta dissertação de mestrado visa o desenvolvimento de mecanismos tolerantes a falhas a serem aplicados na arquitetura WSARCH, o que envolve o desenvolvimento de algoritmos de otimização do atendimento e de suporte à operação tolerante a falhas, para detecção e contorno de defeitos, visando qualidade de serviço e disponibilidade. Além disso, concebe também identificar a interferência das falhas em uma arquitetura distribuída como a WSARCH, com a injeção de falhas e testes, oferecendo alternativas para obter a disponibilidade desejada. O trabalho abrange ainda a modelagem, a instrumentação e monitoração de experimentos de injeção de falhas para a avaliação do comportamento da arquitetura WSARCH. Ao final uma avaliação de desempenho considerando os mecanismos tolerantes a falhas e algoritmos introduzidos é apresentada para validação dessas propostas.

$\mathrm{Na}$ arquitetura WSARCH o componente em destaque é o Broker, responsável por encontrar no repositório UDDI o provedor onde está hospedado o serviço requisitado pelo cliente. Nesse sentido, os algoritmos foram introduzidos nessa estrutura, com a intenção de torná-la mais eficiente, inclusive do ponto de vista de qualidade de serviço. E, uma vez que o Broker depende diretamente dos repositórios UDDI para proceder a um atendimento, foi adicionado um módulo para substituir o UDDI em caso de falha, que é capaz de definir rotas alternativas para os provedores, responsáveis pela execução do serviço. Também nesse caso, os níveis de QoS (Quality of Service) foram uma preocupação, para que o atendimento aos clientes não fosse prejudicado.

\subsection{Organização do texto}

Esta dissertação está estruturada da seguinte forma:

No Capítulo 2 são apresentados os trabalhos relacionados, bem como o detalhamento de Web Services e das técnicas de tolerância a falhas.

O Capítulo 3 por sua vez, discute a configuração da arquitetura WSARCH, na qual são discutidos seus componentes e a interação entre os mesmos. Também são tratados os principais pontos de falhas e como novos mecanismos podem ser associados à arquitetura.

O Capítulo 4 trata dos mecanismos envolvidos no projeto de pesquisa, as ferramentas de tolerância a falhas, e os mecanismos de injeção e detecção de problemas na arquitetura.

O Capítulo 5 descreve a metodologia do projeto de pesquisa, a estrutura utilizada, os experimentos realizados e a avaliação de desempenho.

No Capítulo 6 são apresentadas as considerações finais deste trabalho, bem como dificuldades enfrentadas e também alguns trabalhos futuros oriundos deste.

Finalmente são apresentadas as referências utilizadas nesta dissertação. 


\section{Fundamentação Teórica}

\subsection{Considerações Iniciais}

Neste capítulo são apresentados os conceitos de Web Services e os protocolos envolvidos como SOA, SOAP e XML (Extensible Markup Language). Os Web Services encontram-se no auge de sua utilização nos dias atuais, de forma que as pesquisas buscam expandir os horizontes dessa tecnologia. Também serão tratados os detalhes de tolerância a falhas, técnicas e usos, mostrando a sua importância para arquiteturas SOA. Além disso, as considerações sobre QoS e trabalhos correlatos são expostos e discutidos.

\subsection{Web Services}

Web Services são uma implementação de uma arquitetura orientada a serviços, referenciada na literatura de Web Services como SOA (Erradi et al., 2006). São definidos como aplicações autônomas que podem ser disponibilizadas, localizadas e invocadas na Internet. Apresentam como características o fraco acoplamento e a ligação dinâmica entre os componentes (Mansour e Dillon, 2011) . Pelas definições apresentadas, pode-se observar que diferentes explicações sobre Web Services estão disponíveis, desde as mais simples até as mais completas como a sugerida pela W3C (World Wide Web Consortium). Algumas definições mencionam que as interações entre Web Services ocorrem tipicamente como chamadas SOAP, protocolo de comunicação baseado em XML para a interação de 
aplicações (Papazoglou, 2003). SOAP é apresentado como um backbone para uma nova geração de aplicações de computação distribuída, independente de plataforma e de linguagens. Além disso, as descrições de interfaces dos Web Services são expressas usando uma linguagem denominada WSDL (Web Service Description Language) (Thomas et al., 2003). Na literatura sobre Web Services é apresentado também um protocolo para diretório de serviços que contém as descrições dos Web Services, denominado UDDI. Esse protocolo funciona como um registro de serviços sendo um importante componente da arquitetura orientada a serviços (Farkas, 2003). Uma arquitetura orientada a serviço é uma maneira lógica de construção de um sistema de software para prover serviços ou para aplicações de usuários finais ou para outros serviços distribuídos em uma rede, por meio de interfaces públicas disponíveis, onde destaca-se a WSDL. (Papazoglou, 2003). A pilha conceitual dos Web Services envolve três camadas principais: camada de rede, camada de descrição e camada de descoberta. Na camada de descoberta está o UDDI, responsável por armazenar e disponibilizar as informações dos serviços. Na camada de descrição se encontram os detalhes dos Web Services, as linguagens utilizadas e suas interações. A camada de rede conta com especificações de roteamento, criptografia, qualidade de serviço, anexos e gerenciamento de transações. Abaixo desta estão os demais protocolos de Internet, como é mostrado na Figura 2.1.

O núcleo central dos padrões de Web Services inclui:

- XML como uma linguagem padrão para a representação dos dados (mensagens) trocadas entre as aplicações;

- Um esquema XML para os tipos de dados, isto é, um formato de mensagens comum e extensível;

- Protocolo SOAP para o transporte de mensagens;

- Uso da linguagem WSDL para a descrição do serviço oferecido;

- UDDI para a descoberta de um serviço que está sendo oferecido (um mecanismo para localizar os serviços).

Em resumo, pode-se definir um Web Service como um serviço de software publicado na $W e b$ pelo protocolo SOAP (Gudgin et al., 2001), descrito em um arquivo WSDL e registrado em um repositório UDDI (Ehnebuske e Riegen, 2001), como pode ser observado na Figura 2.2.

Em Web Services a confiabilidade e a disponibilidade são dois pontos chave. A confiabilidade é a probabilidade da execução de um serviço não apenas proporcionar o resultado desejado, mas também manter a qualidade de serviço (velocidade de atendimento, 
CAPÍTULO 2. FUNDAMENTAÇÃO TEÓRICA

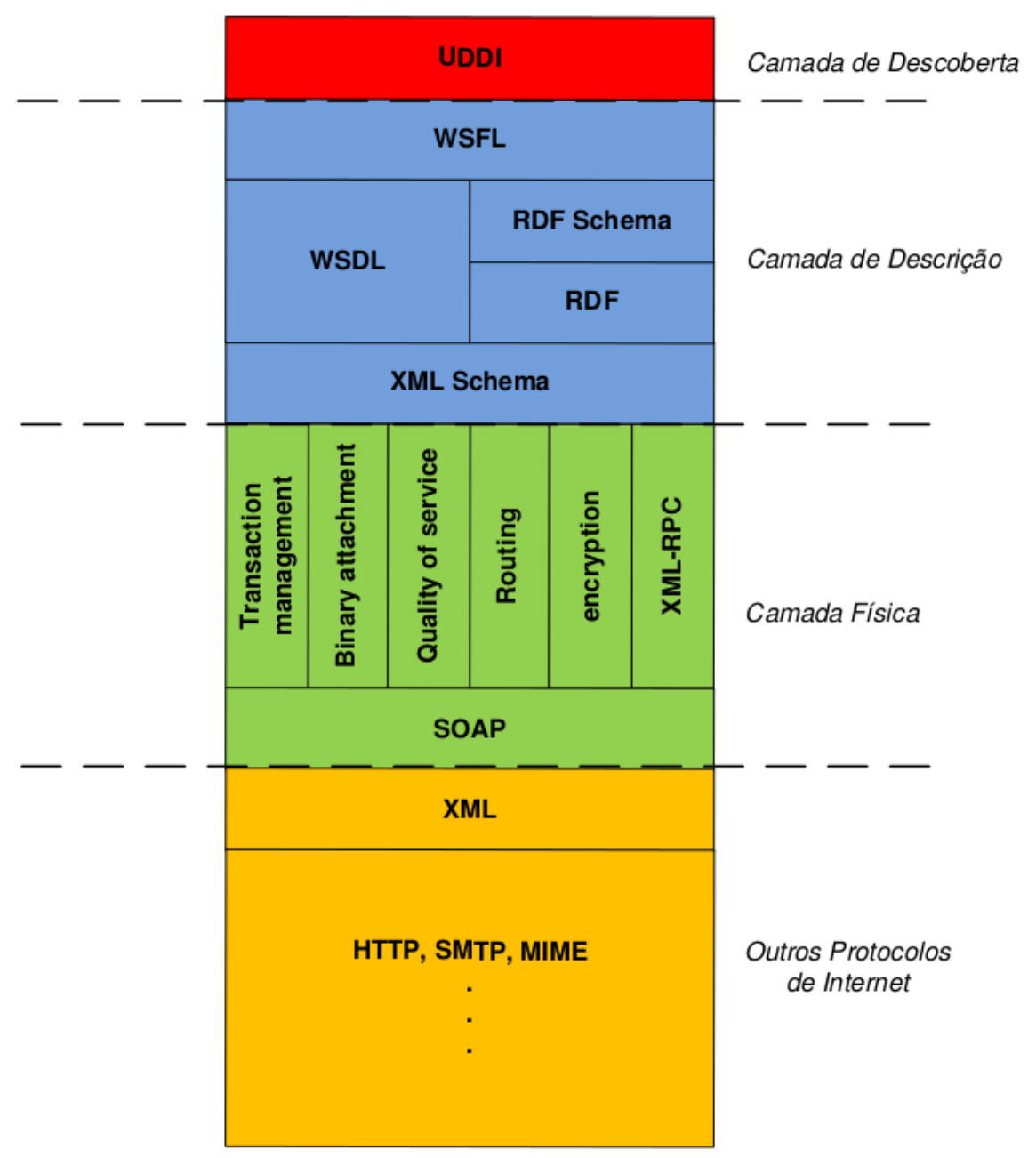

Figura 2.1: Pilha conceitual dos Web Services. Adaptado de (Brooks, 2002)

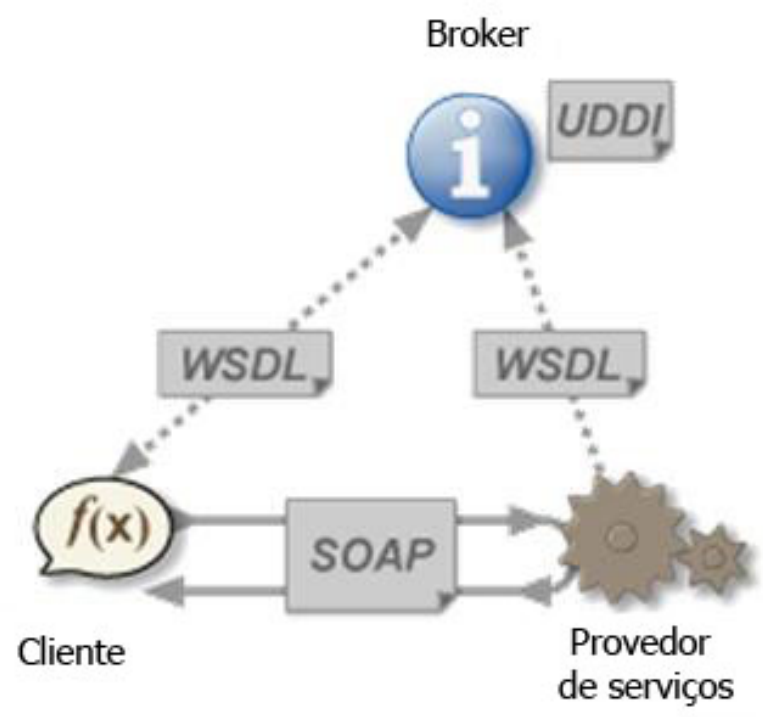

Figura 2.2: Fluxo de execução em Web Services. Adaptado de (W3C, 2011) 
abrangência de dados, prioridade, etc.) contratada pelo cliente. Por outro lado, a disponibilidade é a probabilidade de que um Web Service é em primeiro lugar, acessível e, em seguida, operacional para aceitar solicitações dos usuários (Faci et al., 2011). Esses requisitos podem ser alcançados com a utilização de políticas de tolerância a falhas.

\subsection{Tolerância a Falhas}

Tolerância a falhas é a capacidade de um sistema continuar em operação apesar da presença de uma ou mais falhas (Mohamed e Al-Jaroodi, 2012). Em aplicações onde a perda de dados ou comunicação pode gerar grandes danos ou prejuízos, a tolerância a falhas é de fundamental importância para o seu bom funcionamento. Pesquisas em tolerância a falhas tem por objetivo fazer sistemas mais confiáveis por meio da manipulação de falhas em ambientes complexos, como por exemplo, a Internet. Um sistema tolerante a falhas é importante em aplicações críticas, como um sistema que controla uma usina nuclear ou o que controla o tráfego aéreo (Pullum, 2001). As consequências de falhas nesses casos podem variar de levemente irritante para catastrófico, como a ocorrência de ferimentos graves ou vidas perdidas, sistemas destruídos, violação de segurança, ou oportunidades perdidas (Erradi et al., 2006).

Analisar reputação dos componentes é uma técnica largamente utilizada em modelos que exigem segurança e tolerância a falhas (Echtle e Masum, 2000). Isso permite manter apenas os melhores componentes da arquitetura no alvo de ação do cliente. Quando um dos serviços está com problemas, ele será automaticamente excluído até que alguma providência seja tomada (Mohamed e Al-Jaroodi, 2012).

Há três conceitos distintos que discriminam os problemas em sistemas computacionais: erro, falha e defeito. Falha (Fault) é a causa identificada ou hipotética de um erro, também conhecida como bug. Pode ser visto como um problema originado em outro sistema (inclusive o programador), que está emitindo o erro para o sistema corrente. Falha ativa é a que causa um erro. Erro (Error) é parte do estado do sistema que pode conduzir a uma falha. Pode não ser reconhecido (latente) ou detectado. Um erro pode ser propagado, causando outros. Falhas são reconhecidas quando são detectados erros. Por fim, Defeito (Failure) ocorre quando o serviço oferecido pelo sistema desvia de sua especificação, apresentando resultados incorretos. Isso implica que o serviço esteja descrito por especificações e requisitos (Pullum, 2001). A Figura 2.3 ilustra o esquema.

Porém, tolerância a falhas não resolve todos os problemas de softwares. Tem sido utilizada com sucesso, principalmente em sistemas críticos, entretanto é importante frisar que não significa segurança, e não cobre atributos como resistência, disponibilidade, confidencialidade e integridade, assim como nenhum deles compreende a tolerância. 


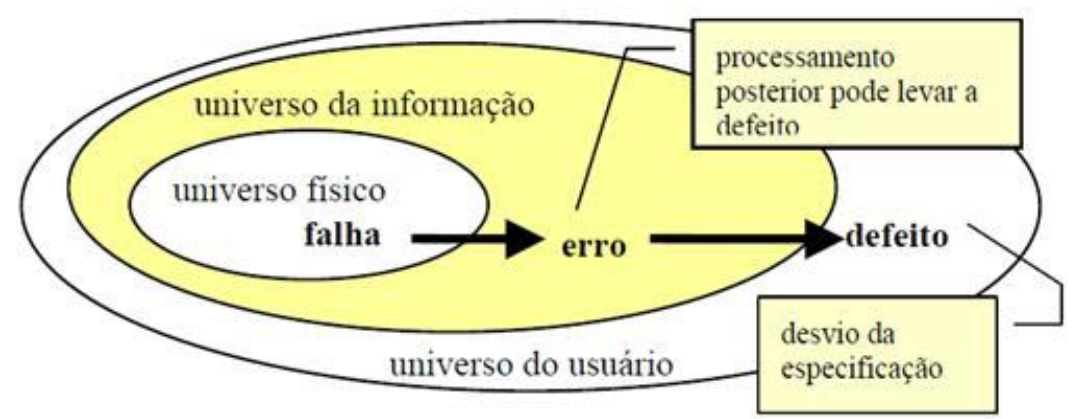

Figura 2.3: Modelo de três universos: falha, erro e defeito (Jalote, 1994)

Com relação ao tratamento das falhas há quatro princípios básicos. A Prevenção de falhas é a que busca evitar ou prevenir ocorrências das mesmas em um sistema. A Remoção de falhas possui mecanismos para detectar a existência de problemas e eliminá-los. A Previsão de falhas utiliza métricas para estimar a presença de falhas, bem como a ocorrência e as prováveis consequências de defeitos no ambiente. E a Tolerância a falhas tenta garantir o cumprimento de serviços, dentro das especificações, mesmo que na presença de falhas.

No contexto de arquiteturas orientadas a serviços a preocupação com falhas em serviços, provedores, barramento de serviços e outras entidades também não seria diferente. Quando considerado um fluxo de execução de Web Services, em que haja dependência entre as tarefas, a falha em uma das execuções pode impedir que o fluxo seja finalizado. Por outro lado, se provedores de serviços tornam-se indisponíveis por alguma falha de hardware ou software, uma aplicação cliente do serviço pode não ter sua requisição atendida, ou seus dados processados.

Uma arquitetura SOA permite que sistemas distintos e que executam em plataformas computacionais diferentes possam se comunicar de forma a garantir a interoperabilidade entre as aplicações. Ao mesmo tempo, viabiliza um grande número de recursos computacionais que consiste em computadores, sistemas de armazenamento de dados, os quais são distribuídos em diversas instituições e domínios. Uma arquitetura SOA como a WSARCH possui uma infraestrutura que pode ser reconfigurada ou alterada dinamicamente. O elevado número de componentes e sua distribuição, assim como a estrutura dinâmica, aumentam o risco de falhas. Assim, fornecer um serviço de detecção de falhas escalável é de primordial importância para esse tipo de sistema.

Segundo (Macedo e Gorender, 2009) pesquisas têm sido desenvolvidas no intuito de se conseguir soluções satisfatórias para tolerância a falhas, mesmo em um ambiente assíncrono como é caracterizado o serviço padrão da Internet. Em um ambiente de alta disponibilidade, as falhas não são percebidas pelos clientes, visto que elas são sanadas ou escondidas pelo sistema. 
Inicialmente, deve ser introduzido um sistema de detecção de falhas, para que seja possível saber quando ocorrem e quais são os defeitos da arquitetura. Uma das formas de se verificar a execução correta de alguns processos é chamada heartbeat, onde são enviadas mensagens de estado em intervalos de tempo pré-definidos. Se dentro desse tempo a mensagem não é recebida, significa que o processo falhou. Após a detecção do erro, é preciso garantir que o sistema continue em funcionamento. Assim, são necessárias estratégias de desvio de fluxo, replicação e espelhamento para impedir que os serviços se tornem indisponíveis. Ainda que um dos módulos de um programa deixe de funcionar, os demais não deverão ser interrompidos, além de um módulo reserva que deverá entrar em operação. Por fim, deve haver um algoritmo de correção de falhas, que possa recolocar em funcionamento as partes inconsistentes do sistema. Um exemplo pode ser visto na Figura 2.4 .

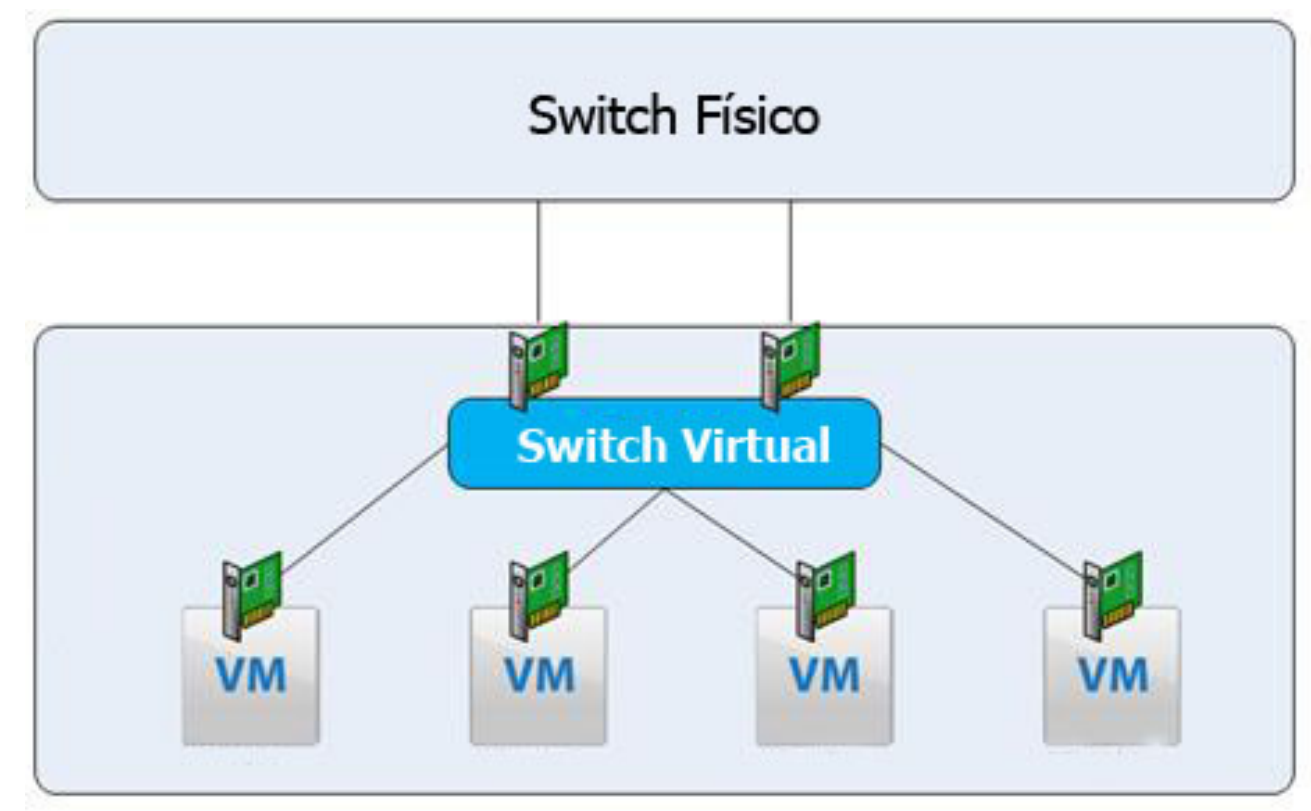

Figura 2.4: Exemplo de sistema de tolerância a falhas. O switch virtual escolhe entre as máquinas em bom estado para atender a uma solicitação do cliente. Adaptado de (Cline, 2009)

\subsection{Qualidade de Serviço}

Qualidade de serviço são métricas pré-definidas para garantir o atendimento aos clientes de um sistema. Essas métricas são usadas como parâmetros para coleta de dados de satisfação dos usuários do serviço. Os parâmetros podem ser definidos por meio do contrato estabelecido com o cliente. Neste contrato são definidos os requisitos mínimos esperados do programa, os quais podem ser o tempo máximo de resposta tolerável ou a variação da 
temperatura de um ambiente por exemplo. Isso pode ser pré-fixado, tanto pelo cliente como diretamente configurado no software ou ainda definido em tempo real. Em todos os casos o sistema deverá ser capaz de garantir os termos acordados, para que se possa ter uma experiência de utilização satisfatória. QoS pode ser alcançado de diferentes formas.

A primeira delas é um trabalho mais cuidadoso do desenvolvedor do sistema, de maneira a evitar problemas de projeto e futuras falhas, o que pode assegurar um ambiente mais confiável para a utilização. Porém é notória a dificuldade de criação de componentes livres de problemas, para não dizer ser impossível criar um sistema perfeito. Nesse sentido os softwares de teste são de grande valor para verificar os possíveis caminhos que a codificação pode percorrer, verificando saídas incorretas ou inconsistentes (Sargeant et al., 2012).

Outra forma de evitar panes em um ambiente é ter uma capacidade de atendimento superior ao nível de utilização. Isso pode evitar sobrecargas, falhas de respostas e competição por recursos (Jhawar e Piuri, 2012). Contudo essa abordagem promove o desperdício de recursos computacionais, deixando diversos componentes ociosos e consumindo quantidades desnecessárias de energia. Em tempos de computação verde (Somasundaram et al., 2012) e com as preocupações de todas as empresas em reduzir custos operacionais, esse modelo pode ser considerado absurdo. Nesse sentido a computação em nuvem pode ser um aliado valioso (Tchana et al., 2012). Devido às suas características de elasticidade, ela pode prover os recursos necessários de acordo com a demanda, reduzindo significativamente as ocasiões de desperdício, ao mesmo tempo em que atende um número variável de clientes. Outro meio de promover bons níveis de atendimento aos clientes está em evitar ou contornar defeitos do sistema. Se uma plataforma está programada para evitar, suportar ou corrigir falhas em geral, ela proporciona um ambiente mais seguro de utilização aos interessados.

Qualidade de serviço pode ser definida como um conjunto de parâmetros, os quais um determinado sistema deve cumprir para atender satisfatoriamente objetivos pré-definidos (Zuquim e Garcia, 2007). Pode ser avaliado tomando como base a aplicação, visando o usuário final, onde devem ser limitados atrasos, perdas de pacotes e tempo de espera. De acordo com os padrões ISO 95, QoS pode ser definido como a visão global do desempenho de um determinado serviço, obtida por coleta de dados de satisfação do usuário. Esse conceito é considerado subjetivo, uma vez que a percepção de qualidade varia de acordo com cada pessoa. Com relação às redes de computadores, o QoS pode ser medido em termos de tempo de resposta, vazão de dados e largura de banda, onde pode ser estabelecido um valor mínimo a ser atingido pelas aplicações. Assim é possível determinar bons níveis de tráfego de dados nos meios em questão. 
O QoS pode ser obtido automaticamente em determinadas ocasiões, graças à evolução dos softwares e o aumento da velocidade da Internet (Kamienski e Sadok, 2000). Por outro lado, em casos mais específicos é necessário um esforço do projetista do sistema para permitir as condições que garantam níveis mínimos de bom funcionamento. Há que se considerar também os sistemas críticos, onde é imperativo a excelência do serviço, sem a qual podem ocorrer danos graves, sejam financeiros, ambientais ou vazamento de informações secretas.

A metas para alcance de QoS são definidas no SLA (Service Level Agreement) (Martins e Santana, 1999), e envolvem os equipamentos e componentes utilizados. O SLA visa estabelecer os parâmetros a serem atingidos pelo sistema, para garantir a satisfação do usuário. As organizações e os clientes possuem padrões próprios de satisfação a serem atendidos pelos Web Services, os quais devem considerar o grande leque de canais multimídia disponíveis (Zuquim e Garcia, 2007). Em linhas gerais, os requisitos de QoS são os limites nas métricas de SLA definidas, como por exemplo um atraso máximo de $10 \%$ no tempo de resposta (Misailovic et al., 2010).

Se por um lado, na visão dos clientes, os parâmetros mínimos aceitáveis podem variar, de acordo com os costumes ou recursos disponíveis (Martins e Santana, 1999), pela visão das empresas e dos sistemas em geral, os atributos são definidos buscando-se uma universalidade de acesso e atendimento, o que os torna estáveis, e facilita a visualização de problemas e necessidade de atualização (Zuquim e Garcia, 2007). Alguns requisitos gerais de qualidade de serviço são, entre outros, interoperabilidade, confiabilidade, disponibilidade, segurança e desempenho (Liu e Zhu, 2009).

Teoricamente é possível utilizar qualquer métrica de QoS que, dada duas saídas (uma a partir de um pedido inicial e outra a partir de um resultado da aplicação), produz uma medida da diferença entre as saídas. Baseando-se nesses números é possível medir a distorção coletada com relação aos resultados esperados. Quanto mais próxima de zero a distorção, menos o software fugiu dos requisitos de qualidade esperados. Isso pode ser calculado na Fórmula 2.1, onde dados os valores iniciais de QoS são representados pelas variáveis de $O_{1}$ até $O_{m}$ e os valores esperados na saída do sistema vão de $\tilde{O}_{1}$ até $\tilde{O}_{m}$. A partir destes pontos, pode-se obter o valor de distorção retornado (Misailovic et al., 2010).

$$
d=\frac{1}{m} \sum_{i=1}^{m}\left|\frac{O_{i}-\tilde{O}_{i}}{O_{i}}\right| .
$$

Por padrão, a equação distorção pesa cada componente da mesma forma, mas é possível modificá-la para pesar alguns componentes mais fortemente do que os outros.

Uma vez definida corretamente a relação entre requisitos de QoS e características de desenvolvimento é possível definir as metas do sistema, as melhorias necessárias nos atrib- 
utos e as técnicas a serem utilizadas (Liu e Zhu, 2009). Nesta dissertação, os parâmetros de Qos são utilizados para seleção de Web Services e ferramentas de tolerância a falhas são apresentadas como auxiliares no cumprimento dos SLAs.

\subsection{Trabalhos Relacionados}

Frameworks para tratamento de falhas foram apresentados por (Hall e Kotonya, 2007), (Zhao, 2007), (Zibi e Lyu, 2009), (Liu et al., 2009). O primeiro deles trata de um mecanismo adaptável a redes P2P (Peer to Peer). O segundo traz uma estrutura que permite a replicação dos Web Services em diversos nós, com garantias de ordem de requisições e associações de conteúdo. Por ser independente de protocolos, é facilmente portável a diversas estruturas, e apresentou bom desempenho na avaliação. O terceiro abrange um modelo para lidar com a composição automática de serviços, que lida tanto com a seleção da estratégia quanto com a tolerância a falhas. Ainda que bastante escalável, a proposta é limitada para atuar em arquiteturas SOA com muitos elementos. O último trabalho citado descreve o Framework for Web Services (F4WS), um mecanismo de detecção de falhas, com cálculos de carga, utilização de freshpoint, frequência de mensagem e probabilidade de perdas. O objetivo é aumentar a confiabilidade dos Web Services, aumentar a exatidão da detecção e realizar as variações de velocidade de transmissão necessárias.

A diversidade como alternativa de tolerância a falhas foi tratada por (Faci et al., 2011). A diversidade decorre da similaridade de funcionalidades entre diferentes softwares. Para um mesmo produto final, diferentes companhias desenvolvem aplicações distintas, utilizando cada qual seus próprios softwares, hardwares e linguagens de programação. Devido à heterogeneidade proporcionada pelos Web Services, é possível se beneficiar da competição do mercado. Em outro exemplo, há a arquitetura desenvolvida por (Souza e Siqueira, 2008), que utiliza componentes projetados em diferentes tecnologias, com mecanismos para aumentar a confiabilidade dos serviços e permitir a integração com sistemas legados. A diversidade foi uma das formas escolhidas para atuar como tolerância a falhas na WSARCH. Novos seletores de serviços, baseados em diferentes tecnologias foram integrados, e serão detalhados na Seção 4.

Para a obtenção de parâmetros de QoS, (Lakhal et al., 2005) propõe a coleta de informações quando da composição dos serviços, por supor que neste momento os componentes da arquitetura estarão disponíveis e funcionais. Isso permite avaliar tanto a composição quanto as ferramentas de tolerância introduzidas. Em (Yiyan e Xiaoyong, 2010) os autores consideram que as composições podem ser longas e o fracasso das transações, uma situação frequente. A partir disso, utilizam Redes de Petri para implementar uma compensação parcial ou total das tarefas solicitadas e por meio do monitoramento do tempo 
de execução com WS-BPEL (Web Services Business Process Execution Language), o que permite verificar a coerência dos serviços oferecidos. Essa técnica é semelhante à encontrada em (Erradi et al., 2006) em que as teorias de redes de Petri ajudam a provar a consistência de estados de processamento e confiabilidade da estratégia de composição de serviços utilizada. Na WSARCH o QoS dos componentes da arquitetura é constantemente avaliado, e é um parâmetro importante no comportamento geral e no atendimento a os clientes.

O artigo de (Aghaei et al., 2011) propõe uma arquitetura para aumentar a confiabilidade e a disponibilidade dos Web Services. Esta arquitetura é baseada em registros das requisições e respostas em nível de aplicação e de transporte, $N$-Version e técnicas de replicação ativa. Oferece tolerância mesmo a erros ocorridos durante o processamento das requisições.

Em alguns casos pode ser utilizada a colaboração do usuário como ferramenta de suporte à decisão. Em (May, 2010) é feita uma pesquisa prévia para determinar a abordagem de redundância mais adequada de acordo com o tipo de cliente. Em (Zheng e Lyu, 2008) os autores propõem um middleware que utiliza informações de QoS fornecidas pelos clientes, que permite alterar dinamicamente a técnica de tolerância a falhas mais indicada em cada transação. Essa adaptabilidade é muito utilizada em sistemas com suporte a falhas, como pode ser também visto em (Chen e Lin, 2009), em que é utilizado um sistema detecção em camadas, outro de detecção dinamicamente ajustável e um sistema de reinicialização adaptativo, que busca diminuir reinicializações desnecessárias dos sistemas e ajuda a tornar mais precisas a detecção de problemas. Quando um sistema é reiniciado, é necessário aguardar que todos os módulos sejam desligados e depois disponibilizados novamente, causando uma pausa que não pode ocorrer com frequência. Com essa preocupação (Moon et al., 2006) apresenta modelos de recuperação, sendo quatro automáticos (To Continue, To Restart, To do the Backward Recovery e To do the Backward Recovery Then Restart) e um manual (To notify), com objetivo de reduzir a intervenção humana com o ambiente. Técnicas de autorecuperação também são discutidas em (Nabuco et al., 2008) com uma arquitetura que gerencia ações como a substituição de um serviço defeituoso por exemplo.

(Gomaa e Hashimoto, 2011) descreve uma abordagem de adaptação dinâmica de software e ambiente para as linhas de produtos orientados a serviço. Utiliza-se um modelo de característica dinâmica, que define uma linha de produtos para uma família de arquiteturas orientadas a serviços em que um componente pode ser adaptado em tempo de execução, e passar a integrar um membro diferente da família. A abordagem integra a linha de produtos de software, conceitos de funcionalidade de modelagem com SOA e conceitos de adaptação dinâmica de software. Em (Fan et al., 2009) é proposto um conjunto 
de políticas de recuperação extensível para especificar como manipular e recuperar de falhas típicas na composição de Web Services. Os construtores identificados foram incorporados a um serviço de gestão de middleware chamado Manageable and Adaptive Service Composition (MASC) para promulgar as políticas de gerenciamento de falhas e facilitar a configuração, monitoramento e controle de serviços gerenciados, de forma transparente.

Outro problema sério para os sistemas computacionais são as falhas bizantinas. São falhas arbitrárias, podendo ser um colapso, falha no envio ou recebimento de informações ou quebra de segurança. (Zhou e Wang, 2010) apresentam um protocolo para tolerância a falhas bizantinas em composições de Web Services. Diferentemente de outros métodos, são criadas réplicas em ambos os lados da arquitetura, junto a uma implementação modular, e resultados experimentais demonstraram apenas uma leve sobrecarga, o que torna o protocolo viável para uso em larga escala.

No ambiente de computação em nuvem, as técnicas de tolerância a falhas devem considerar três camadas: hosts, máquinas virtuais e aplicações. Em (Tchana et al., 2012) são avaliados dois modelos, o primeiro em que o administrador do serviço e o cliente lidam separadamente com as questões de falhas e um segundo em que ambos colaboram na manutenção do ambiente. Esta última proposta foi avaliada como mais promissora. No artigo de (Jhawar e Piuri, 2012) encontra-se uma métrica para ferramentas virtualizadas que tem como fim aumentar a transparência e a confiabilidade em nuvem. Uma avaliação que considera as diversas camadas envolvidas em transações como essa é utilizada para a seleção dos mecanismos corretos que deverão atender os clientes.

Em (Jiang et al., 2012) é apresentado um modelo de reputação que, combinado com um sistema de estimativa Bayesiana auxilia os usuários na composição de comunidades onde são obtidos os serviços desejados. Outra forma de obter dados de reputação é a partir da recomendação obtida em outras transações. Em (Yue e Wang, 2012) é apresentado um sistema que utiliza o cálculo da entropia da informação e a similaridade entre pares para aumentar a precisão dos dados coletados. Já (Mougouei et al., 2012) há uma preocupação em avaliar o grau de tolerância a falha necessário em determinados web services de acordo com as definições do mesmo. A tolerância é medida levando-se em conta o custo, a capacidade técnica, o impacto e a flexibilidade das metas de segurança estabelecidas. A análise de reputação dos componentes também foi escolhida como mecanismo de trabalho da WSARCH, como avanço dos componentes do projeto inicial.

A pesquisa de (Ayday e Fekri, 2012) mostra que o cálculo das funções de probabilidade marginais, utilizado em diversas abordagens de reputação, é computacionalmente proibitivo para sistemas de grande escala. A partir disso, foi proposto um esquema de propagação de opinião, que coleta informações qualitativas de fornecedores e usuários em um grafo de fator. Em seguida o cálculo da reputação é feito com base nas trocas de men- 
sagens entre os nós do grafo. Esse sistema se mostrou muito eficiente em ambientes pouco confiáveis e de grande volume. Em (Alnemr e Meinel, 2012) foram utilizadas técnicas de $W e b$ semântica na avaliação de reputação dos componentes utilizados. Os resultados encontrados foram bastante promissores.

Dos trabalhos avaliados, as técnicas de diversidade de tecnologias e as ferramentas de reputação de componentes foram escolhidas para serem utilizadas neste trabalho. A primeira por prover uma abrangência maior no tratamento de falhas, devido à variação dos mecanismos de software utilizados, evitando que erros de projeto se propaguem pelo sistema. E a segunda por ser capaz de reduzir as probabilidades de falhas, ao selecionar para utilização os componentes mais confiáveis de acordo com seu histórico recente. As técnicas são usadas complementarmente como políticas de tolerância a falhas e auxílio à manutenção dos requisitos de QoS.

\subsection{Considerações Finais}

Neste capítulo foram apresentados os conceitos de Web Services, os principais mecanismos, as características e os padrões das arquiteturas orientadas a serviços e os requisitos de alta disponibilidade. Também foram discutidas as teorias de tolerância a falhas, sua importância e a necessidade crescente de utilização. Juntamente com os requisitos de qualidade de serviço, integram parte importante da satisfação de atendimento aos clientes. Finalmente foram expostos os trabalhos relacionados a essa dissertação, com o objetivo de discutir as ideias e métodos atualmente empregados. Na seção seguinte serão apresentados os detalhes da arquitetura WSARCH e seus componentes 


\section{A arquitetura WSARCH}

\subsection{Considerações Iniciais}

A arquitetura SOA utilizada no desenvolvimento desta dissertação é denominada WSARCH, a qual se encontra implementada e funcional. O protótipo serviu como base para o desenvolvimento dos mecanismos tolerantes a falhas, bem como para os testes e avaliação de desempenho dos algoritmos propostos.

\subsection{Arquitetura WSARCH}

Para os propósitos do desenvolvimento desta dissertação de mestrado é importante mencionar a utilização de uma arquitetura denominada WSARCH (Web Services Architecture). Trata-se de um projeto de doutorado finalizado em 2010, com o apoio da FAPESP (Fundação de Amparo à Pesquisa do Estado de São Paulo), cujo objetivo foi desenvolver uma arquitetura para a provisão de Web Services com qualidade de serviço.

Ressalte-se ainda que as pesquisas com o protótipo da WSARCH (Estrella, 2010), (Estrella et al., 2010), (Estrella et al., 2011) prosseguem sob um projeto regular de pesquisa, também apoiado pela FAPESP, que prevê extensões de suas funcionalidades e integração de novos projetos. Um dos aspectos até então não considerados no protótipo era a preocupação com falhas decorrentes dos diversos componentes da arquitetura, que podem degradar o desempenho geral do sistema. Foi preciso entender e considerar como as fa- 
lhas no UDDI e nos provedores de serviços podem prejudicar, por exemplo, o tempo de resposta percebido por uma aplicação cliente ou aplicações de um processo de composição de serviços (situação em que um fluxo de execução precisa ser completado para a obtenção do resultado desejado), entre outros.

WSARCH é uma arquitetura projetada para estudar em detalhes as características de interoperabilidade dos Web Services (Estrella et al., 2011). Problemas, configurações e implementações podem ser projetados, instalados e avaliados. A gama de assuntos envolvida no projeto é variada, passando por rede de comunicação, segurança em mensagens SOAP, caracterização de carga de trabalho (Tavares et al., 2008), composição de serviços (Kuehne et al., 2010) e tolerância a falhas. A Figura 3.1 mostra de forma geral o funcionamento da arquitetura WSARCH:

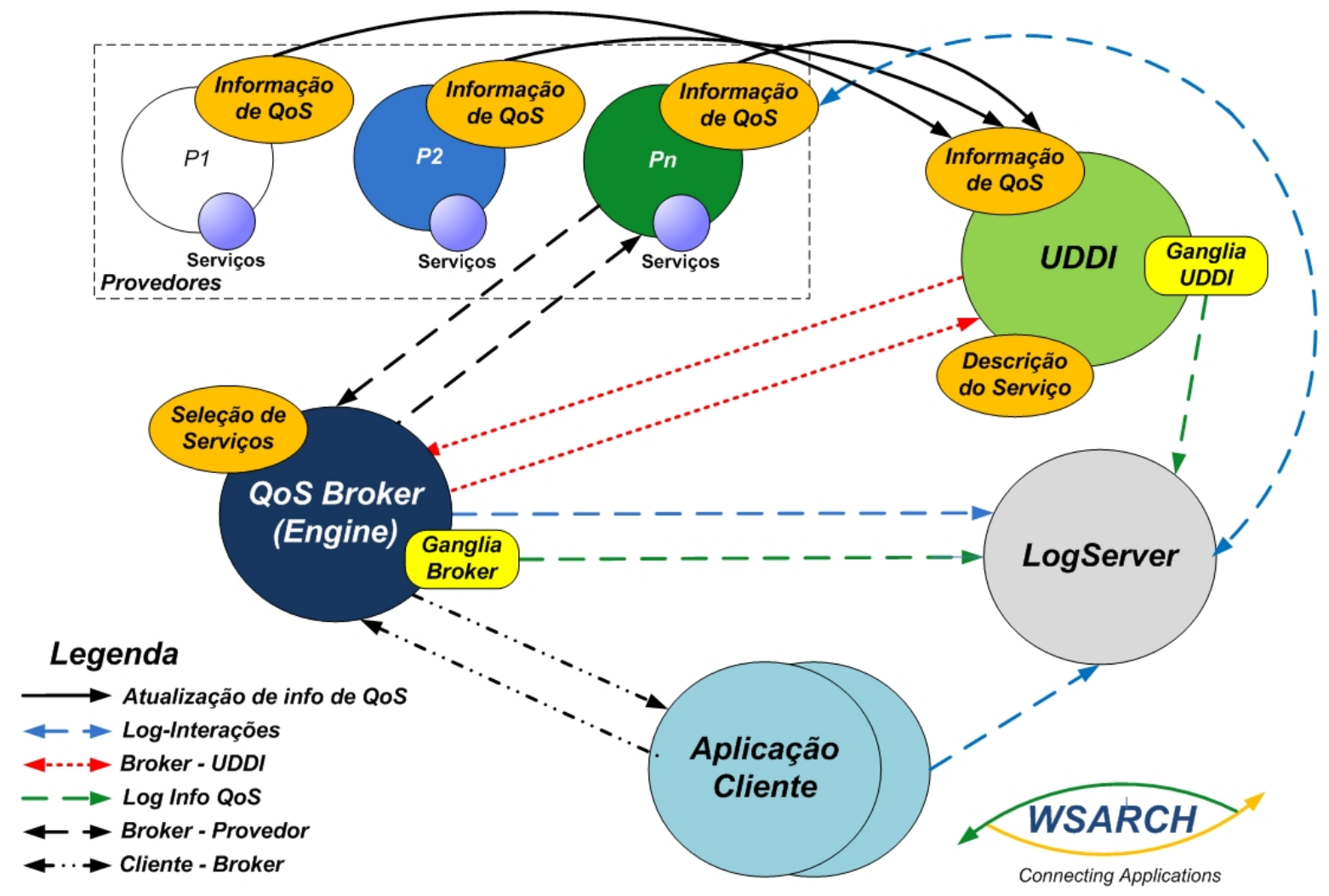

Figura 3.1: A arquitetura WSARCH e seus componentes (Estrella et al., 2011)

Os componentes da arquitetura são descritos a seguir:

- Provedor de serviços: É o responsável por oferecer os serviços aos clientes. Mantém informações sobre sua localização e QoS no repositório UDDI.

- Broker: É o componente que faz a busca de um provedor, conforme o serviço solicitado por um cliente e suas necessidades de atendimento. Conhece os valores dos melhores provedores que contém determinado serviço em um instante de tempo, 
baseado nas informações de QoS armazenadas no UDDI. É responsável também pela negociação, direcionando as conexões vindas dos componentes da arquitetura de acordo com as informações atuais. Em caso de impossibilidade no atendimento, os critérios podem ser alterados ou a requisição descartada. Apresenta também uma base de dados, para armazenamento das informações de QoS.

- UDDI: É o repositório onde ficam armazenados os dados de localização dos provedores e respectivos serviços oferecidos. Quando é realizada uma solicitação, o Broker faz a seleção do melhor provedor disponível e em seguida pergunta qual a localização deste ao UDDI, o qual retorna os dados armazenados das trocas de mensagens com os provedores. A partir disso, o Broker pode responder ao cliente e entregar o serviço solicitado.

- Cliente: É o componente interessado nos serviços oferecidos pela arquitetura. O cliente precisa dos serviços hospedados nos provedores, porém não faz a requisição diretamente a estes. Qualquer solicitação de um cliente é feita ao Broker, o qual possui informações dos melhores provedores e das necessidades de atendimento daquele cliente. A partir disso, é possível fazer a negociação das conexões, e informar qual a descrição e como solicitar o provedor.

- LogServer: Recebe informações dos componentes da arquitetura, e mantém as transações armazenadas para verificação. É responsável também por guardar os dados coletados pelo monitor Ganglia, que interage com vários módulos (Estrella, 2010), (Estrella et al., 2010), (Estrella et al., 2011).

- Monitor Ganglia: Aplicação presente nos provedores de serviços, no UDDI e no Broker, o responsável por coletar os índices de desempenho desses componentes. Os provedores possuem monitores escravos, os quais reportam as informações ao monitor mestre, encontrado no UDDI. Assim o Broker possui dados de QoS dos serviços, para fazer a seleção e atender aos clientes. Esses dados são atualizados a cada um segundo. (Massie et al., 2004) (Estrella, 2010), (Estrella et al., 2010), (Estrella et al., 2011).

A comunicação entre os componentes da WSARCH é feita por meio de uma rede dedicada, com switches próprios da arquitetura, e alguns canais exclusivos para tráfego de dados de qualidade de serviço. Um dos módulos que possui esse canal de monitoração é o Broker, que utiliza essas informações para escolher os melhores provedores. O LogServer também usa um meio próprio para receber dados dos demais componentes e armazená-los em um banco de dados, como apresentado na Figura 3.2. 


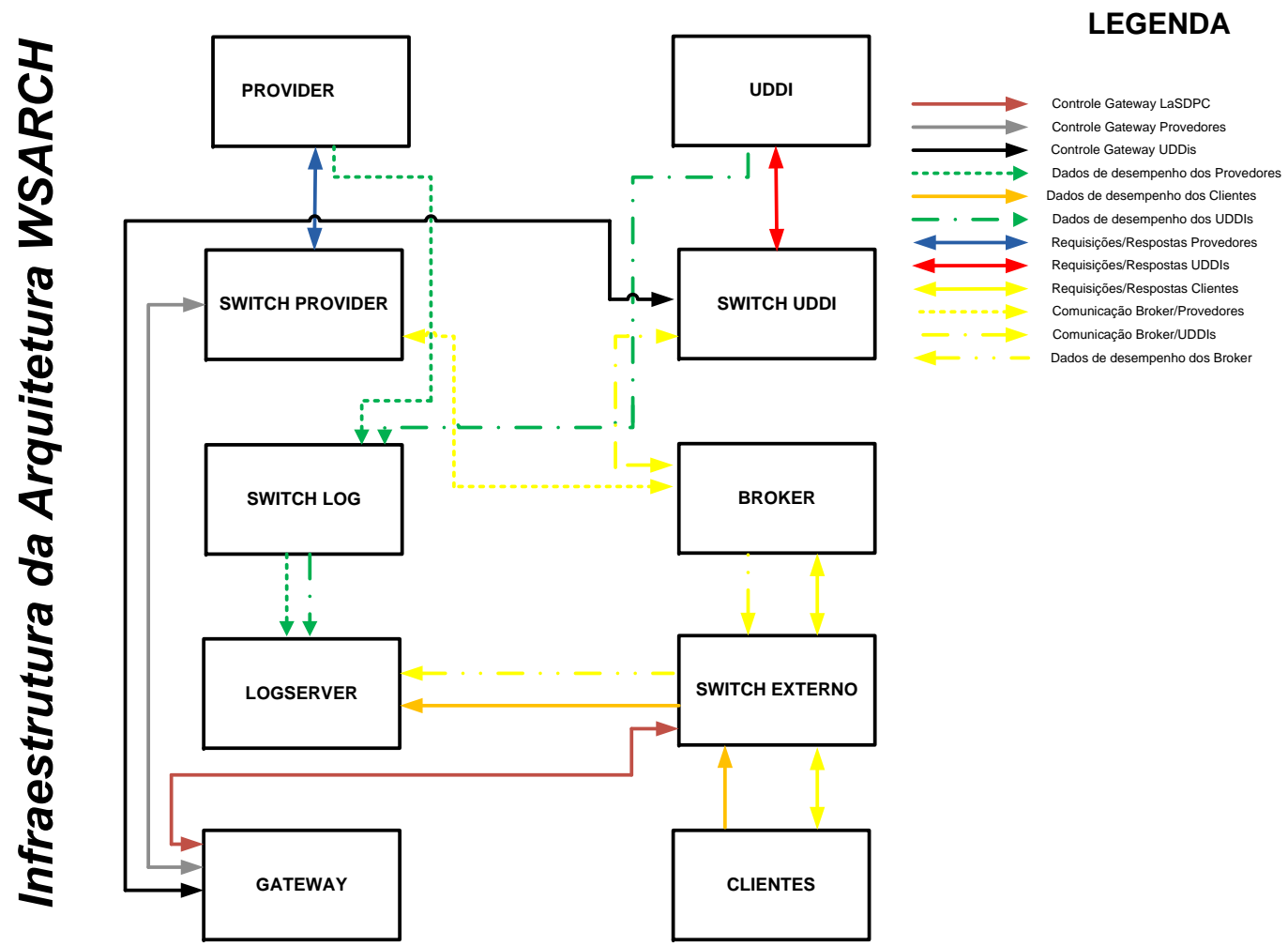

Figura 3.2: Interrelação entre os componentes da WSARCH (Estrella et al., 2011)

\subsubsection{Seletor de serviços}

O Broker da arquitetura apresenta módulos responsáveis pelo balanceamento de carga, roteamento de requisições e seleção de provedores de serviço. No projeto inicial da WSARCH foi desenvolvido um seletor de serviços padrão, o qual foi projetado para escolher os provedores de acordo com os níveis de QoS exigidos pelos clientes. Este seletor, denominado Default Selector utiliza o princípio da distância euclidiana para calcular os valores de QoS, que variam entre 0 e 1 (Estrella, 2010). Esse valor serve tanto para diferenciação dos clientes em classes quanto para informar ao Broker qual o nível do serviço a ser oferecido àquele usuário. Seu funcionamento é detalhado no pseudo-código 3.1. O fluxo de eventos na arquitetura, quando utilizado o Default Selector pode ser acompanhado no diagrama de sequência da Figura 3.3.

Devido à natureza de fraco acoplamento de arquiteturas orientadas a serviço, foi possível desenvolver algoritmos distintos, como evolução da WSARCH, os quais utilizam valores do Default Selector para fins de comparação e avaliação de desempenho.

Da maneira como foi originalmente projetada, a arquitetura não previa nenhum tipo de garantia de dados ou transações. Não havia políticas de redundância, recuperação ou registro de requisições, o que pode ser prejudicial aos clientes. A falta dessas estratégias compromete a disponibilidade do sistema, podendo ocorrer quedas no serviço e esperas 


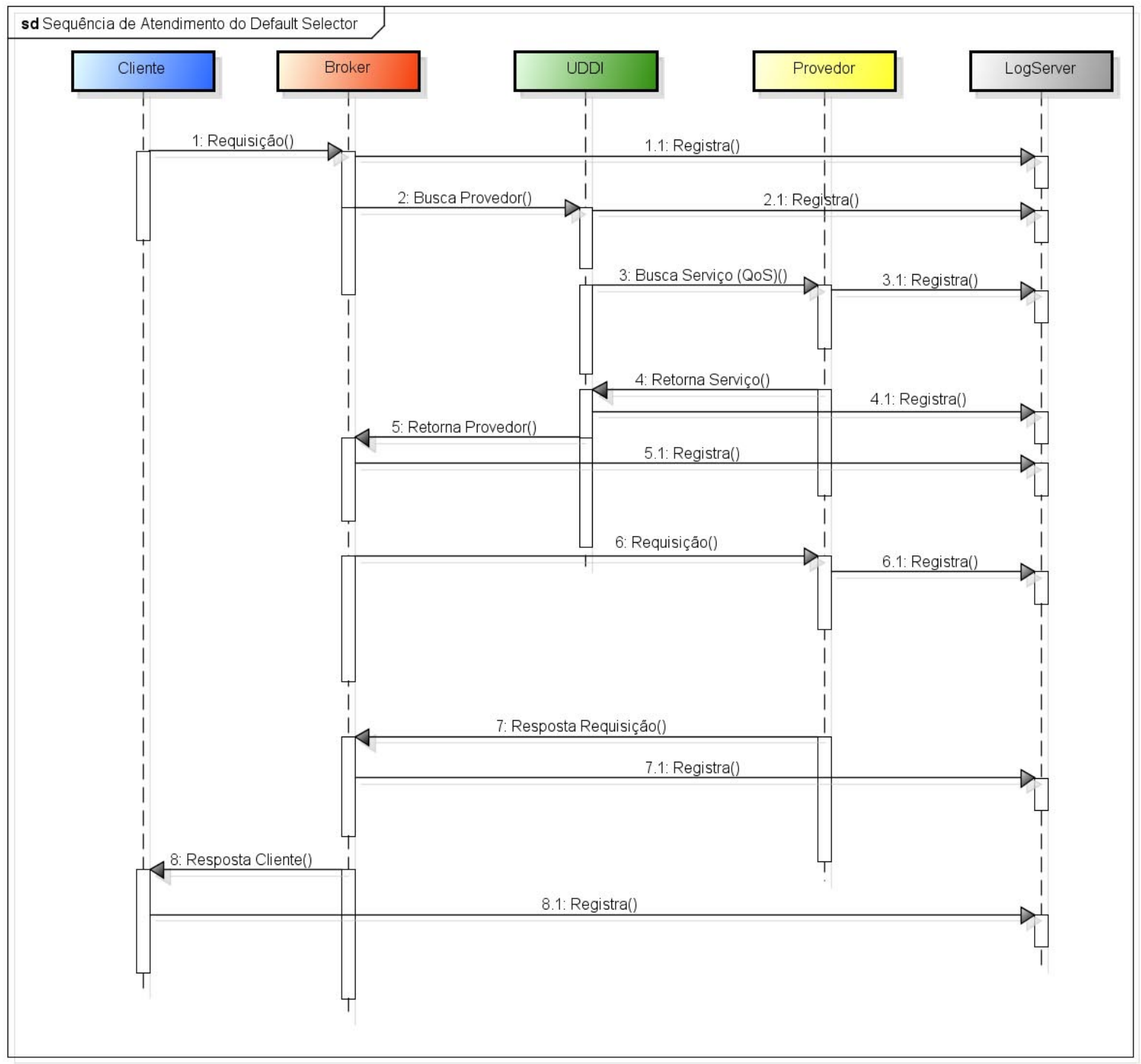

powered by Astahate

Figura 3.3: Diagrama de sequência do funcionamento do Default Selector 


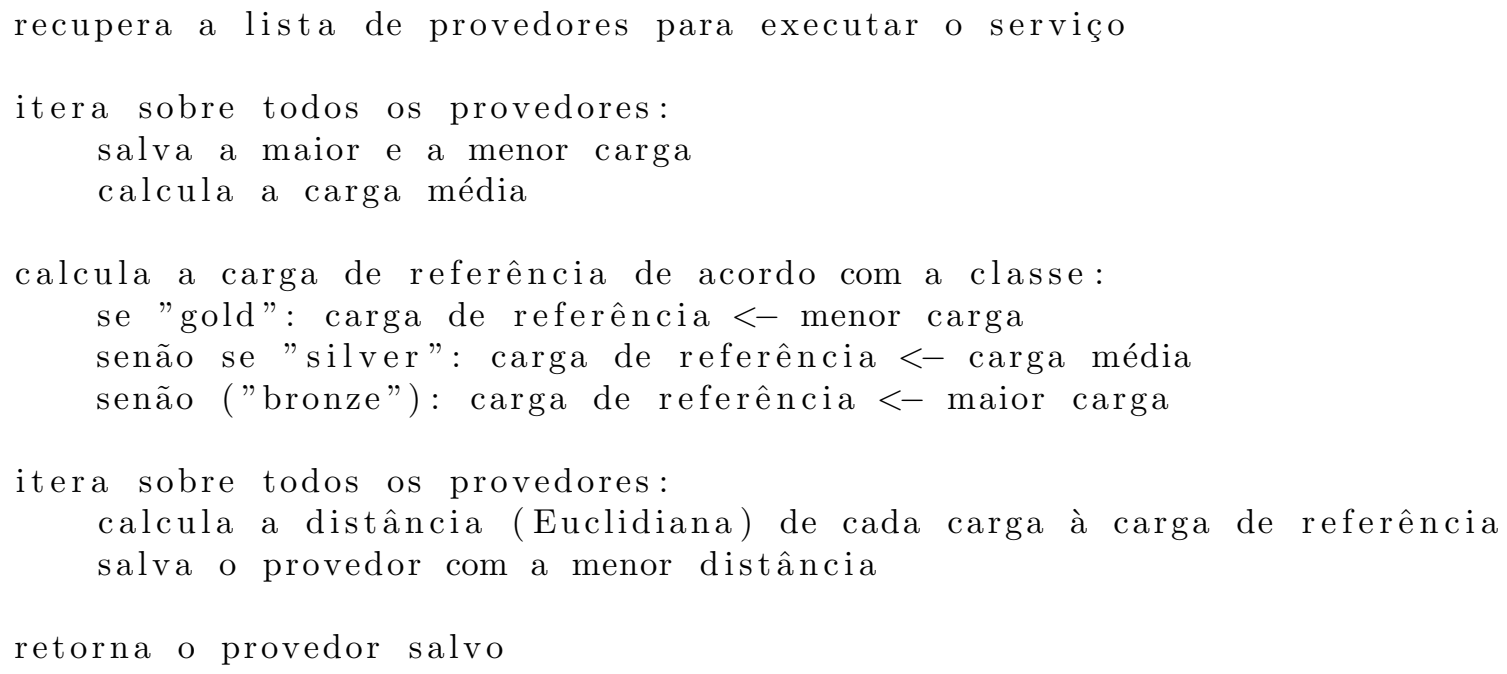

Código 3.1: Default Selector Algorithm

intermináveis por respostas. Além disso, requisições podem ser perdidas, uma resposta, mesmo enviada, pode não ser recebida pelo cliente ou um serviço pode continuar aceitando requisições, mesmo sem ter capacidade de atendê-las. Inclusive não havia uma avaliação do histórico recente de falhas ocorridos nos componentes. Um sistema que estivesse com falhas constantemente poderia continuar sendo escolhido para o atendimento, ainda que fosse grande a probabilidade de uma queda.

\subsection{Mecanismos Tolerantes a Falhas}

Ferramentas de tolerância a falhas são aquelas que proporcionam disponibilidade e confiança aos sistemas. Essas ferramentas são indispensáveis para os sistemas críticos, que não podem deixar de funcionar ou que possuem limites de indisponibilidade (Pullum, 2001). Como exemplos desses mecanismos podem ser citados os servidores de backup, que fazem o espelhamento dos dados armazenados no servidor principal. Em caso de falha neste último, as cópias de segurança podem ser acionadas para atender as necessidades dos clientes, sem que estes notem o problema. Outra opção são os mecanismos de desvio de fluxo. Nesse caso, havendo um problema em uma máquina, as requisições são direcionadas para outra que esteja em pleno funcionamento. Também podem ser citados softwares de monitoramento de estado, como os heartbeats. Essa estratégia consiste em enviar requisições de verificação de tempos em tempos para um equipamento, de modo a certificar-se do seu bom funcionamento. Em caso de falha na resposta, ele pode acionar os mecanismos de reserva para manter o funcionamento do serviço enquanto o problema não é solucionado (Nakamuta et al., 2007). Há ainda os saltos condicionais. Nesse caso, 
quando é encontrado um problema em um software, ele é simplesmente ignorado, seguindo com o fluxo do programa, e sendo futuramente verificada a necessidade de conserto no código. Em caso negativo, o problema é descartado. Contudo essa estratégia é prejudicial em operações de composição de serviço

\subsubsection{Ferramentas de Injeção de Falhas}

Um dos maiores desafios da manutenção de sistemas de alta disponibilidade é a garantia de suas caraterísticas, como localização, latência e recuperação (Ningfang Song e Deng, 2011). De acordo com (Bessayah et al., 2009), injeção de falhas é uma estratégia poderosa para testar protocolos de segurança e sistemas tolerantes a falhas. Há outras técnicas para validar os conceitos de alta disponibilidade de uma arquitetura, como modelagem analítica e técnicas experimentais. A dificuldade com a modelagem reside no fato de que os protótipos podem ser muito abrangentes, e os testes feitos em ambiente controlado podem não representar com fidelidade os problemas reais. Com relação à experimentação, o sistema fica sob observação até que ocorra um defeito, o que é bastante interessante em diversos casos, mas inapropriado para aqueles considerados de alta confiança (Ningfang Song e Deng, 2011). Injeção de falhas são meios de motivar problemas e defeitos em um sistema, para contribuir na avaliação do sistema e validar estratégias de tolerância a falhas. Para fins de testes e observação de comportamento são utilizadas ferramentas de injeção de falhas. Esses mecanismos atuam simulando problemas reais, e permitem conhecer na prática a reação do sistema às dificuldades. Essa técnica é utilizada em sistemas onde se busca a recuperação de erros e tolerância a falhas (Bessayah et al., 2009). Podem também ajudar a corrigir falhas no projeto, e expor falhas graves, que devem ser evitadas a todo custo. O primeiro passo na construção de uma falha completa por meio do processo de injeção é a especificação de um cenário de falha para o experimento. Isto inclui a especificação do injetor de falhas, a localização, o tipo e o tempo de falhas injetadas (Bessayah et al., 2009). Um exemplo desse processo pode ser observado no modelo FARM, na Figura 3.4. Esses conjuntos definem:

- F: as falhas a serem injetadas no sistema;

- A: os comandos e ações que levarão as falhas do conjunto F a serem acionadas;

- R: as saídas encontradas ao final do processo de injeção de falhas;

- M: as métricas predefinidas que podem ser avaliadas ao final do processo;

- Sistema destino: é aquele onde serão injetadas as falhas, e que está sob avaliação. 


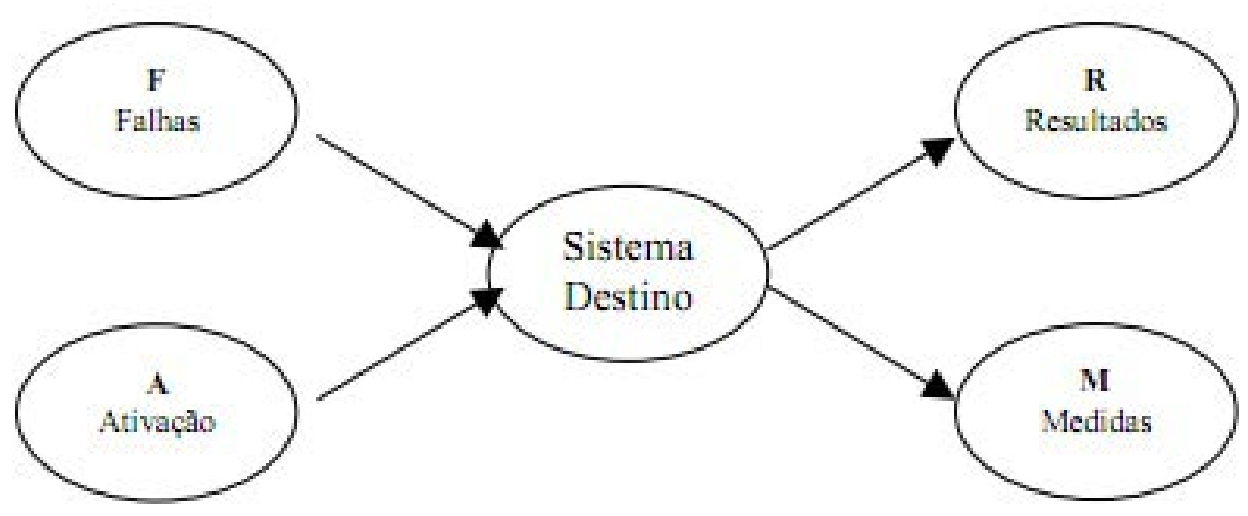

Figura 3.4: Conjuntos FARM (Manfredini, 2001)

Com essa técnica, as falhas são inseridas para identificar gargalos de disponibilidade, comportamento do sistema e determinar a cobertura da detecção e recuperação de falhas, além de validar a segurança contra perda de desempenho (Ping, 2010). Uma ferramenta de injeção de falhas pode, por exemplo, simular um volume excessivo de acessos simultâneos, o que pode sobrecarregar o sistema e consequentemente colocá-lo fora do ar. Baseado nesse ataque simulado é possível estimar o volume regular de acessos, e o limite dos servidores, o que permite planejar o sistema para suportar uma carga considerável de clientes concorrentemente. Aliada aos diversos meios de se prover disponibilidade, a injeção de falhas pode corroborar as hipóteses levantadas nos estudos de caso, tornando válidos os modelos propostos. A Figura 3.5 ilustra um esquema de injeção de falhas. O modelo de falhas é configurado e armazenado em um arquivo para fins de análise. Esses detalhes são transmitidos ao injetor, responsável por fazer as alterações no ambiente do sistema. Junto do sistema em avaliação são acionados os monitores, responsáveis por observar as reações do ambiente e armazenar os dados em um registro. Ao final são disponibilizados os dados de saída do sistema e as informações coletadas pelos monitores, quando é iniciada a avaliação.

\subsubsection{Ferramentas de Detecção de Falhas}

Sistemas para detecção de falhas são aqueles destinados a informar um gerente (seja ele humano ou eletrônico) que algo não está adequado em uma arquitetura. O monitoramento pode ser feito basicamente de duas formas: orientado a eventos ou orientado a amostragem. Quando baseado em eventos, uma alteração de estado aciona um sistema de notificação ou monitoramento. Esse caso é tipificado como assíncrono e indicado para aqueles sistemas onde a sobrecarga deve ser menor. No caso da amostragem, a monitoração é feita constantemente, em intervalos de tempos regulares. É mais utilizado para 


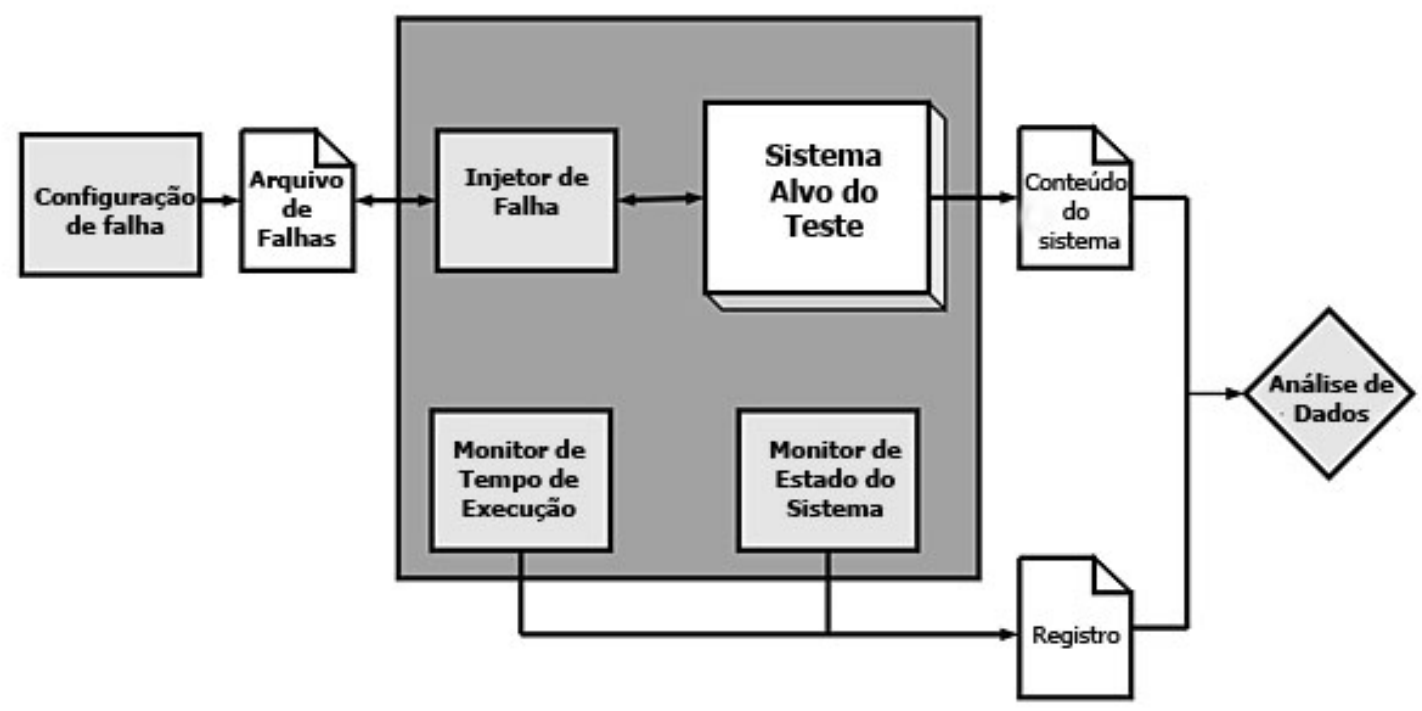

Figura 3.5: Modelo de injeção de falhas em um sistema. Adaptado de (Touloupis et al., 2007).

coletar dados de eventos frequentes, e uma das problemáticas é o tempo a ser utilizado como espaço entre os monitoramentos. Caso o intervalo seja muito pequeno, a sobrecarga será muito alta. Caso contrário, alguns eventos importantes podem ser perdidos, o que descaracterizaria a avaliação (Pullum, 2001). Em um esquema de monitoração orientado à aplicação, o detector separa os atores envolvidos em três classes identificáveis:

- Monitores: os componentes responsáveis por escutar o sistema e perceber qualquer comportamento anômalo ao esperado

- Objetos monitoráveis: os componentes alvo do processo de monitoração, que terão seu comportamento acompanhado pelos monitores

- Objetos notificáveis: os componentes a serem informados em caso de problemas, os quais deverão registrar os eventos ou tomar decisões para manter o sistema em funcionamento (Felber et al., 1999).

Essa abstração permite ao modelo de detecção de falhas focar-se no universo das falhas, sem se preocupar com demais detalhes da arquitetura. Quando utilizado um mesmo software em diversos meios, os monitores serão iguais para os diversos usos, porém os objetos monitoráveis e os notificáveis serão inerentes ao ambiente monitorado, sendo necessárias configurações adequadas para permitir a intercomunicação (Nakamuta et al., 2007). Por outro lado, no modelo orientado a serviço, informações de defeitos na arquitetura são divulgadas pela rede do sistema, utilizando as políticas Pull ou Push basicamente. No modelo Push os objetos monitoráveis enviam periodicamente informações de heartbeat junto com 
o fluxo normal de informação. Assim, eles são atuantes no processo de monitoramento, e um objeto é considerado suspeito quando ele não envia dados dentro de determinado período de tempo. É uma opção bastante eficiente quando o sistema trabalha com fluxo de dados unidirecional (Nakamuta et al., 2007). Um exemplo desse modelo pode ser visto na Figura 3.6:

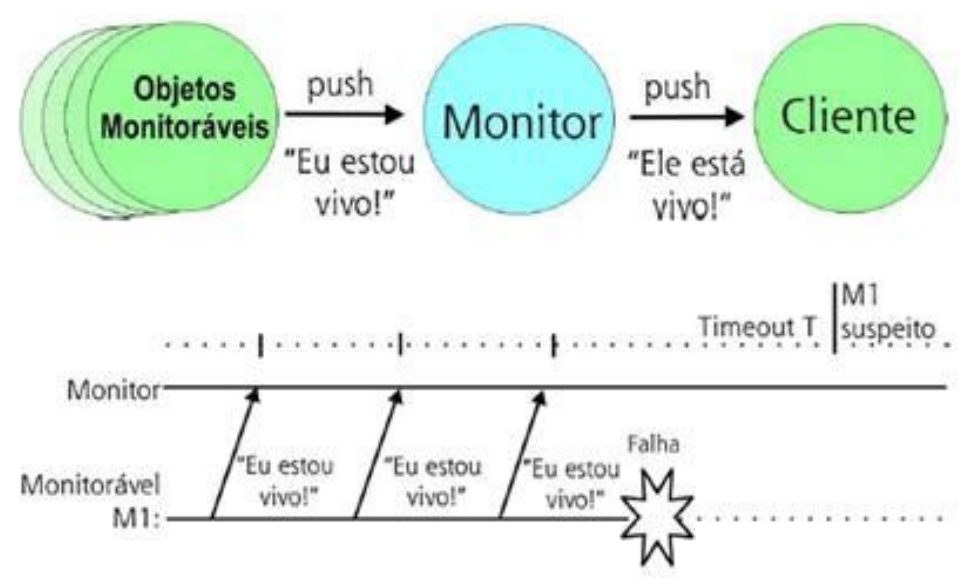

Figura 3.6: Modelo Push (Felber et al., 1999)

Por sua vez, no modelo Pull as informações de funcionamento de um serviço são enviadas apenas quando solicitadas por um cliente. Os monitores enviam requisições de liveness para os objetos monitoráveis de tempos em tempos, e quando estes respondem, significam que continuam funcionando. Se não é obtida resposta, o objeto entra em estado de suspeição. Ainda que mais simples de ser projetado pelo desenvolvedor, esse modelo é menos eficiente, devido ao esquema de mensagens bidirecionais (Nakamuta et al., 2007). Esse modelo é ilustrado pela Figura 3.7:

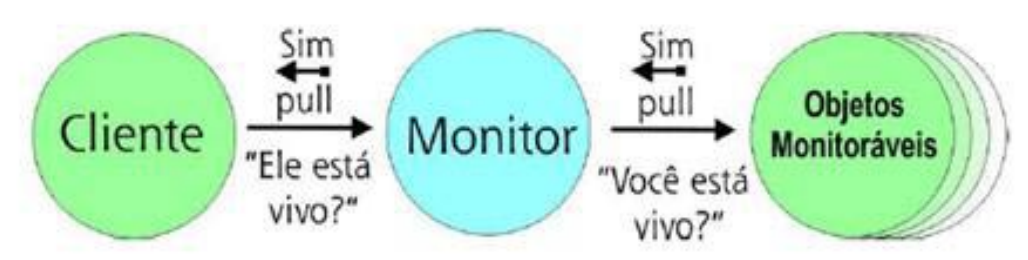

Figura 3.7: Modelo Pull (Felber et al., 1999)

Outra alternativa possível, é o modelo que mescla as duas técnicas anteriormente descritas, denominado Dual. Nesse esquema, os objetos são mantidos no sistema Push, e os objetos enviam periodicamente informações de funcionamento. Em caso de atraso no envio dessas mensagens, o sistema aciona o modelo Pull, enviando requisições de liveness àqueles objetos que aparentemente não estão funcionando. Se ainda assim não for obtida 
nenhuma resposta, o objeto é reportado como suspeito ao monitor (Nakamuta et al., 2007).

\subsection{Considerações Finais}

Este capítulo descreveu a arquitetura utilizada no trabalho e o seletor principal. Foram apresentadas ferramentas de tolerância a falhas que abordam a ideia geral da técnica, bem como ferramentas de injeção de falhas, as quais simulam ataques ou quedas de rendimento no sistema e são de grande utilidade para mensurar problemas reais. Além disso foram apresentados mecanismos de detecção de falhas, que monitoram o ambiente em busca de comportamentos inesperados. O próximo capítulo trata da metodologia utilizada para o desenvolvimento dos mecanismos integrados à arquitetura. 


\section{Desenvolvimento do Projeto}

\subsection{Considerações Iniciais}

A expansão dos Web Services trouxe novas preocupações aos desenvolvedores desses sistemas. A busca por serviços mais confiáveis tornou-se um objetivo básico dos pesquisadores da área, devido à sua utilização em áreas de risco ou dependentes de alta disponibilidade (Li et al., 2009). Para possibilitar a confiabilidade necessária aos clientes, os conceitos de tolerância a falhas passaram a ser empregados no contexto de Web Services, tornando esses serviços mais robustos. Alta disponibilidade está atrelada a um overhead causado pelos mecanismos adicionados ao sistema, para evitar quedas, sendo importante ter muito critério na escolha desses componentes, buscando minimizar os custos (Echtle e Masum, 2000).

\subsection{Reputação em Web Services}

Mecanismos de reputação vem sendo cada vez mais empregados como importantes ferramentas de apoio ao trabalho de seleção de serviços. São baseados em informações das transações passadas dos componentes de uma arquitetura, as quais permitem classificar os Web Services mais aptos a atenderem as requisições dos clientes, de acordo com critérios de qualidade. A reputação dos Web Services é regular e dinamicamente recalculada. Possíveis parâmetros de QoS utilizados são tempo de resposta, disponibilidade e segurança. 
A reputação pode ser usada para estabelecer a confiança, onde interações ou desempenho passados são utilizados para futuras seleções e também ajudar a prever prováveis níveis de QoS nas próximas iterações (Li et al., 2009).

Reputação é considerada um modelo colaborativo de classificação dos serviços (Zhu et al., 2011). O retorno obtido dos usuários do sistema pode complementar os mecanismos de ranqueamento automáticos. Isso permite uma visão detalhada do passado do sistema, considerando que a avaliação dos clientes é fiel e coerente, uma vez que visa um melhor atendimento aos mesmos. A oportunidade dos clientes interagirem com o sistema de seleção de Web Services se deve ao elevado número de fornecedores de serviços semelhantes (Zhu et al., 2011). Como o resultado final é o que interessa, o usuário tem a oportunidade de definir seus critérios, da maneira como achar conveniente, podendo optar por maior precisão ou velocidade, por exemplo.

Para esta dissertação de mestrado, foi desenvolvido um modelo de reputação que busca reduzir as possibilidades de falhas, selecionando provedores mais confiáveis ao fazer uma transação, por meio de um seletor de serviços. Esse seletor é capaz de escolher entre os provedores mais confiáveis de acordo com um ranking atualizado em tempo real. Quando um provedor fica indisponível, ele é marcado com um valor indicando o nível de risco correspondente. Quanto mais tempo offline, pior será sua classificação. Assim, o seletor selecionará preferencialmente os provedores melhor qualificados, sem esquecer a qualidade do serviço.

Como pode ser observado na Figura 4.1, foi adicionado o módulo LOGDAM (Data Analyzer Module for Logs of Service Oriented Architecture) (Adami e Estrella, 2012), originário de um projeto de iniciação científica e anteriormente utilizado no contexto de de mineração de dados. Nesta dissertação, ele passa a ser utilizado como mecanismo de substituição do UDDI, como será apresentado no decorrer desta Seção. No Broker da arquitetura foram desenvolvidos mais dois seletores de serviços, o primeiro deles denominado Risk Selector, o qual é responsável por fazer a análise do histórico de disponibilidade dos provedores e que será detalhado a seguir. O segundo, chama-se Round Robin Selector e é utilizado como auxiliar no processo de seleção, quando o Intelligent Selector apresenta resultados inadequados. A monitoração desses resultados e a escolha do momento da troca para o Round Robin Selector são feitas por um algortimo denominado Intelligent Swap Mode, o qual também decide quando o Intelligent Selector pode voltar a atuar.

Na Tabela 4.1 são descritos os tipos de seletores de serviço encontrados na arquitetura, desde o seu seletor original quanto os demais acrescentados para essa dissertação. Todos operam diretamente do Broker, inclusive o Intelligent Selector cujo módulo é integrado ao componente principal. 
Tabela 4.1: Default Selector e novos seletores adcionados à WSARCH

\begin{tabular}{|c|c|c|c|}
\hline \multicolumn{4}{|c|}{ Seletores da arquitetura WSARCH } \\
\hline Seletor & Parâmetros & Mecanismo & Acionamento \\
\hline Default Selector & Qos & Distância Euclidiana & Pré-definido \\
\hline Risk Selector & Qos + Reputação & Disponibilidade do provedor & Pré-definido \\
\hline Intelligent Selector & Histórico de atendimento & Mineração do LogServer & Falha no UDDI \\
\hline Round Robin Selector & Provedores pré-selecionados & Lista circular & Intelligent Swap Mode \\
\hline
\end{tabular}

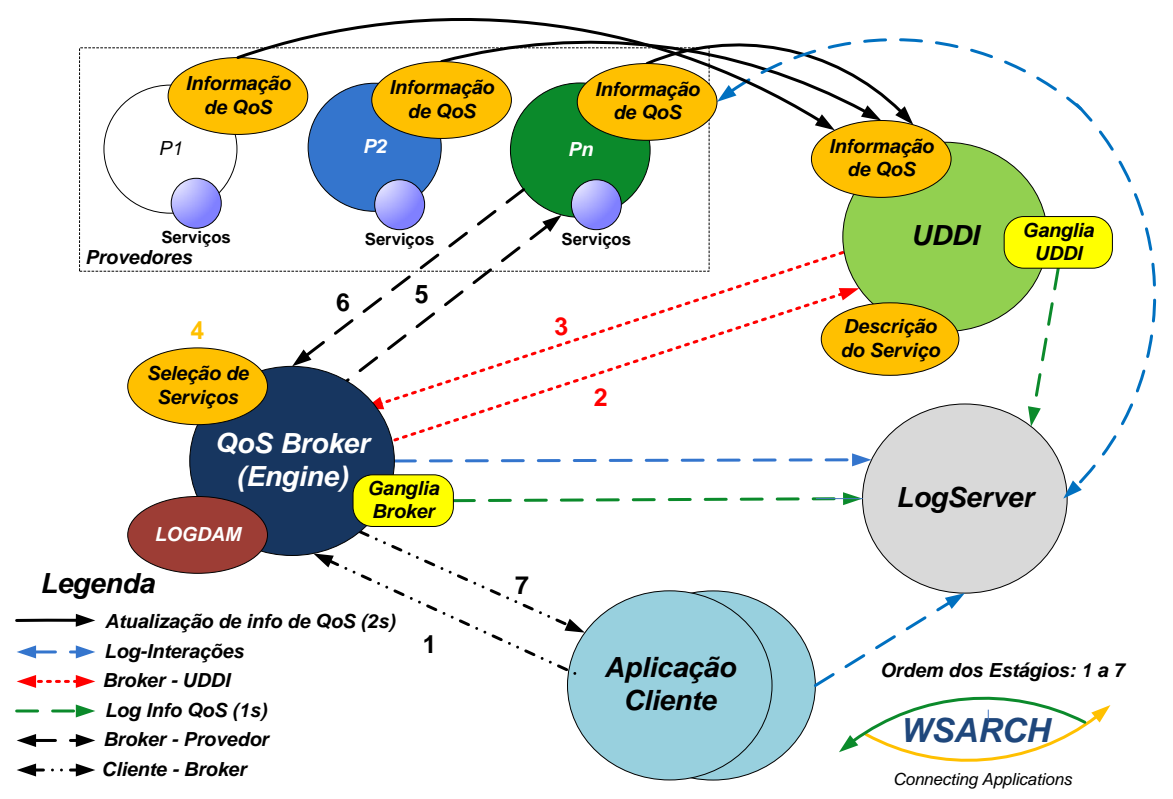

Figura 4.1: Arquitetura WSARCH, com adição do Intelligent Selector e demais seletores no Broker

\subsection{Risk Selector}

O Risk Selector é um seletor de Web Services que une as diretivas de qualidade de serviço com dados de reputação dos provedores, no intuito de proporcionar resultados mais adequados para os clientes da arquitetura.

Este seletor se preocupa em escolher os provedores mais aptos para atender as requisições dos clientes. Busca, com base em parâmetros predefinidos deixar de fora do escopo de selecionáveis os provedores com alto risco de queda no serviço, ou com mau histórico de atendimentos.

O Risk Selector cria em tempo real um ranking dos provedores, de acordo com o seus comportamentos ao atender as múltiplas requisições. Um provedor que sofra uma queda, terá o seu risco aumentado, diminuindo a possibilidade de ser selecionado em um futuro próximo. Quanto pior o comportamento de um provedor, mais tempo ele ficará fora da lista de provedores aptos a fazer os atendimentos das requisições. 
Em operações de risco, sejam financeiras ou de risco à vida, é imprescindível garantir a qualidade no serviço oferecido. É imperativo assegurar que apenas os melhores e mais confiáveis componentes estarão envolvidos nas transações, para evitar grandes perdas e ao mesmo tempo, permitir ao usuário sentir confiança no sistema.

O modelo desenvolvido faz com que um provedor em estado offline tenha o valor de risco acrescido periodicamente. Da forma como foi desenhado, os provedores são testados a cada um segundo. Caso o último tempo de resposta seja maior que cinco segundos, o risco é acrescido de um. Esses parâmetros foram definidos empiricamente e reajustados após experimentos iniciais, com objetivo de adequarem-se aos padrões da arquitetura. Saliente-se que a classificação no ranking considera apenas a avaliação de risco, sendo o QoS avaliado separadamente, uma vez que são duas medidas distintas.

Com a utilização de um seletor que calcula o nível de risco de determinado provedor ao enviar uma requisição, a WSARCH torna-se mais confiável e robusta, já que o cliente não dependerá apenas dos requisitos de QoS para ser bem atendido. Enquanto a qualidade de serviço se preocupa com os pontos como velocidade do atendimento, respeito aos níveis de serviço contratados e completude das informações trafegadas, o Risk Selector deve garantir que os componentes com histórico recente de problemas sejam mantidos fora das transações até que sejam solucionadas as inconsistências.

Um provedor mal posicionado no ranking poderá ser escolhido pelo seletor, dependendo da situação do ambiente em um determinado momento. Por exemplo, apenas os provedores com rank igual a zero estão atendendo as solicitações durante um intervalo. Com o passar do tempo, eles podem começar a ficar sobrecarregados, de acordo com a taxa de requisições feitas, e isso fará com que a qualidade do serviço fique reduzida. Como QoS é o outro critério de seleção, o seletor poderá então optar por acionar um dos provedores com rank mais alto, uma vez que seu QoS estará ótimo, disponível para entrar em ação. Essa alternativa garante que os clientes não fiquem sem o atendimento desejado, ainda que arriscando uma perda maior de dados ao escolher um provedor pouco confiável. A qualidade de serviço também é um ponto chave no atendimento de Web Services, portanto a escolha por componentes menos sobrecarregados faz-se necessária nesses casos.

O seletor padrão do Broker da arquitetura é denominado Default Selector, e é utilizado como ponto de partida para os demais seletores desenvolvidos para experimentos. Este seletor tem como único parâmetro de trabalho os valores de QoS dos provedores, buscando sempre os provedores com melhores dados nesse quesito.

Quando um provedor recebe muitas requisições, seus valores de QoS começam a se degradar, indicando que ele pode estar sobrecarregado. Nessa situação, os clientes podem ter problemas em receber as respostas desejadas, seja por uma elevação no tempo de espera, seja por respostas incompletas ou incorretas. O Default Selector busca evitar 
essas situações, redirecionando as requisições para outros provedores menos ocupados no momento. Os índices de qualidade de serviço são atualizados periodicamente, em intervalos de tempo muito pequenos, para que a arquitetura tenha sempre os valores corretos. O controle de tráfego é feito por um monitor Ganglia que funciona dentro de cada provedor de serviços e transmite os dados para o UDDI, onde são consultados pelo Broker. Dessa forma, o seletor está apto a fazer a escolha mais adequada para os usuários.

Além disso, este seletor também trabalha pelo equilíbrio dos serviços, evitando sobrecargas que possam levar a uma queda em alguns componentes. Quando um serviço apresenta uma elevação na carga de trabalho, ele passa a ser evitado, até que o número de requisições diminua, e possa novamente trabalhar com eficiência.

O Risk Selector é uma extensão do Default Selector, mantendo a atenção aos requisitos de QoS dos provedores, para preservar o nível desejado pelos usuários, e inclui o modelo de reputação, oferecendo mais segurança e confiança, para que se possa fazer as escolhas mais adequadas a cada situação. O pseudo-código que descreve em linhas gerais seu funcionamento pode ser visto em no Código 4.1:

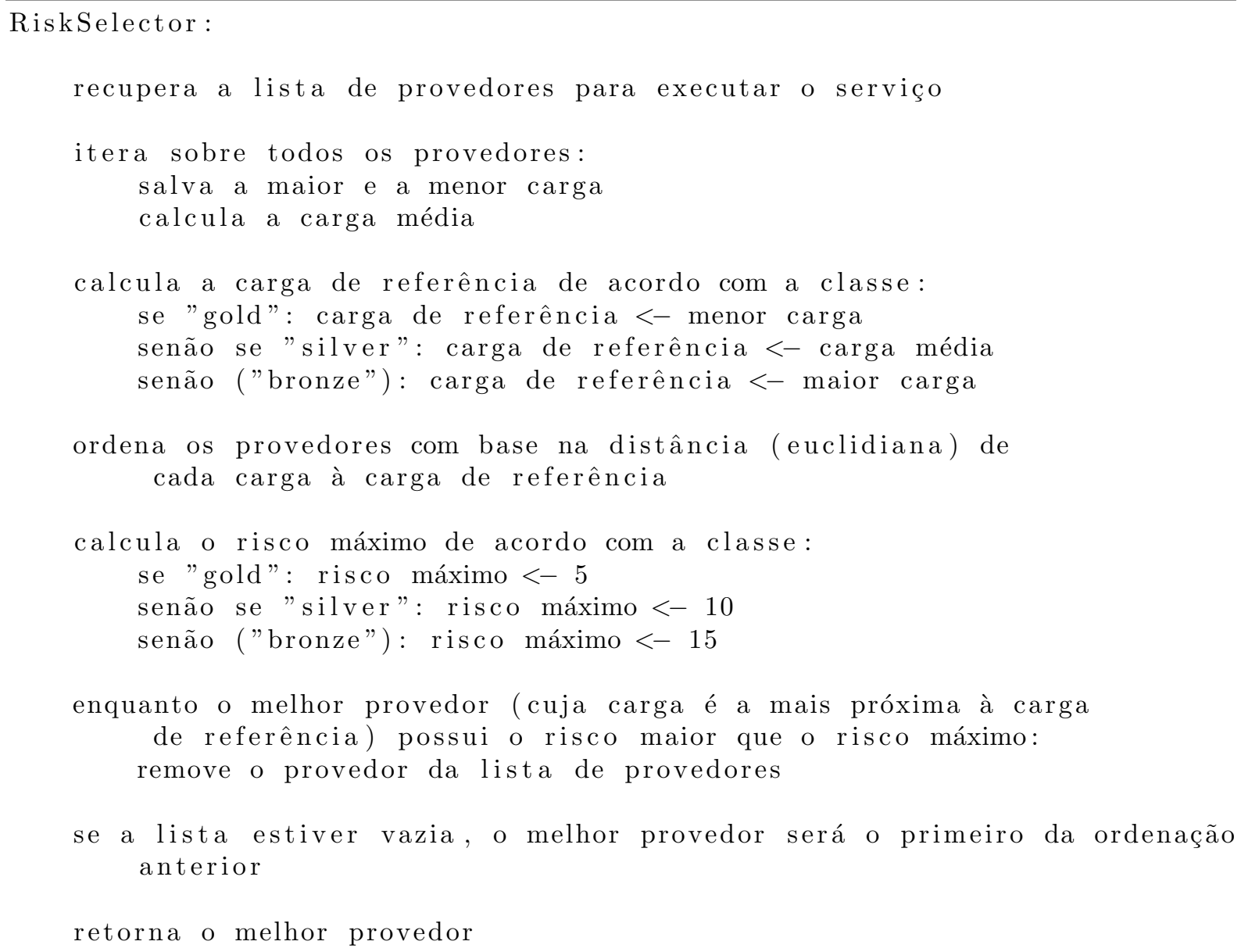

Código 4.1: Algoritmo do Risk Selector 


\section{CAPÍTULO 4. DESENVOLVIMENTO DO PROJETO}

A sequência de funcionamento da arquitetura com o Risk Selector é representada na Figura 4.2. Com esse seletor, os valores de reputação são requisitados junto com o QoS, permitindo ao Broker fazer a seleção com ambos os parâmetros.

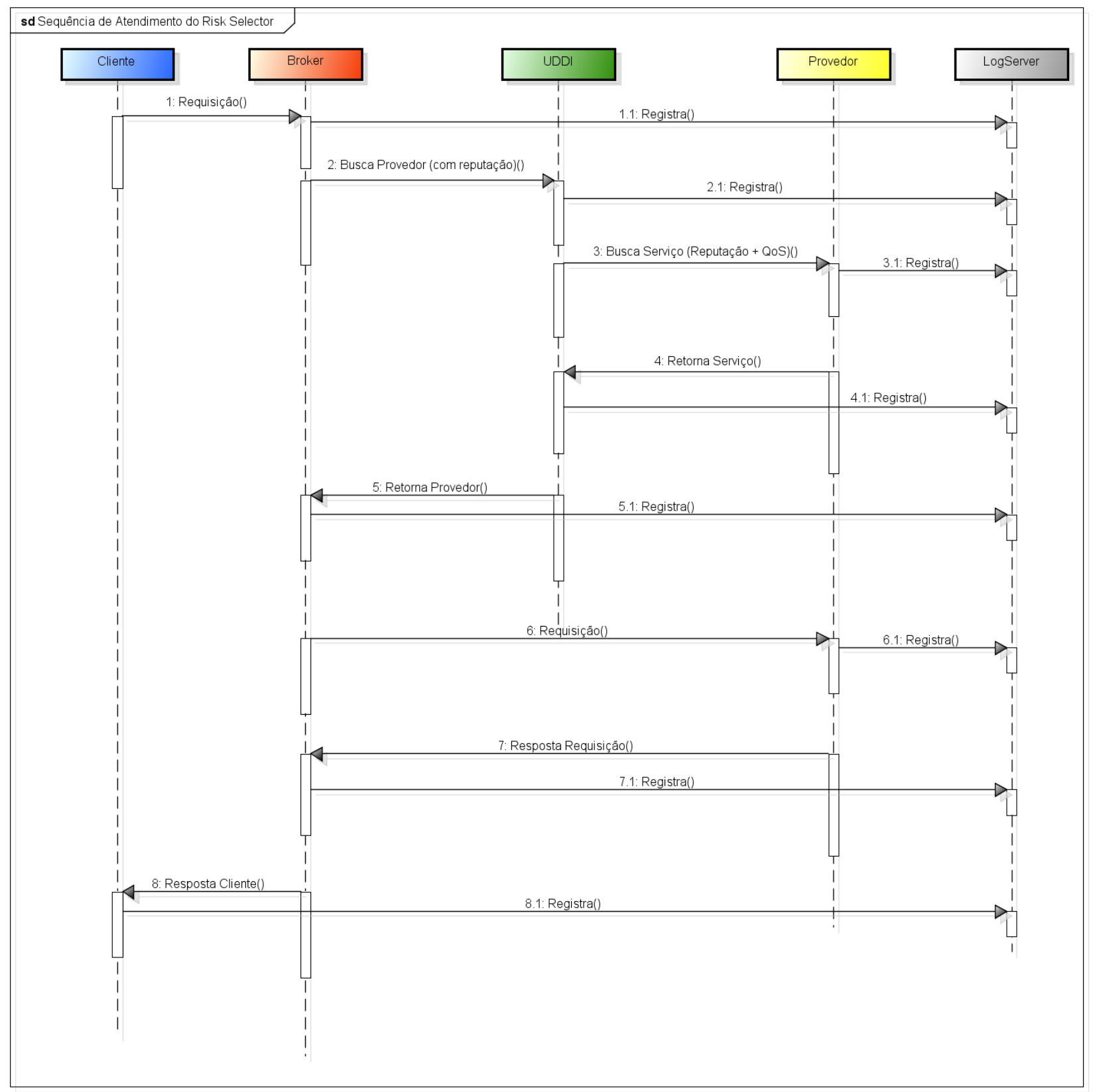

Figura 4.2: Diagrama de sequência do funcionamento do Risk Selector

\subsection{Intelligent Selector}

Com o propósito de funcionar como um módulo de tolerância a falhas, foi introduzido na arquitetura o Intelligent Selector. Este seletor é originário de um projeto de iniciação 
científica denominado LOGDAM (Data Analyzer Module for Logs of Service Oriented Architecture) (Adami e Estrella, 2012), é mais um seletor inserido no Broker da arquitetura, e que funciona em conjunto com este para manter o atendimento disponível, ainda que o repositório UDDI esteja fora de funcionamento.

O Intelligent Selector coleta informações do LogServer onde são registradas todas as transações da WSARCH, e faz uma mineração dos dados para definir quais provedores apresentam um histórico de atendimento favorável, para cada tipo de cliente. Um treinador mantém a classificação feita por algoritmos de aprendizado de máquina, e em seguida utiliza os parâmetros de IP (Internet Protocol) do cliente, nome do serviço, nome da operação e classe do cliente para fazer a seleção do provedor correto. Todos esses dados são coletados do LogServer (Adami e Estrella, 2012).

Este seletor dispõe de três algoritmos de mineração de dados, o IBk (Aha e Kibler, 1991), o Naïve Bayes (John e Langley, 1995) e Multilayer Perceptron (MLP) (Haykin e Simon, 1998). O algoritmo o IBk (também conhecido como K-nearest neighbors ou k-NN) faz o treinamento baseado no cálculo das distâncias entre um exemplo e as demais instâncias do treinamento. Uma vez encontrado o provedor do novo exemplo, este será o provável melhor provedor para seus k-vizinhos mais próximos (Aha e Kibler, 1991).

O algoritmo Multilayer Perceptron utiliza os conceitos de conexão entre os neurônios de uma rede, e o treinamento é feito por meio da atualização dos pesos dessas ligações. As atualizações dos valores são propagadas através das camadas a partir da entrada até a última. A seguir, é feito o caminho inverso, partindo da camada de saída, quando são reajustados os pesos das conexões (Haykin e Simon, 1998).

De acordo com o estudo do Intelligent Selector apresentado em (Adami e Estrella, 2012), avaliou-se que para este trabalho o algoritmo de treinamento mais indicado é o Naïve Bayes. Este é um classificador probabilístico simples baseado no teorema de Bayes. Ele considera que os atributos das classes que compõem o sistema são independentes, não necessitando de informação de atributos de outras classes (por esse motivo denominado naïve) (John e Langley, 1995). Os passos deste algoritmo estão detalhados no Código 4.2. Para cada novo exemplo gerado é calculada a probabilidade deste ser relacionado a um provedor. O provedor escolhido será o que tiver a maior probabilidade.

O modelo básico de funcionamento do seletor é exibido na Figura 4.3. O Intelligent Selector integra-se ao Broker da arquitetura. Uma vez acionado, o seletor utiliza os parâmetros recebidos do cliente para consultar o treinador a fim de obter o provedor mais adequado para atender à requisição. O treinador utiliza-se dos dados registrados no LogServer para definir quais os melhores provedores disponíveis. O treinamento do algoritmo de aprendizado de máquina é realizado constantemente, atualizando-se a cada 


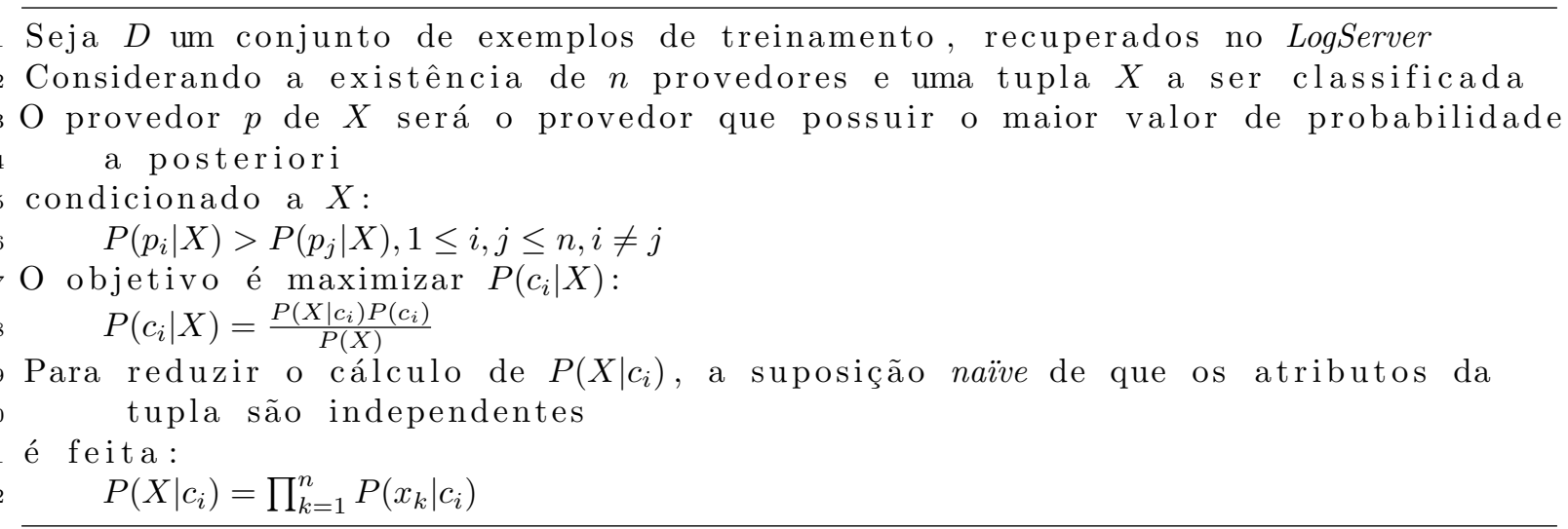

\section{Código 4.2: Algoritmo Naïve Bayes}

10 segundos. Após consultar o treinador, o seletor retorna ao Broker o IP do provedor que será responsável por atender ao cliente.

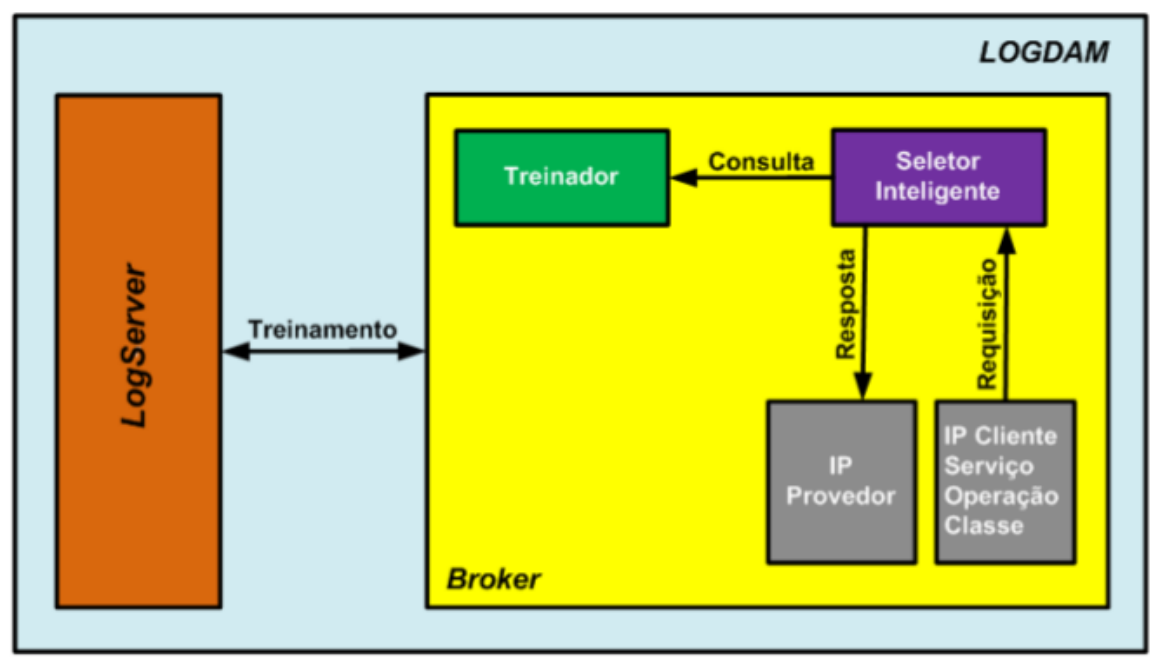

Figura 4.3: Funcionamento básico do Intelligent Selector (Adami e Estrella, 2012)

Um diagrama de sequência que representa o funcionamento da arquitetura com o Intelligent Selector pode ser observado na Figura 4.4.

O Intelligent Selector será ativado sempre que o Broker identificar que o UDDI não está disponível. O monitoramento é feito por um heartbeat contínuo, no qual o Broker envia comandos ping frequentes ao repositório. Se o tempo de retorno desse comando for maior do que 5 segundos, considera-se que o UDDI está indisponível, e o sistema de seleção é alterado.

Dessa forma, o próprio Broker atua como monitor e objeto notificável, sendo o UDDI o objeto monitorável. O sistema de monitoramento por amostragem foi escolhido, no qual os dados são requisitados em intervalos regulares e o modelo de monitoramento utilizado 


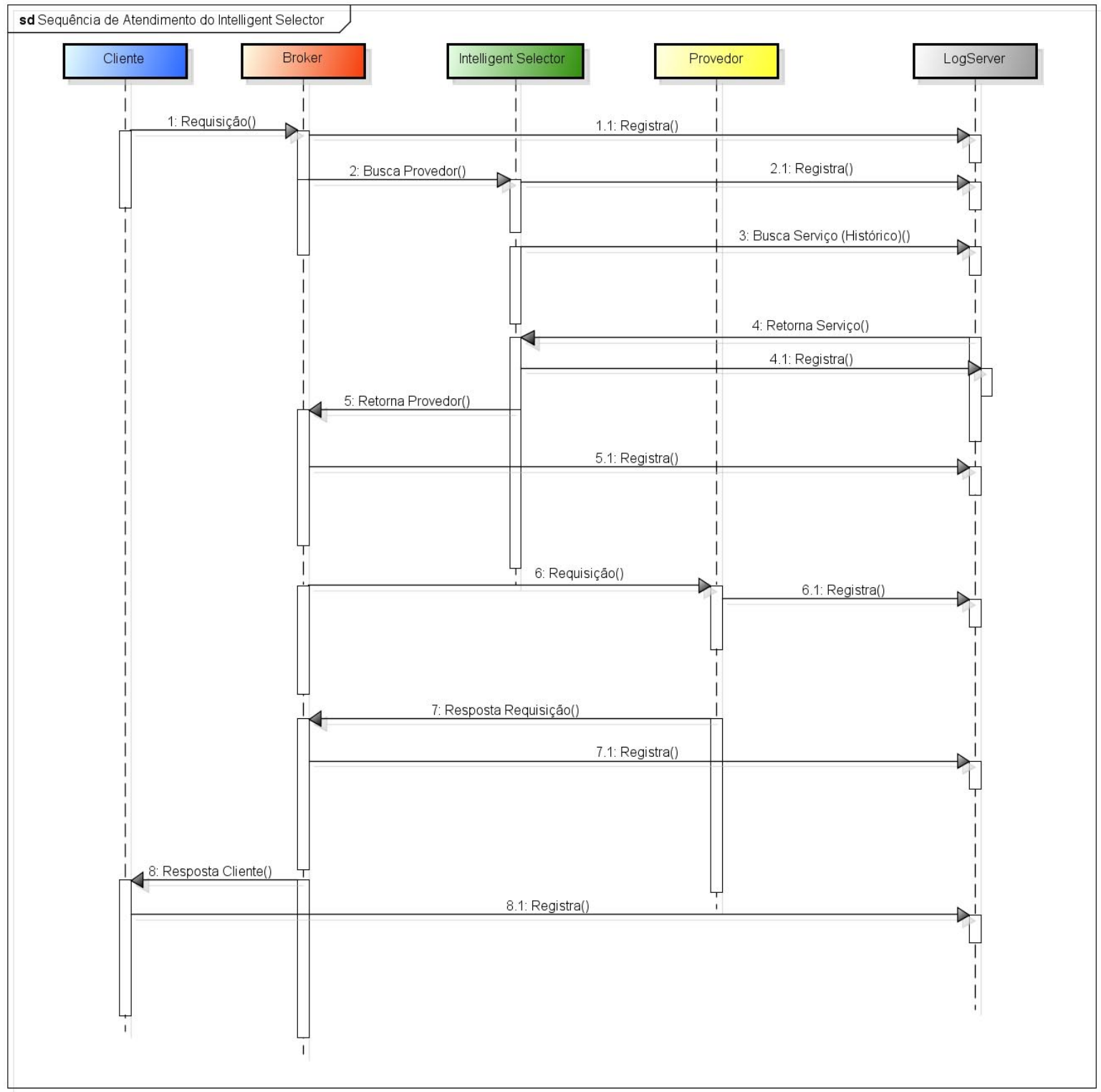

powered by Astaha

Figura 4.4: Diagrama de sequência do funcionamento do Intelligent Selector. 
é o Pull (Vide Figura 3.7) (Felber et al., 1999). Essas decisões foram tomadas devido à grande dinamicidade do ambiente em que ocorrem muitas trocas de mensagens, variação nos níveis de carga de trabalho e interação entre os componentes.

\subsubsection{Round Robin Selector}

Uma vez que o Intelligent Selector realiza a mineração de dados de requisições passadas, há uma preocupação de que os dados a serem utilizados no treinamento não sejam viciados. Se o UDDI ficar fora de funcionamento por muito tempo, a base não será atualizada, e a mineração será feita em dados antigos. Assim, o seletor poderá indicar sempre os mesmos provedores para o atendimento aos clientes, o que não só retorna resultados inválidos como, no caso da WSARCH, pode levar a sobrecargas do provedores que foram escolhidos com muita frequência.

Com essa preocupação, acrescentou-se mais um módulo de seleção à arquitetura, denominado Round Robin Selector. Esse seletor estático não realiza as avaliações de qualidade de serviço feita por seus pares, nem possui tecnologias para avaliar a reputação dos provedores. Ele simplesmente faz a rotação dos mecanismos a serem selecionados a partir de uma lista circular, ficando cada um responsável pelo atendimento.

O objetivo deste seletor é desviar o fluxo dos provedores que possam estar sobrecarregados no atendimento, por conta da falta de atualização do LogServer. Essa monitoração é feita pelo Intelligent Swap Mode, que observa os tempos de resposta obtidos. Definiu-se que, sempre que o tempo de resposta de um seletor quando em funcionamento o Intelligent Selector, ultrapassar em $25 \%$ a média geral dos tempos de resposta obtidos pelo seletor principal (Default ou Risk Selector), o Round Robin Selector deve ser acionado. Assim, como ele vai selecionar o próximo na lista de provedores, o qual deve estar sem realizar atendimentos, o tempo de resposta da requisição será muito pequeno, e diminuirá a taxa de atendimento do provedor sobrecarregado. Tão logo ele identifique que a sobrecarga no sistema reduziu, o Intelligent Selector é novamente acionado.

A desvantagem do Round Robin Selector é justamente a seleção cega realizada, sem atentar para níveis de QoS exigidos, acordos de nível de serviço, ou risco de encaminhar pedidos para componentes problemáticos. Entretanto, em volume reduzido, e como medida paliativa de tolerância a falhas, considerando que em outro caso a arquitetura deixaria de funcionar, é um recurso válido a ser utilizado. Este é um balanceador de cargas padrão, largamente utilizado em sistemas com alta carga de requisições, quando o objetivo é oferecer um tratamento equivalente aos usuários (Chaskar e Madhow, 1999). É utilizado em Web Services nos trabalhos de (Bjorkqvist et al., 2010) e (Chan et al., 2007), porém não é considerado o mais adequado para fazer a diferenciação de níveis de serviço e manutenção de QoS. 


\subsection{Considerações Finais}

Este capítulo apresentou o funcionamento dos algoritmos introduzidos na WSARCH. O Risk Selector é uma evolução do seletor padrão da arquitetura, e foi atualizado para ser capaz de fazer avaliações de reputação dos provedores da arquitetura. Ele evita escolher os provedores com histórico recente de problemas, assumindo que eles apresentam maior probabilidade de falhar novamente em um futuro próximo.

Também foi apresentado o Intelligent Selector, o qual é o módulo reserva do UDDI. Quando este último apresenta problemas, o seletor é capaz de informar ao Broker quais os provedores indicados a atenderem as requisições. O Intelligent Selector utiliza técnicas de mineração de dados para avaliar informações do LogServer, e descobrir os provedores com melhores resultados. Para evitar que o Intelligent Selector informe dados viciados para o Broker, sobrecarregando alguns provedores, foi adicionado um Round Robin Selector, para atuar como uma alternativa no processo de seleção.

O capítulo a seguir trata dos experimentos realizados e a avaliação de desempenho dos algoritmos propostos. 


\section{Avaliação Experimental}

\subsection{Considerações Iniciais}

Neste capítulo são detalhadas a ferramenta de injeção de falhas, as configurações do ambiente de testes e caracterizados os experimentos realizados para validação dos algoritmos propostos nesse trabalho.

\subsection{Injeção de Falhas}

Foi desenvolvida uma ferramenta para simulação de falhas em uma arquitetura orientada a serviços. Na WSARCH os provedores funcionam a partir de máquinas virtuais baseadas em KVM (Kernel-based Virtual Machine), sendo três máquinas virtuais para cada host físico, totalizando 12 provedores disponíveis.

O seletor de risco foi projetado para desviar as requisições de provedores com problemas de atendimento. Quando um provedor é novamente listado como disponível, ele não é imediatamente selecionado, visto que o seu rank havia sido modificado, sendo considerado inseguro pelo seletor. Uma vez desligado um provedor, o risco é incrementado constantemente. O valor de risco varia de 0 a 100, sendo 0 o melhor caso, quando o provedor não tem registro de falhas. Após o provedor entrar em funcionamento, o valor do risco começa a ser decrementado, sendo reduzido a cada 2 segundos. 
Para simular esse comportamento, foi escrito um shell script que consegue pausar as máquinas virtuais, emulando uma falha, seja por queda no servidor ou falha de rede. $\mathrm{O}$ mesmo script faz com que a VM (Virtual Machine) retorne a seu estado anterior, ficando disponíveis novamente os serviços, a partir de quando o risco começa a ser decrementado.

O intervalo entre falhas refere-se ao tempo em que um provedor fica disponível até que sofra um problema. Esses intervalos são definidos aleatoriamente de acordo com a fórmula exponencial utilizada, porém com um comportamento estipulado e previsível matematicamente. O tempo de recuperação da falha refere-se ao tempo que o provedor leva para ficar novamente ativo e disponível para a utilização. Foi utilizada uma função exponencial como base para definir os intervalos das falhas durante os testes, sendo considerados dois tempos distintos: o intervalo entre falhas e o tempo de recuperação de uma falha.

Para o intervalo entre falhas, foi utilizada a média da função exponencial, calculada dentro do script, que gera um número aleatório, variando o valor de pausa entre uma falha e outra. Por outro lado, para o tempo de recuperação de falhas, foi considerado a média da mesma função exponencial, porém utilizando uma fração do intervalo entre falhas. Isso foi definido para que houvesse tempo dos provedores recuperarem sua classificação no rank e pudessem atender requisições dos clientes novamente. O Código 5.1 demonstra tais definições.

\subsection{Configuração do Ambiente}

Os experimentos presentes neste trabalho foram realizados utilizando a infraestrutura da WSARCH para atender as requisições dos clientes e realizar as transações dos Web Services. Como clientes da arquitetura foram utilizados 16 computadores e outros 16 nós do cluster presentes no LASDPC (Laboratório de Sistemas Distribuídos e Programação Concorrente). O ambiente de testes disponível é representado na Tabela 5.1.

Os provedores utilizados neste trabalho são em total de 12 e são identificados na arquitetura pelos dois últimos algarismos de seu IP. Por exemplo, o provedor 11 possui o IP 192.168.1.111, e assim por diante.

A estrutura física da WSARCH pode ser observada nas imagens da Figura 5.1. Na Figura 5.1(a) são exibidas as máquinas host da arquitetura, que abrigam os módulos. Na Figura 5.1(b) são mostradas as conexões de rede em cada máquina, inclusive as configuradas para cada máquina virtual. 


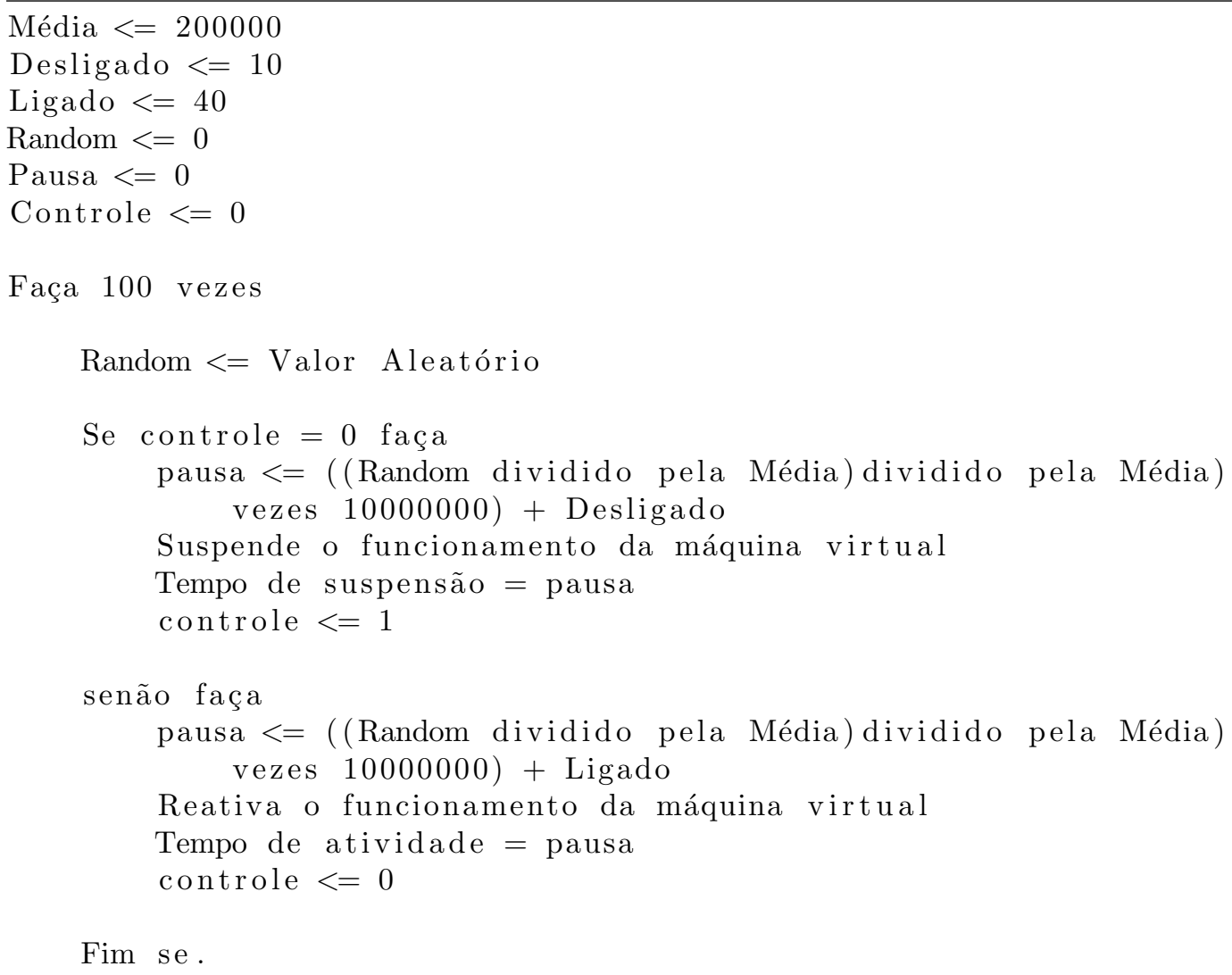

Código 5.1: Algoritmo do Script de Injeção de Falhas

Tabela 5.1: Infraestrutura

\begin{tabular}{|l|l|l|l|}
\hline \multicolumn{2}{|c|}{ UDDI } & \multicolumn{2}{c|}{ Provedor } \\
\hline Processador & 4 núcleos - Intel Core 2 Quad 8400 & Processador & 1 núcleo - Intel Core 2 Quad 8400 \\
\hline Memória & 4GB - DDR3 & Memória & 2 módulos com (512MB) e 1 com (1GB) - DDR3 \\
\hline HD & HD Virtual de 50GB & HD & HD Virtual - 50GB \\
\hline SO & Linux Ubuntu 11.10 Server & SO & Linux Ubuntu 11.10 Server \\
\hline Qtde & $\mathbf{1 2}$ & Qtde & $\mathbf{1 2}$ \\
\hline \multicolumn{2}{|c|}{ Broker } & \multicolumn{1}{c|}{ Cliente } \\
\hline Processador & 6 núcleos - AMD Phenom II X6 1090T & Processador & 4 núcleos ou 2 núcleos virtuais \\
\hline Memória & 16GB - DDR3 & Memória & 8 / 4 GB (virtual \\
\hline HD & 500GB & HD & $500 / 15$ GB (virtual) \\
\hline SO & Linux Ubuntu 11.10 Server & SO & Linux Ubuntu 12.04 \\
\hline Qdte & $\mathbf{1}$ & Qdte & $\mathbf{4 6}$ \\
\hline
\end{tabular}

\subsection{Desenho de Experimentos}

Foram realizados dois experimentos distintos. O primeiro deles com o objetivo de comparar o desempenho do Default Selector com o Risk Selector no roteamento de requisições quando há falhas nos provedores. Neste experimento foram considerados cenários com 1 e 12 UDDIs, para avaliar como a distribuição de carga afeta o tempo de resposta das requisições. Os cenários de falhas são comparados com um cenário ideal, onde não são inseridas falhas nos provedores. As configurações desse experimento são apresentadas na Tabela 5.2 . 

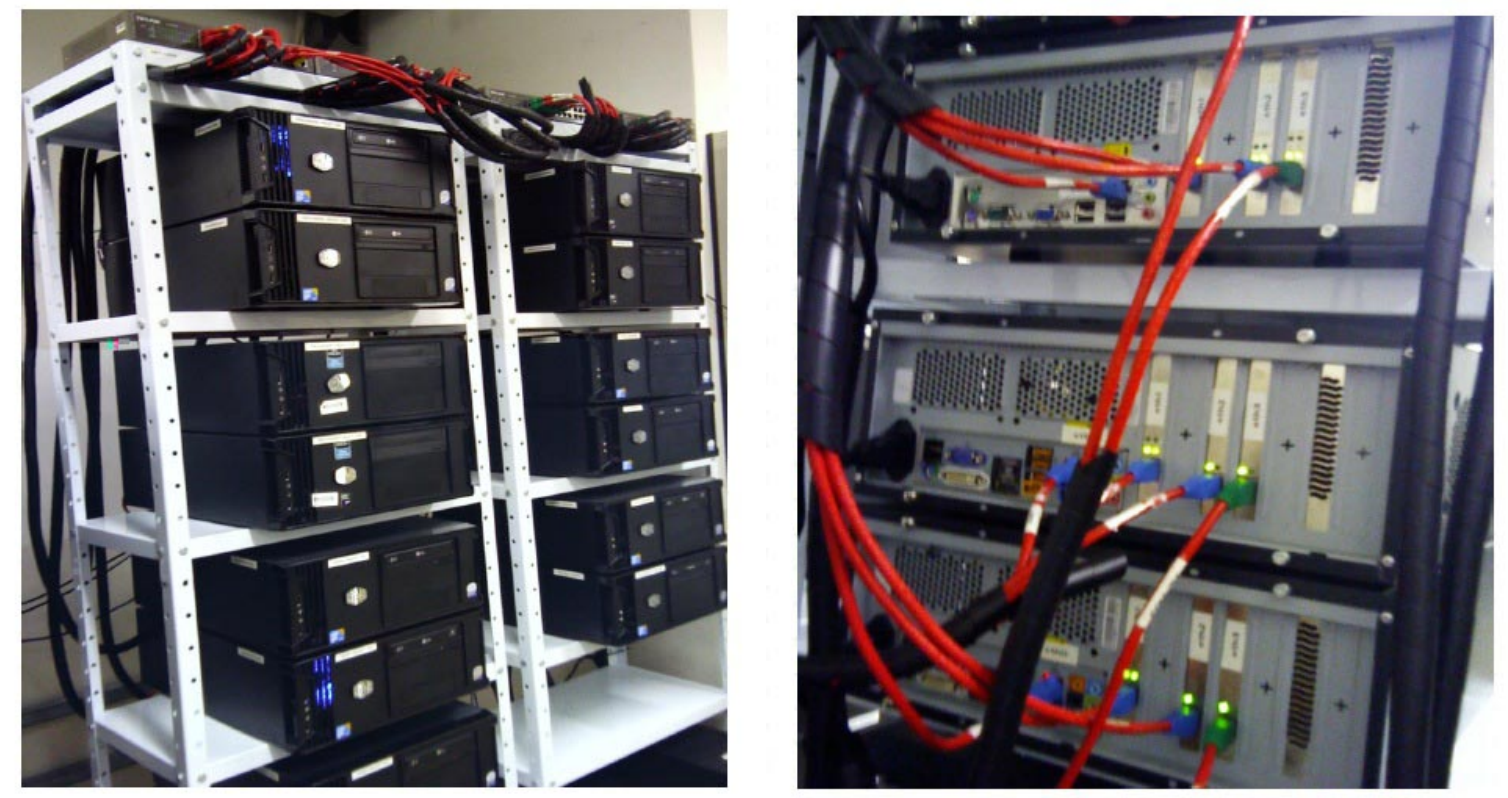

Figura 5.1: Imagens da estrutura física da WSARCH.

Tabela 5.2: Tabela com os fatores, níveis e cenários do $1^{\circ}$ Experimento

\begin{tabular}{|c|c|c|c|}
\hline \multicolumn{4}{|c|}{ Configuração do $1^{\circ}$ Experimento } \\
\hline Fatores & & Níveis & \\
\hline Seletor & Default & \multicolumn{2}{|c|}{ Risk } \\
\hline Número de UDDIs & 1 & \multicolumn{2}{|c|}{12} \\
\hline Falha & Sim & \multicolumn{2}{|c|}{ Não } \\
\hline \multicolumn{4}{|c|}{ Cenários } \\
\hline & Cenário 1 (SF) & Cenário 2 (DS CF) & Cenário 3 (RS CF) \\
\hline Seletor & Risk & Default & Risk \\
\hline Número de UDDIs & 1 ou 12 & 1 ou 12 & 1 ou 12 \\
\hline Falha & Não & Sim & Sim \\
\hline \multicolumn{4}{|c|}{ Parâmetros Fixos } \\
\hline Clientes & Processos por Cliente & Chamadas por Cliente & Replicações \\
\hline 46 & 8 & 5 & 10 \\
\hline
\end{tabular}

Como o Default Selector apresenta como única preocupação a qualidade do serviço oferecida pelos provedores, o objetivo desses experimentos é mostrar não apenas que o Risk Selector é eficiente ao manter o balanceamento de carga entre os provedores e evitar sobrecargas, mas também de ser capaz de desviar o fluxo dos componentes faltosos, oferecendo uma experiência de utilização mais satisfatória. O seletor padrão pode escolher repetidamente componentes muito instáveis, que podem falhar em meio a um atendimento, retornando uma resposta incompleta ou nenhuma resposta, situação que o novo seletor busca sanar.

As requisições dos clientes são disparadas a partir de scripts, que tem a função de simular rajadas de requisições. Eles disparam processos simultâneos e repetem as chamadas do cliente gerando a carga para a realização dos testes, como especificado na Tabela 5.2. 
Para alcançar o número de 46 clientes, foram utilizadas máquinas virtuais hospedadas no cluster.

No segundo experimento realizado são considerados os mecanismos de tolerância a falhas introduzidos na WSARCH, englobando o Risk Selector, o Intelligent Selector e o Round Robin Selector. Os experimentos contam com simulações de falhas com o objetivo de observar a eficiência dos algoritmos propostos, não esquecendo dos níveis de atendimento do serviço realizado. As falhas programadas para afetar o UDDI permitem que o Intelligent Selector seja acionado. E nas variações dos cenários em que o Risk Selector é utilizado, há injeção de falhas também no provedores, para demonstrar suas funcionalidades. Os níveis e fatores desse experimento são especificados na Tabela 5.3.

Tabela 5.3: Tabela com os fatores, níveis e parâmetros do $2^{\circ}$ Experimento

\begin{tabular}{|c|c|c|}
\hline \multicolumn{3}{|c|}{ Configuração do $2^{\circ}$ Experimento } \\
\hline Fatores & \multicolumn{2}{|c|}{ Níveis } \\
\hline Seletor Principal & Default & Risk \\
\hline Número de Clientes & 16 & 32 \\
\hline Tipo de Falha & Estática & Dinâmica \\
\hline \multicolumn{3}{|c|}{ Parâmetros Fixos } \\
\hline Processos por Cliente & \multicolumn{2}{|c|}{10} \\
\hline Chamadas por Cliente & \multicolumn{2}{|c|}{20} \\
\hline Replicações & \multicolumn{2}{|c|}{10} \\
\hline
\end{tabular}

O tipo de falha que afeta o UDDI pode ser estática ou dinâmica. No caso da falha estática, o UDDI estará ativo durante as 1000 primeiras requisições, e depois ficará desligado até o fim do experimento. Para a falha dinâmica, o repositório sofrerá pausas durantes intervalos aleatórios de tempo, forçando o mecanismo a fazer diversas trocas de contexto, alternando entre os seletores conforme o funcionamento da arquitetura. Os cenários de testes desse experimento estão especificados na Tabela 5.4 .

Tabela 5.4: Tabela com os cenários do $2^{\circ}$ Experimento

\begin{tabular}{|c|c|c|c|c|}
\hline & \multicolumn{4}{|c|}{ Cenários } \\
\hline Fatores & $\mathbf{1}$ & $\mathbf{2}$ & $\mathbf{3}$ & $\mathbf{4}$ \\
\hline Seletor Principal & Default ou Risk & Default ou Risk & Default ou Risk & Default ou Risk \\
\hline Número de Clientes & 16 & 32 & 16 & 32 \\
\hline Tipo de Falha & Fixa & Fixa & Dinâmica & Dinâmica \\
\hline
\end{tabular}

\subsection{Análise dos Resultados}

Nesta seção são apresentados os resultados obtidos nos experimentos realizados nesse trabalho. Os diferentes experimentos e seus cenários de teste são especificados e também é apresentada a avaliação de desempenho. 


\subsubsection{Experimento 1 - Teste Inicial}

No primeiro cenário deste experimento foi utilizado o Risk Selector, sem a adição de falhas e com variação no número de UDDIs. Esse cenário servirá como parâmetro de comparação para os demais. Como pode ser observado na Figura 5.2 o número de UDDIs sinalizou influência determinante no desempenho das requisições, visto que o mecanismo de balanceamento de carga otimizou a entrega dos serviços. Isso ocorre por conta da maior facilidade de se encontrar os serviços, com todos os repositórios disponíveis para consulta. Cada UDDI indexa os mesmos serviços e provedores, de forma que todos são capazes de atingir os mesmos objetivos.

No segundo cenário de testes os tempos de resposta aumentaram, por conta das subsequentes quedas programadas para afetarem os provedores, falhas que o Default Selector não é capaz de tratar. Na variação do número de UDDIs desse cenário, com elevação para 12, mais uma vez foi observada uma melhora nos tempos médios de atendimento.

O terceiro cenário de observação utiliza o Risk Selector submetido ao mesmo ambiente com falhas, para demonstrar suas funcionalidades. O resultado obtido foi próximo da execução sem falhas, e superior aos tempos alcançados pelo seletor padrão, mostrando a capacidade de organização do fluxo de requisições feita pelo seletor. Como observado nos demais experimentos, o número de UDDIs mais um vez influenciou positivamente os valores do tempo de resposta. As legendas de cada cenário são equivalentes às especificadas na Tabela 5.2.

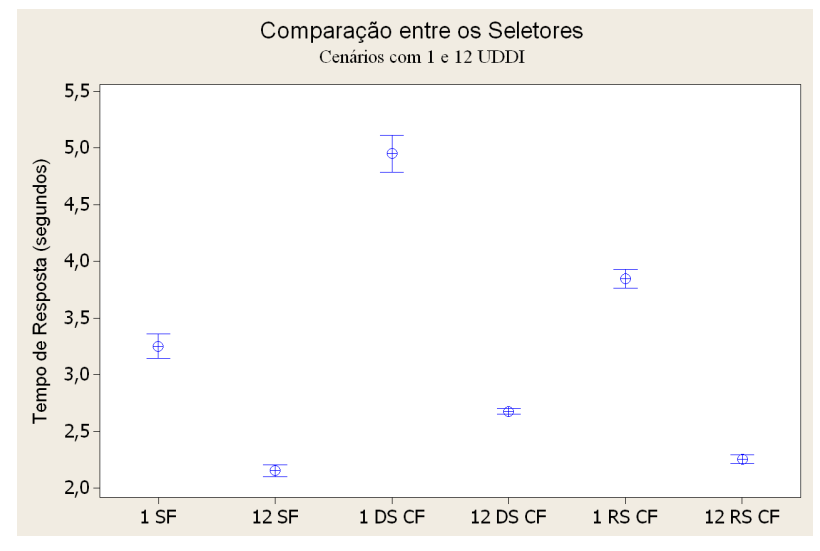

Figura 5.2: Médias dos tempos de resposta dos cenários do primeiro experimento.

No decorrer desses experimentos, foram armazenadas informações das falhas ocorridas nos provedores, como o tempo do experimento e o tempo em que esses provedores estiveram fora de operação. Assim, foi feita uma análise dos tempos dos provedores, calculando a porcentagem de tempo que cada um deles ficou offline. Os resultados são vistos na Figura 5.3. 


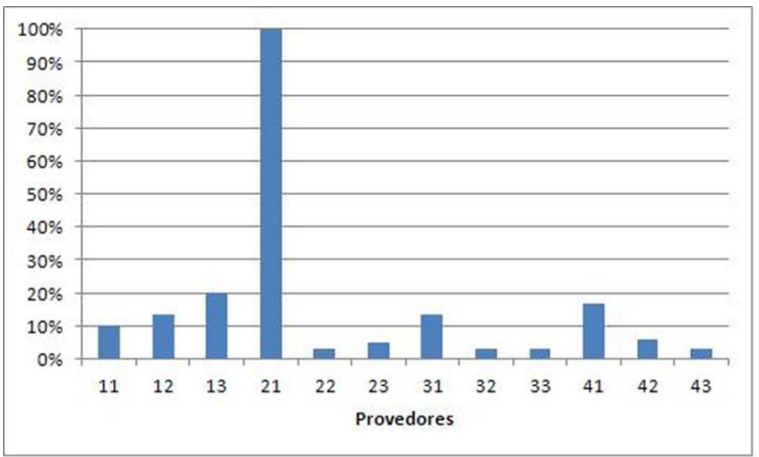

Figura 5.3: Porcentagem de tempo offline.

A única discrepância foi observada no provedor 21, que esteve sempre desligado durante os testes. Isso ocorreu devido a problemas além dos provocados pelo script de injeção de falhas. Os demais provedores variaram o tempo de queda dentro das médias propostas, observando a função aleatória.

Os resultados mostram uma preferência dos seletores pelo provedor 31 nos cenários de testes considerados. Além de apresentar bom nível de QoS, o provedor sofreu pouco com as falhas injetadas, estando disponível na maior parte do tempo. Ainda que as falhas apresentadas por este provedor sejam superiores a de alguns de seus pares, o QoS alcançado por ele foi capaz de garantir que fosse o principal alvo dos atendimentos.

\subsubsection{Experimento 2 - Detalhamento}

Para uma visão mais minuciosa do segundo experimento, são apresentadas nesta seção algumas comparações detalhadas das duas variações do Cenário 3 especificado na Tabela 5.4. Esse cenário traz o modelo de falhas fixo e o número de clientes é igual a 32, sendo variado o seletor. Na primeira variação o utilizado foi o Default Selector.

Na primeira bateria de experimentos notou-se uma deficiência em dois dos parâmetros utilizados na arquitetura. O primeiro deles é o intervalo de atualização do valor de QoS dos provedores, informado pelo Monitor Ganglia ao Broker a cada 1 segundo. Pelos resultados obtidos, percebeu-se que essa taxa de atualização não era suficiente para informar a real condição dos provedores, o que levou ao direcionamento incorreto de requisições.

O outro problema encontrado estava no intervalo de disparo das requisições dos clientes. Da forma como estava previsto no script, as requisições de todos seriam disparadas simultaneamente, em intervalos de 2 segundos. Isso acarretou um congestionamento de requisições ao Broker em alguns provedores, afetando negativamente o resultado dos experimentos.

Como pode ser observado na Figura 5.4(a) o Default Selector apresentou o tempo mais alto entre os três seletores, mesmo descontando-se o tempo de busca do serviço no UDDI. 
O tempo de busca do Intelligent Selector é de apenas 2 milisegundos, uma vez que o treinamento dos dados do LogServer é feito em background, enquanto o Round Robin não apresenta nenhum acréscimo nesse sentido. Esse resultado indicou que o seletor principal não estava sendo capaz de informar corretamente qual era o melhor provedor em um determinado momento e que estava ocorrendo um gargalo de atendimento nos mesmos.

Foi decidido então alterar os parâmetros que comprometiam a realização dos experimentos. Com relação ao tempo de atualização dos valores de QoS, resolveu-se empiricamente baixar o intervalo para 0,5 segundo, o que considerou-se suficiente para corrigir o desvio de precisão detectado. Quanto ao script de acionamento dos clientes, passou-se a utilizar um intervalo aleatório de disparo, com o objetivo de simluar requisições de baixa e alta frequência.

Como se pode perceber na Figura 5.4(b), o tempo dos seletores tornou-se mais uniforme, provando que o provedor utilizado foi sempre o melhor disponível. O tempo maior do Default Selector deve-se ao tempo de busca do serviço.

É importante salientar que o Round Robin Selector não faz simplesmente o sorteio entre os provedores disponíveis. Ele escolhe entre os melhores, definidos anteriormente pelo Default Selector e disponibilizados a ele em uma lista estática. Isso explica os tempos de atendimento tão bons em relação aos demais seletores.
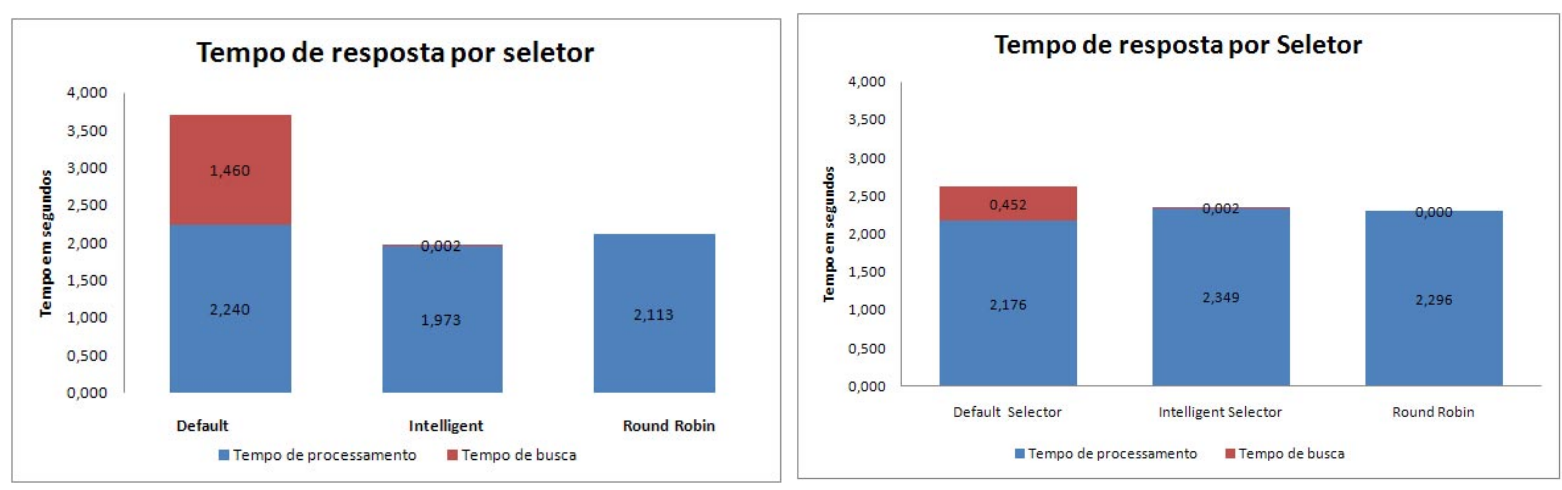

Figura 5.4: Gráfico com a diferença de resultados antes e após a configuração correta dos parâmetros do experimento. Tempo médio de resposta para cada seletor.

O tempo médio de atendimento em cada provedor também teve seu comportamento alterado após o calibramento dos parâmetros de teste. Com os valores anteriores, os provedores apresentaram grandes variações de tempo, o que acabou por comprometer o resultado final, como pode ser observado na Figura 5.5(a). Após a correção, o tempo dos provedores mostrou-se mais uniforme devido à melhor distribuição da carga e ao maior número de provedores utilizados, como pode ser visto na Figura 5.5(b). As legendas utilizadas neste gráfico estão especificadas na Tabela 5.5. O tipo do seletor é seguido pelo 
indicador do provedor responsável pelo atendimento, por exemplo se o Default Selector encaminhou uma requisição ao provedor 11, a legenda será DF 11 e assim por diante.

Tabela 5.5: Tabela com as legendas utilizadas no Experimento 2

\begin{tabular}{|c|c|c|c|c|}
\hline \multicolumn{5}{|c|}{ Legendas } \\
\hline Seletor & Default Selector & Risk Selector & Intelligent Selector & Round Robin Selector \\
\hline Legenda & DF & RS & IS & RR \\
\hline
\end{tabular}
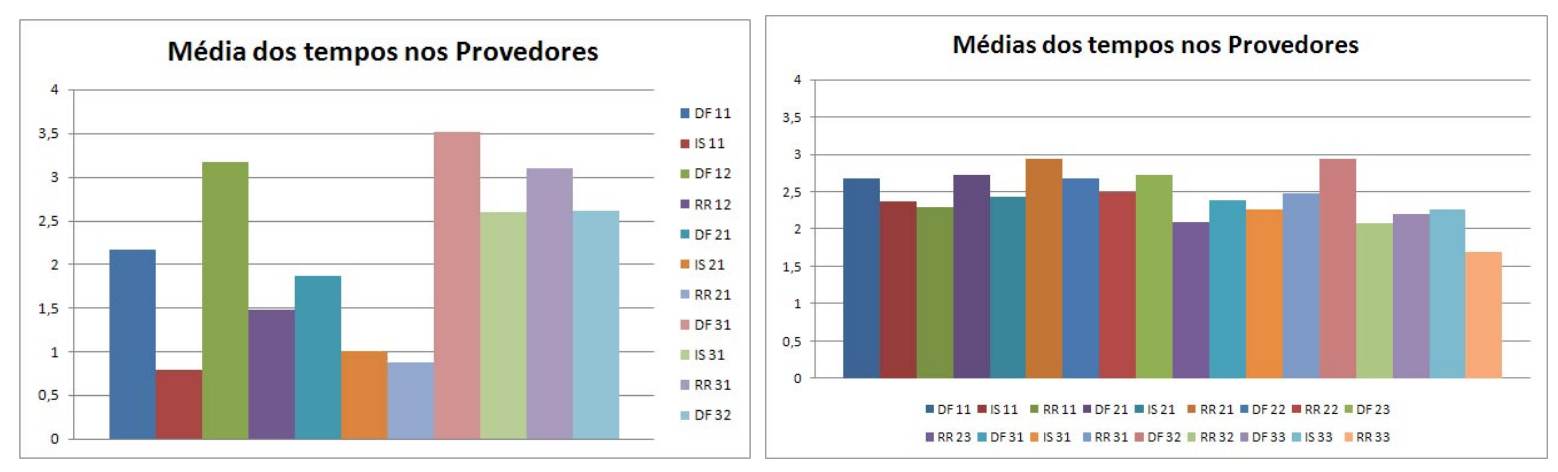

Figura 5.5: Resultados com os diferentes parâmetros de monitoração e disparo de requisições. Tempo médio de resposta de cada provedor de acordo com o seletor atuante.

A Figura 5.6(a) mostra que o Intelligent Selector registrou uma taxa de $76 \%$ de atendimentos, o Default Selector foi responsável por $17 \%$ e os $7 \%$ restantes ficaram a cargo do Round Robin. Foi registrada uma taxa de requisições atendidas com sucesso de $93 \%$, apresentada na Figura 5.6(b). A perda de requisições ocorre no momento em que são introduzidas as falhas nos componentes da arquitetura. Como acontece de haver requisições em tráfego nesse momento, elas ficam sem o atendimento devido, uma vez que elas não são armazenadas para serem redirecionadas.
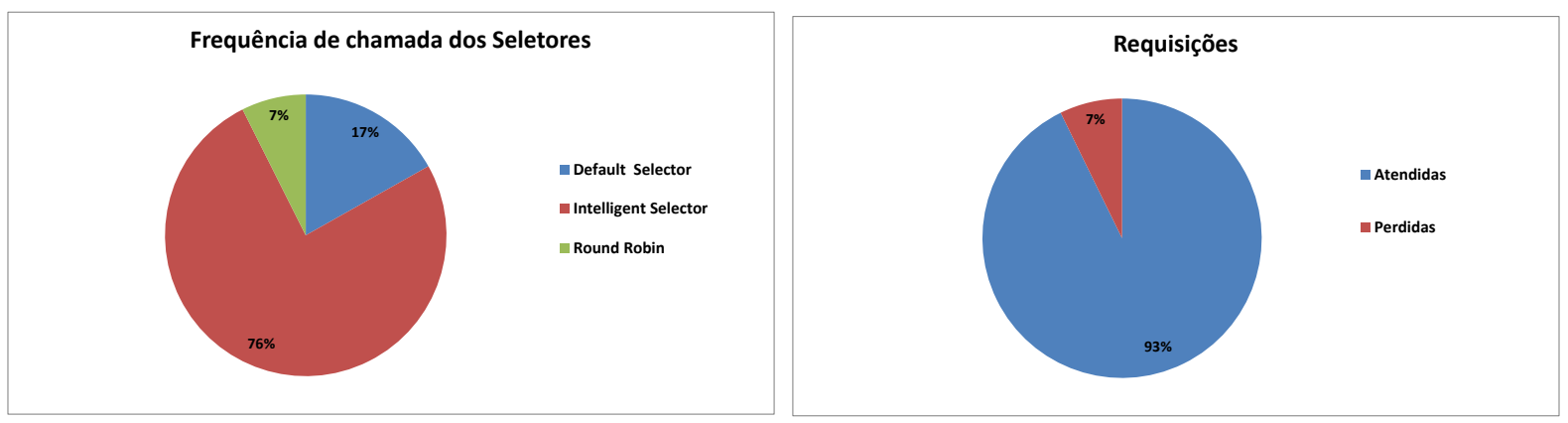

Figura 5.6: Taxa de atendimento de cada seletor e taxa de requisições atendidas.

A porcentagem de atendimento feita por cada provedor de acordo com o direcionamento dos diferentes seletores da WSARCH pode ser vista na Tabela 5.6: 
Tabela 5.6: Tabela com a taxa de atendimento de cada provedor de acordo com os seletores

\begin{tabular}{|c|c|c|c|c|c|c|c|c|c|c|}
\hline Seletor & \multicolumn{9}{|c|}{ Provedores } & \multicolumn{3}{c|}{ Resultados } \\
\hline & $\mathbf{1 1}$ & $\mathbf{2 1}$ & $\mathbf{2 2}$ & $\mathbf{2 3}$ & $\mathbf{3 1}$ & $\mathbf{3 2}$ & $\mathbf{3 3}$ & Total & Média & Desvio Padrão \\
\hline Default Selector & $6 \%$ & $1,7 \%$ & $2 \%$ & $0,8 \%$ & $4 \%$ & $2 \%$ & $1 \%$ & $17,5 \%$ & $2,5 \%$ & $2 \%$ \\
\hline Intelligent Selector & $25 \%$ & $21 \%$ & - & - & $16 \%$ & - & $14 \%$ & $76 \%$ & $10,86 \%$ & $4,96 \%$ \\
\hline Round Robin & $2 \%$ & $0,3 \%$ & $1 \%$ & $0,2 \%$ & $1 \%$ & $1 \%$ & $1 \%$ & $6,5 \%$ & $0,93 \%$ & $0,44 \%$ \\
\hline
\end{tabular}

Na segunda variação do Cenário 3 o seletor é alterado para o Risk Selector e por ele ser capaz de identificar qual o risco de selecionar determinado provedor dado o histórico de falhas, foram introduzidas falhas também para o provedores de serviço. Busca-se mostrar que o algoritmo tem condições de manter o mesmo nível de atendimento da arquitetura quando esses módulos não enfrentam problemas. Também para este cenário foram feitos experimentos com as duas taxas de atualização de QoS dos provedores e os dois intervalos de disparo de requisições.

O tempo médio de resposta de cada seletor no experimento com as configurações incorretas de parâmetro é mostrado na Figura 5.7(a). O Risk Selector teve pouco mais de 3,5 segundos de média, contando ainda com acréscimo significativo do tempo de busca. O Round Robin teve média 0,5 segundo maior do que o Intelligent Selector, que como na amostra anterior registrou 2 milisegundos de tempo para informar ao Broker. Esses tempos indicaram que os problemas descritos anteriormente continuaram acontecendo, assim como a necessidade de mudança nos parâmetros.

Uma vez atualizados os valores das variáveis de configuração, os tempos de resposta obtidos tornaram-se adequados. Como pode ser visto na Figura 5.7(b) a diferença do Risk Selector para os demais se deu por conta apenas do tempo de busca. Quando comparados com o cenário anterior, percebe-se que o tempo aumentou, por dois motivos. Primeiramente por conta das falhas introduzidas nos provedores, que exigiram um tratamento nos direcionamentos realizados pelo seletor. E também porque de acordo com a avaliação de reputação feita, um número menor de provedores foi selecionado para o atendimento, elevando a carga de trabalho dos mesmos.

Como no cenário anterior, o atendimento de cada provedor foi afetado pela calibragem dos experimentos. Na primeira bateria, como pode ser visto na Figura 5.8(a), a diferença de tempo entre cada módulo foi grande, indicando a sobrecarga em alguns deles. Feitas as alterações, o comportamento tornou-se mais uniforme demonstrando o maior equilíbrio na distribuição dos serviços, como mostra a Figura 5.8(b). As legendas utilizadas nesse gráfico são idênticas às especificadas na Tabela 5.5.

Nesse caso, o Intelligent Selector registrou $77 \%$ de atendimentos, $16 \%$ foram feitos pelo Risk Selector e o Round Robin atendeu $7 \%$, como visto na Figura 5.9(a). Foi registrada uma taxa de requisições atendidas com sucesso de $95 \%$, apresentada na 

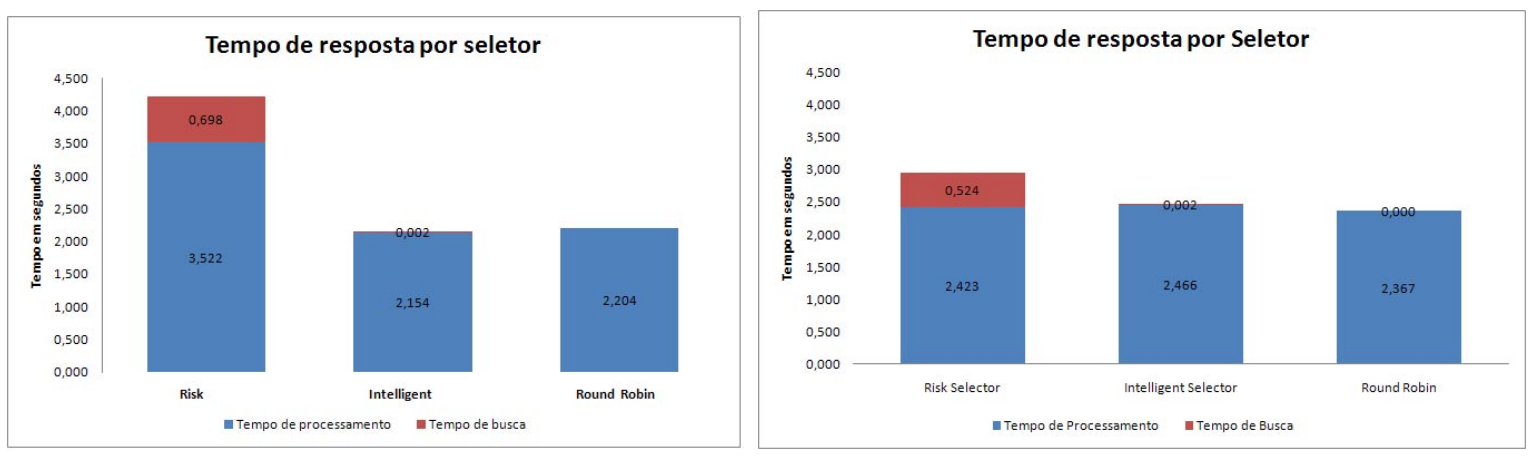

Figura 5.7: Comparação dos experimentos antes e depois da configuração dos parâmetros. Médias dos tempos de resposta em cada seletor.
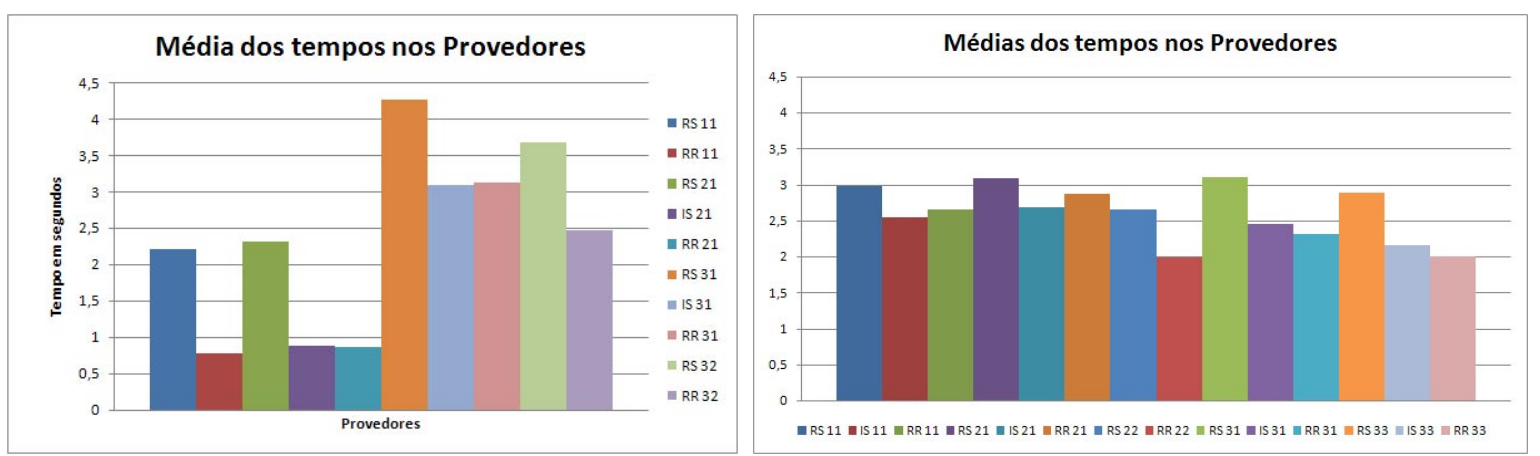

Figura 5.8: Comparação dos experimentos antes e depois da alteração dos parâmetros. Tempo médio de resposta de cada provedor de acordo com o seletor atuante. 
Figura 5.9(b). As requisições perdidas ocorrem no momento da troca do seletor principal da arquitetura.
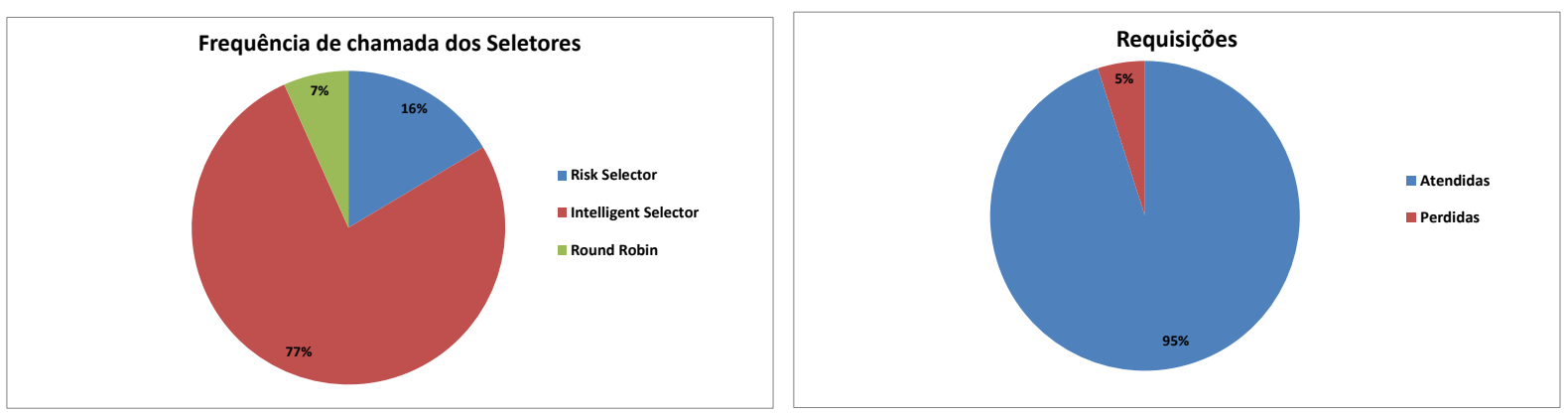

Figura 5.9: Taxa de atendimento de cada seletor e taxa de requisições atendidas.

A porcentagem de atendimento feita por cada provedor de acordo com o direcionamento dos diferentes seletores da WSARCH pode ser vista na Tabela 5.7:

Tabela 5.7: Tabela com a taxa de atendimento de cada provedor de acordo com os seletores

\begin{tabular}{|c|c|c|c|c|c|c|c|c|}
\hline Seletor & \multicolumn{5}{|c|}{ Provedores } & \multicolumn{3}{c|}{ Resultados } \\
\hline & $\mathbf{1 1}$ & $\mathbf{2 1}$ & $\mathbf{2 2}$ & $\mathbf{3 1}$ & $\mathbf{3 3}$ & Soma & Média & Desvio Padrão \\
\hline Risk Selector & $4 \%$ & $3 \%$ & $2 \%$ & $4 \%$ & $3 \%$ & $16 \%$ & $3.2 \%$ & $0,84 \%$ \\
\hline Intelligent Selector & $25 \%$ & $23 \%$ & - & $18 \%$ & $11 \%$ & $77 \%$ & $15,4 \%$ & $6,24 \%$ \\
\hline Round Robin & $1 \%$ & $1 \%$ & $1 \%$ & $1 \%$ & $3 \%$ & $7 \%$ & $1,4 \%$ & $0,89 \%$ \\
\hline
\end{tabular}

\subsubsection{Experimento 2 - Análise Comparativa}

Nessa seção são apresentadas análises dos quatro cenários definidos, de acordo com a Tabela 5.8. Recorda-se que para o Risk Selector são inseridas falhas também nos provedores de serviço, o que não ocorre para o Default Selector. Foram feitos experimentos na arquitetura sem a injeção de falhas em qualquer dos componentes, para servir como parâmetro de comparação.

Tabela 5.8: Tabela com os cenários do $2^{\circ}$ Experimento

\begin{tabular}{|c|c|c|c|c|}
\hline & \multicolumn{4}{|c|}{ Cenários } \\
\hline Fatores & $\mathbf{1}$ & $\mathbf{2}$ & $\mathbf{3}$ & $\mathbf{4}$ \\
\hline Seletor Principal & Default ou Risk & Default ou Risk & Default ou Risk & Default ou Risk \\
\hline Número de Clientes & 16 & 32 & 16 & 32 \\
\hline Tipo de Falha & Fixa & Fixa & Dinâmica & Dinâmica \\
\hline
\end{tabular}

Os resultados encontrados para o Cenário 1 são exibidos na Figura 5.10, onde se observa que embora os tempos do Risk Selector sejam maiores, a diferença foi pequena, considerando-se a dificuldade de desviar o fluxo de requisições dos componentes problemáticos. É exibido também o tempo para a arquitetura quando não há nenhum tipo de 
falha, caracterizando o caso ideal. O Default Selector obteve um acréscimo de 16,7\% com relação ao experimento sem falhas, enquanto o Risk Selector teve um aumento de $37 \%$.

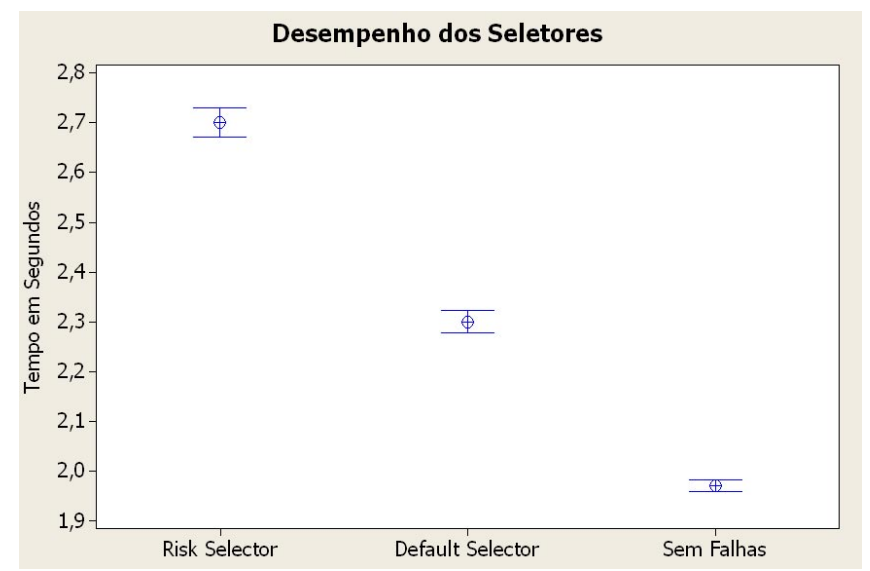

Figura 5.10: Comparação dos tempos de resposta entre os seletores, com 16 clientes e falha estática.

Os resultados para o Cenário 2 encontram-se na Figura 5.11, onde se observa um comportamento semelhante ao do cenário anterior, com a elevação natural do tempo devido ao aumento de clientes. A diferença de desempenho do Default Selector para o Risk Selector se dá por conta das falhas nos provedores que este último tem o trabalho de tratar. Nesse caso, o Default Selector apresentou 18,6 \% de elevação com relação ao cenário ideal, enquanto o Risk Selector sofreu um acréscimo 41,8\%. Note-se que, ainda que seja registrado um aumento comparado ao experimento anterior, os valores subiram moderadamente, não sendo observada uma explosão nos valores, ainda que o número de clientes tenha dobrado.

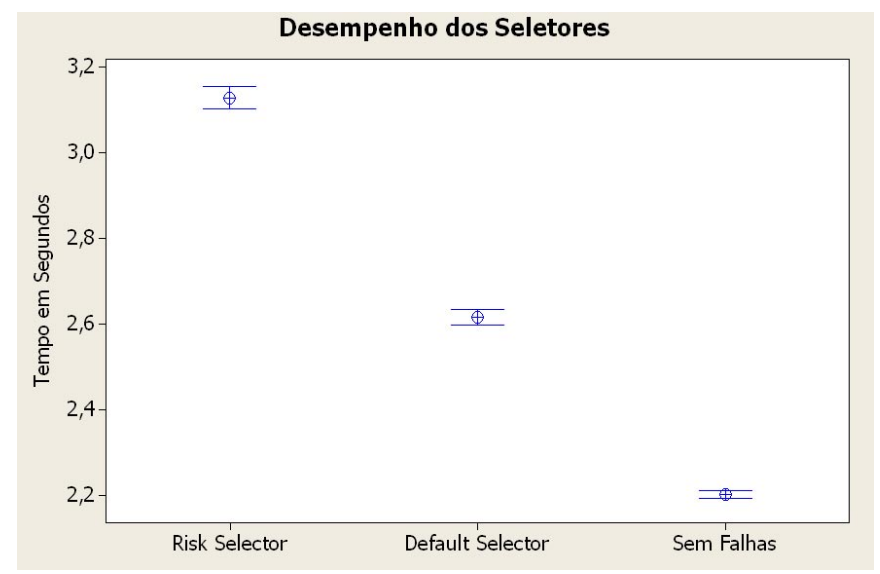

Figura 5.11: Comparação dos tempos de resposta para os seletores, com 32 clientes e falha estática. 
O Cenário 3 apresenta uma situação mais comumente encontrada em sistemas reais, haja vista que é mais comum ocorrer algumas falhas de curta duração em componentes de uma arquitetura do que uma falha grave, onde o sistema não volta a funcionar sem intervenções. Nesse caso, a diferença entre os seletores foi menor, pois ainda que as ocasiões de falhas sejam maiores, o tempo que o UDDI fica desligado é reduzido. Isso levou a acréscimos mais moderados nos tempos de respostas com relação ao teste do ambiente sem falhas. A comparação pode ser vista na Figura 5.12. O Default Selector apresentou acréscimo de 9,6\% dado o caso ideal, enquanto para o Risk Selector foi registrada uma elevação de $21,3 \%$.

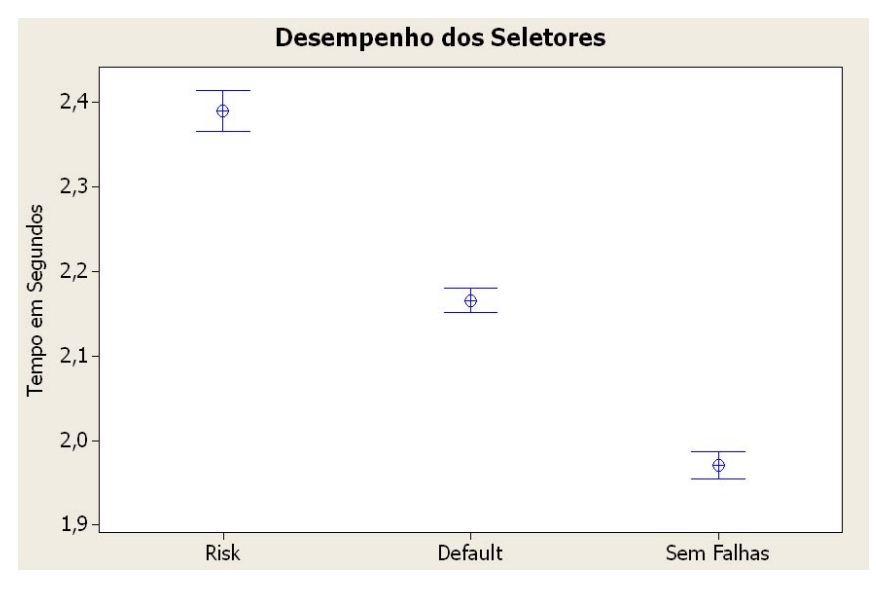

Figura 5.12: Comparação dos tempos de resposta entre os seletores, com 16 clientes e falha dinâmica.

Finalmente são apresentados os tempos alcançados pelos seletores no Cenário 4. O crescimento natural dos tempos devido ao aumento do número de clientes não resultou em uma degradação no comportamento da WSARCH. Os resultados são os exibidos na Figura 5.13. De fato, as elevações com relação ao ambiente sem falhas, foram levemente menores do que no cenário com 16 clientes. O Default Selector obteve um acréscimo de $6,8 \%$, enquanto o Risk Selector apresentou 20,4\% de aumento.

\subsubsection{Influência de Fatores}

Considerando os dados coletados, foi calculada qual a influência de cada um dos fatores avaliados nos experimentos. A partir da linha da distribuição normal, pode-se avaliar quais os fatores mais fizeram diferença nos cenários de teste considerados. Para os cenários desse trabalho, levando-se em conta que a variável de saída é o tempo de resposta, o valor positivo no gráfico equivale ao aumento na espera pela conclusão da requisição, o que significa uma piora no atendimento ao cliente. 


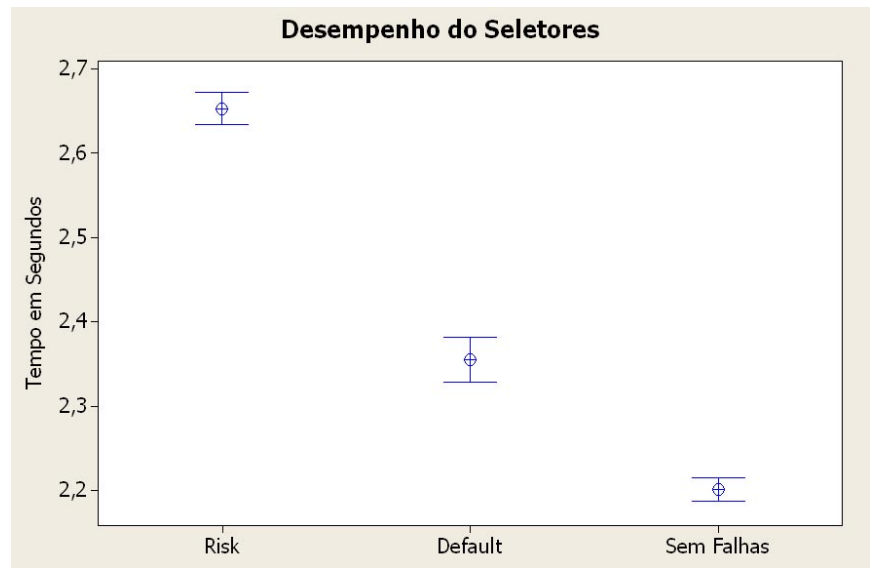

Figura 5.13: Comparação dos tempos de resposta dos seletores, com 32 clientes e falha estática.

Como pode ser visto na Figura 5.14, o tipo de seletor (Default ou Risk Selector) é o fator que mais afeta o ambiente da arquitetura. O segundo fator que mais influenciou nos testes foi o número de clientes, o que é natural, pois quanto mais clientes, maior o número de requisições e consequentemente maior a concorrência pelos recursos. Os demais fatores, seja individualmente ou combinados, não influenciaram nas avaliações.

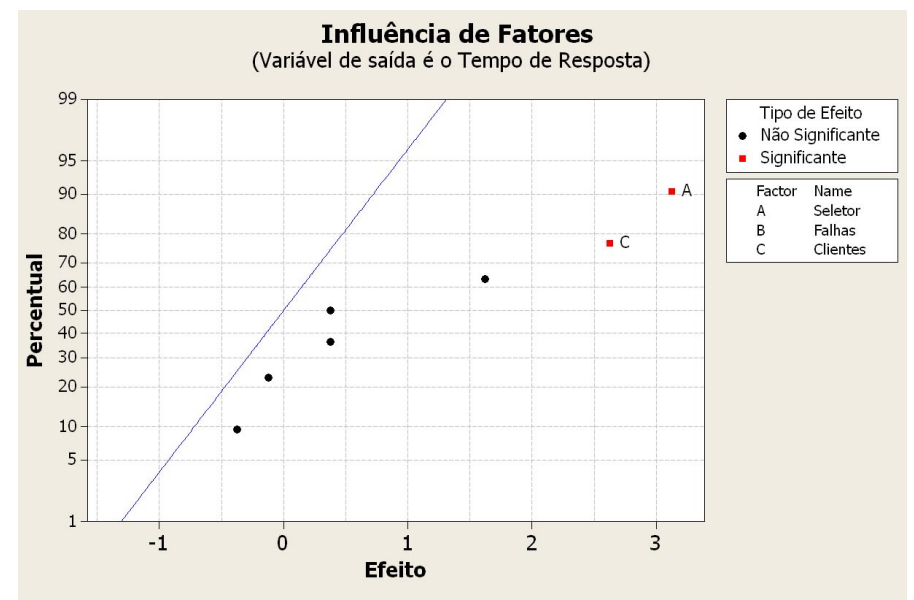

Figura 5.14: Efeito individual de cada fator

Na Figura 5.15(a) observa-se o comportamento das variações de cada um dos fatores. No caso do tipo de seletor, o Risk Selector mostra desempenho inferior que o Default Selector, devido à necessidade de tratar as falhas dos provedores. Para as falhas, a do tipo fixo degradou mais o ambiente, por conta do maior tempo de funcionamento da arquitetura sem o UDDI. E quanto ao número de clientes, o cenário com maior número apresenta piores resultados, explicados pela maior concorrência pelos recursos. Na Figura 5.15(b) observa-se a interação dos fatores dois a dois. Os comportamentos condizem com as análises apresentadas anteriormente. 


\section{CAPÍTULO 5. AVALIAÇÃO EXPERIMENTAL}
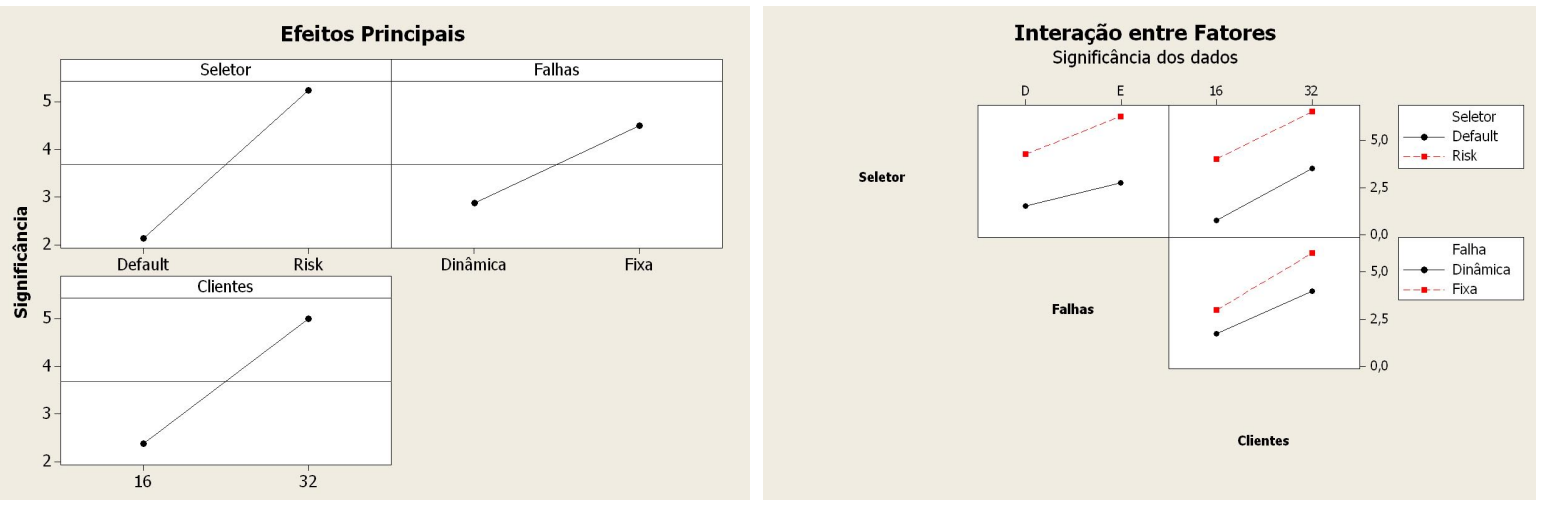

Figura 5.15: Interação entre os fatores dos experimentos

\subsection{Considerações Finais}

Com os resultados alcançados nos experimentos, chega-se à conclusão que o Risk Selector tem a capacidade de otimizar a distribuição da carga de trabalho entre os componentes mais aptos, quando na presença de falhas. O Default Selector apresenta boa capacidade de operação, mas não trata das quedas e recuperações dos provedores, ignorando históricos desfavoráveis de trabalho.

O sistema de reputação se mostrou importante ao manter os provedores com falhas recentes em espera, até que seus níveis de avaliação se estabilizassem e pudessem atender as chamadas de requisições. Os tempos de resposta mostram a eficiência do modelo, que mantém tempos de atendimento adequados. Em alguns casos, o UDDI sofreu com o alto número de requisições, o que causou uma elevação no tempo de busca.

Além do mecanismo de reputação, as ferramentas tolerantes a falhas apresentaram comportamentos adequados, sendo capazes de suportar as falhas ocorridas nos componentes, mantendo a arquitetura em funcionamento.

O Intelligent Selector apresentou resultados excelentes, sendo um substituto muito confiável para o UDDI. Ele foi capaz de fazer as buscas por provedores corretamente, mantendo o Broker em condições de organizar os pedidos de serviços e suas respectivas respostas.

Para evitar que o Intelligent Selector sobrecarregasse alguns provedores, devido à falta de atualização na base onde é feita a mineração de dados, foi adicionado um seletor Round Robin, cujo objetivo é alternar entre outros provedores, aliviando a carga de trabalho. O funcionamento deste seletor também foi correto, sendo sua participação importante no contexto geral. Os tempos alcançados por este seletor foram os melhores registrados, uma vez que não é utilizada nenhum métrica de qualidade de serviço ou qualquer outra em seu algoritmo, e que ele faz a rotação entre os melhores provedores definidos pelo 
seletor principal. Porém é importante salientar que seu desempenho tende a piorar com o decorrer do tempo, seja selecionando provedores indisponíveis, relacionando requisições para provedores onde não há possibilidade de atendimento ou mesmo escalonando módulos com condições inadequadas de funcionamento.

Finalmente conclui-se que o Risk Selector foi uma importante evolução do seletor-base da WSARCH tornando possível a análise de risco dos componentes em tempo real. E que, aliado aos seletores reserva, atuando como mecanismos tolerantes a falhas, a arquitetura como um todo torna-se mais robusta, capaz de atender a uma alta carga de requisições, contornando problemas de funcionamento e dando retorno aos usuários em tempo satisfatório. Baseado nesse comportamento, pode-se afirmar que este seletor pode ser muito útil quando considerados fluxos de composição de serviço, em que as transações tem que ser completadas para o sucesso, e a escolha dos componentes mais aptos é de grande importância. 


\subsection{Contribuições}

Nesta dissertação de mestrado foram avaliadas as necessidades de uso de mecanismos tolerantes a falhas em arquiteturas orientadas a serviços. O alcance de SOA em diversas áreas do conhecimento e sua consequente utilização em ambientes de missão crítica, geraram a necessidade de mecanismos que garantam a completude das requisições e a disponibilidade do atendimento.

No contexto da WSARCH, foi apresentada uma evolução do seletor padrão da arquitetura, a qual foi denominada Risk Selector. Este novo seletor é capaz de avaliar a reputação dos provedores de serviço, com o objetivo de evitar escolher aqueles com histórico recente de falhas, por considerar que os mesmos possam estar intermitentes. Por meio de uma classificação criada em tempo real, ele permite a seleção de módulos mais estáveis, reduzindo as probabilidades de falhas.

Como ferramenta de tolerância a falhas foi adicionada à arquitetura o Intelligent Selector, com o objetivo de ser uma alternativa ao repositório UDDI. Em caso de falha nesse último, o Intelligent Selector faz uma mineração dos dados armazenados das requisições anteriores, e informa ao Broker quais os provedores mais aptos a atender aos pedidos dos usuários. Para evitar a sobrecarga de provedores, caso a mineração de dados seja feita em uma base sem atualização, é utilizado o Round Robin Selector, o qual faz a rotação dos 
melhores provedores, dentre os que foram utilizados anteriormente, mantendo o nível de atendimento.

Os resultados experimentais mostram que o Risk Selector foi capaz de manter o nível do atendimento aos clientes, optando por provedores mais adequados e com menor histórico de problemas. O tempo médio desse seletor, em comparação com o Default Selector foi levemente mais lento, porém deve-se salientar que esse último apresenta o desempenho diminuído quando na presença de falhas.

O Intelligent Selector foi uma alternativa muito interessante ao UDDI, sendo capaz de manter o atendimento apesar do repositório estar fora de funcionamento. Por realizar a mineração dos dados em background, ele possui a localização dos melhores provedores já calculada quando solicitado pelo Broker, resultando em bons tempos de resposta. O Round Robin Selector cumpriu o seu propósito, atuando bem nos casos em que foi acionado.

Por fim, a partir das avaliações realizadas, conclui-se que a adição de mecanismos tolerantes a falhas à WSARCH foi vantajosa, uma vez que o sistema continua em funcionamento em caso de problemas, e não foi constatado overhead exagerado nos tempos de atendimento, o que torna a arquitetura mais apta a realizar o atendimento com qualidade.

\subsection{Trabalhos Futuros}

Para os trabalhos futuros deverão ser estendidos os mecanismos de tolerância a falhas para os demais componentes da WSARCH, introduzindo políticas de replicação de dados e de serviços. A própria interação entre os seletores básicos e os módulos reservas deverá ser melhorada, de forma a não serem perdidas as requisições em tráfego no momento da queda do UDDI. Para isso serão utilizados sistemas de registro dessas requisições.

O sistema de avaliação da qualidade de serviços deverá ser atualizado para que os módulos informem ao Broker de maneira dinâmica, mais precisa e eficiente quais seus valores de atendimento. Dessa forma, será possível trabalhar com valores mais precisos e direcionar corretamente as requisições.

Um segundo Broker já está pronto para ser utilizado, o qual deverá melhorar o balanceamento de carga e o tempo de resposta do sistema. Nesse contexto, técnicas de reputação serão introduzidas, assim como as falhas nesse componente serão testadas e avaliadas.

Algumas modificações na forma de atualização do LogServer serão feitas no intuito de evitar que os dados se tornem viciados. Diferentes cargas de trabalho e estratégias para popular a base serão avaliadas. 
Os mecanismos introduzidos deverão ser testados também em fluxos de composição de serviços, onde serão avaliadas as vantagens trazidas por eles, bem como possíveis limitações dessas estratégias.

Outro ponto a ser estudado são os tipos de falhas e a frequência das mesmas. A diversidade de problemas que uma arquitetura SOA pode enfrentar é grande, o que abre muitas possibilidades de estudo. E a frequência com que essas falhas ocorrem pode variar muito, permitindo muitas variações nos experimentos. Assim, falhas exploradas e documentadas na literatura serão integradas à WSARCH para estudo do comportamento do sistema. Serão também adicionados contadores que registrem a quantidade de falhas inseridas no sistema durante o experimento, para permitir o cálculo do efeito dessa quantidade nas variáveis de resposta consideradas. 


\section{Referências Bibliográficas}

Adami, L. J.; Estrella, J. C. A data analyzer module for logs of service oriented architeture. In: ERAD-SP - Artigos, 2012.

Aghaei, S.; Khayyambashi, M.; NematBakhsh, M.-a. A fault tolerant architecture for web services. In: Innovations in Information Technology (IIT), 2011 International Conference on, 2011, p. 53-56.

Aha, D.; Kibler, D. Instance-based learning algorithms. Machine Learning, v. 6, p. 37-66, 1991.

Alnemr, R.; Meinel, C. Reputation objects for interoperable reputation exchange : Implementation and design decisions. International Conference on Colaborative Computing, p. $672-680,2012$.

Ayday, E.; Fekri, F. Iterative trust and reputation management using belief propagation. IEEE Transactions on Dependable and Secure Computing, v. 9, n. 3, p. 375-386, 2012.

Bessayah, F.; Cavalli, A.; Martins, E. A formal approach for specification and verification of fault injection process. In: Proceedings of the 2nd International Conference on Interaction Sciences: Information Technology, Culture and Human, New York, NY, USA: ACM, 2009, p. 883-890.

Bjorkqvist, M.; Chen, L.; Binder, W. Load-balancing dynamic service binding in composition execution engines. In: Services Computing Conference (APSCC), 2010 IEEE Asia-Pacific, 2010, p. 67-74.

Brooks, C. A. An introduction to web services. 2002. 
Chan, P.; Lyu, M.; Malek, M. Reliableweb services: Methodology, experiment and modeling. In: Web Services, 200\%. ICWS 200\%. IEEE International Conference on, 2007, p. 679-686.

Chaskar, H.; Madhow, U. Fair scheduling with tunable latency: a round robin approach. In: Global Telecommunications Conference, 1999. GLOBECOM '99, 1999, p. 1328-1333 vol.2.

Chen, N. J.; Lin, P. An adaptive fault-tolerant mechanism for web services based on context awareness. In: Computer Science Education, 2009. ICCSE '09. 4th International Conference on, 2009, p. 898-903.

Cline, K. The great vswitch debate. 2009.

Disponível em http://kensvirtualreality.wordpress.com/2009/03/29/ the-great-vswitch-debate-part-1/

Echtle, K.; Masum, A. A fundamental failure model for fault-tolerant protocols. In: Computer Performance and Dependability Symposium, 2000. IPDS 2000. Proceedings. IEEE International, 2000, p. $69-78$.

Ehnebuske, D. R.; Riegen, C. V. D. Uddi version 2.0 data structure reference. 2001. Disponível em http://uddi.org

Erradi, A.; Maheshwari, P.; Tosic, V. Recovery policies for enhancing web services reliability. In: Web Services, 2006. ICWS '06. International Conference on, 2006, p. 189-196.

Estrella, J. C. Wsarch: Uma arquitetura para a provisão de web services com qualidade de serviço. 2010.

Estrella, J. C.; Santana, R. H. C.; Santana, M. J. Wsarch: An architecture for web services provisioning with qos support - performance challenges. Saarbrucken : VDM Verlag Dr. Muller GmbH \& Co, http://www.amazon.com/WSARCH-Architecture-ProvisioningPerformance-Challenges/dp/3639378245, 2011.

Estrella, J. C.; Toyohara, R. K. T.; Kuehne, B. T.; Tavares, T. C.; Bruschi, S. M.; Santana, R. H. C.; J., M.; Santana A performance evaluation for a qos-aware service oriented architecture. IEEE International Conference on Web services., 2010. 
Faci, N.; Abdeldjelil, H.; Maamar, Z.; Benslimane, D. Using diversity to design and deploy fault tolerant web services. In: Enabling Technologies: Infrastructure for Collaborative Enterprises (WETICE), 2011 20th IEEE International Workshops on, 2011, p. $73-78$.

Fan, G.; Yu, H.; Chen, L.; Liu, D. A method for modeling and analyzing fault-tolerant service composition. In: Software Engineering Conference, 2009. APSEC '09. Asia-Pacific, 2009, p. 507-514.

Farkas, P. Charaf, H. Web services planning concepts. 2003, p. 1-6.

Felber, P.; Xavier, D.; Ag, U. B. S. Failure detectors as first class objects. 1999.

Gomaa, H.; Hashimoto, K. Dynamic software adaptation for service-oriented product lines. In: Proceedings of the 15th International Software Product Line Conference, New York, NY, USA: ACM, 2011, p. 35:1-35:8.

Disponível em http://doi.acm.org/10.1145/2019136.2019176

Gudgin, M.; Hadley, M.; Moreau, J. J.; Nielsen, H. Soap version 1.2 part 1. 2001.

Disponível em http://www.w3.org/TR/2001/WD-soap12-part2-20011217

Hall, S.; Kotonya, G. An adaptable fault-tolerance for soa using a peer-to-peer framework. In: e-Business Engineering, 200\%. ICEBE 200\%. IEEE International Conference on, 2007, p. 520-527.

Haykin; Simon Neural networks: A comprehensive foundation. Prentice Hall, 1998.

Jalote, P. Fault tolerance in distributed systems. PTR Prentice Hall (Englewood Cliffs, N.J.), 1994.

Jhawar, R.; Piuri, V. Fault Tolerance Management in IaaS Clouds. 2012.

Jiang, D.; Xue, J.; Xie, W. A Reputation Model based on Hierarchical Bayesian Estimation for Web Services. International Conference on Computer Supported Cooperative Work in Design, 2012.

John, G. H.; Langley, P. Estimating continuous distributions in bayesian classifiers. In: Eleventh Conference on Uncertainty in Artificial Intelligence, 1995, p. 338-345.

Kamienski, C. A.; Sadok, D. Qualidade de serviço na internet. Quality, p. 1-40, 2000.

Kuehne, B. T.; Estrella, J. C.; Peixoto, M. L. M.; Tavares, T. C.; Santana, R. H. C.; Santana, M. J. Dynamic web service composition middleware: A new approach for 


\section{REFERÊNCIAS BIBLIOGRÁFICAS}

qos guarantees. In = IEEE International Symposium on Network Computing and Applications, Cambridge, MA - USA. The 9th IEEE International Symposium on Network Computing and Applications (IEEE NCA10), p. 174-177., 2010.

Lakhal, N.; Kobayashi, T.; Yokota, H. A failure-aware model for estimating and analyzing the efficiency of web services compositions. In: Dependable Computing, 2005. Proceedings. 11th Pacific Rim International Symposium on, 2005, p. 8 pp.--.

Li, M.; Huai, J.; Guo, H. An adaptive web services selection method based on the qos prediction mechanism. In: Web Intelligence and Intelligent Agent Technologies, 2009. WI-IAT '09. IEEE/WIC/ACM International Joint Conferences on, 2009, p. 395 -402.

Liu, L.; Wu, Z.; Ma, Z.; Wei, W. A fault-tolerant framework for web services. In: Software Engineering, 2009. WCSE '09. WRI World Congress on, 2009, p. 138-142.

Liu, X.; Zhu, L. Design of soa based web service systems using qfd for satisfaction of quality of service requirements. In: Web Services, 2009. ICWS 2009. IEEE International Conference on, 2009, p. 567-574.

Livetime Livetime software. 2009.

Disponível em http://livetime.com

Macedo, R. A.; Gorender, S. Perfect failure detection in the partitioned synchronous distributed system model. In: Availability, Reliability and Security, 2009. ARES '09. International Conference on, 2009, p. 273-280.

Manfredini, R. A. Condução de Experimentos de Injeção de Falhas em Banco de Dados Distribuídos. 2001.

Mansour, H.; Dillon, T. Dependability and rollback recovery for composite web services. Services Computing, IEEE Transactions on, v. 4, n. 4, p. 328-339, 2011.

Martins, J.; Santana, H. Qualidade de serviço (qos) em redes ip: Princípios básicos, parâmetros e mecanismos. 1999.

Massie, M.; Chun, B.; Culler, D. The ganglia distributed monitoring system: design, implementation, and experience. Parallel Computing, v. 30, n. 7, p. 817-840, 2004.

May, N. Dynamic service quality and resource negotiation for high-availability service-oriented systems. Proceedings of the 32nd ACM/IEEE International Conference on Software Engineering - ICSE '10, v. 2, p. 327, 2010.

Disponível em http://portal . acm.org/citation. cfm?doid=1810295.1810376 
Misailovic, S.; Sidiroglou, S.; Hoffmann, H.; Rinard, M. Quality of service profiling. In: Software Engineering, 2010 ACM/IEEE 32nd International Conference on, 2010, p. 25-34.

Mohamed, N.; Al-Jaroodi, J. A collaborative fault-tolerant transfer protocol for replicated data in the cloud. In: Collaboration Technologies and Systems (CTS), 2012 International Conference on, 2012, p. $203-210$.

Moon, J.; Kim, R.; Kim, Y.; Lee, D.; Cho, H. Recovery policies on a web services-based business process for minimizing human intervention. In: Advanced Communication Technology, 2006. ICACT 2006. The 8th International Conference, 2006, p. 2 pp.-1746.

Mougouei, D.; Rahman, W. N. W. A.; Moein Almasi, M. Evaluating fault tolerance in security requirements of web services. Proceedings Title: 2012 International Conference on Cyber Security, Cyber Warfare and Digital Forensic (CyberSec), p. 111-116, 2012.

Disponível em http://ieeexplore.ieee.org/lpdocs/epic03/wrapper.htm? arnumber $=6246125$

Nabuco, O.; Halima, R. B.; Drira, K.; Fugini, M. G.; Modafferi, S.; Mussi, E. Model-based qos-enabled self-healing web services. 2008 19th International Conference on Database and Expert Systems Applications, p. 711-715, 2008.

Disponível em http://ieeexplore.ieee.org/lpdocs/epic03/wrapper.htm? arnumber $=4624802$

Nakamuta, A.; Toyohara, R. K. T.; Souza, V. D. O. Detectores de falhas genéricos para sistemas distribuídos. 2007.

Ningfang Song, Jiaomei Qin, X. P.; Deng, V. Fault injection methodology and tools. Proceedings of 2011 International Conference on Electronics and Optoelectronics, p. V1-47-V1-50, 2011.

Disponível em http://ieeexplore.ieee.org/lpdocs/epic03/wrapper.htm? arnumber $=6013043$

Papazoglou, M. Service-oriented computing: concepts, characteristics and directions. In: Web Information Systems Engineering, 2003. WISE 2003. Proceedings of the Fourth International Conference on, 2003, p. 3-12.

Ping, W. The fault-tolerant design and fault injection test for embedded software. PACCS Second Pacific-Asia Conference on Circuits, Communications and System, p. 307-310, 2010. 
Pullum, L. Software fault tolerance techniques and implementation. Artech House Publishers, 2001.

Sargeant, A.; Townend, P.; Xu, J.; Djemame, K. Evaluating the dependability of dynamic binding in web services. In: High-Assurance Systems Engineering (HASE), 2012 IEEE 14th International Symposium on, 2012, p. 139-146.

Somasundaram, T.; Prabha, V.; Arumugam, M. Scalability issues in cloud computing. In: Advanced Computing (ICoAC), 2012 Fourth International Conference on, 2012, p. $1-5$.

Souza, J. L. R.; Siqueira, F. Providing dependability for web services. Architecture, p. 2207-2211, 2008.

Tavares, T. C.; Santana, R. H. C.; Estrella, J. C.; Santana, M. J. Caracterização dos dados trocados entre serviços web e provedores de serviço. In: Brazilian Symposium on Multimedia and the Web, 2008, Vilha Velha - ES. Proceedings of the 14th Brazilian Symposium on Multimedia and the Web., 2008.

Tchana, A.; Broto, L.; Hagimont, D. Approaches to cloud computing fault tolerance. 2012 International Conference on Computer, Information and Telecommunication Systems (CITS), p. 1-6, 2012.

Disponível em http://ieeexplore.ieee.org/lpdocs/epic03/wrapper.htm? arnumber $=6220386$

Thomas, J.; Thomas, M.; Ghinea, G. Modeling of web services flow. In: E-Commerce, 2003. CEC 2003. IEEE International Conference on, 2003, p. 391-398.

Touloupis, E.; Flint, J. A.; Chouliaras, V. A.; Ward, D. D. Study of the effects of seu-induced faults on a pipeline protected microprocessor. IEEE Transactions on Computers, v. 56, n. 12, p. 1585-1596, 2007.

W3C World wide web consortium. 2011.

Disponível em http://www.w3.org/

Yiyan, F.; Xiaoyong, M. Execution analysis of failure recovery for reliable web services transaction. 2010.

Yue, Z.; Wang, J. Calculation method of P2P reputation based on recommendation. 2012 Third International Conference on Intelligent Control and Information Processing, p. 245-247, 2012.

Disponível em http://ieeexplore.ieee.org/lpdocs/epic03/wrapper.htm? arnumber $=6391536$ 
Zhao, W. A lightweight fault tolerance framework for web services. In: Web Intelligence, IEEE/WIC/ACM International Conference on, 2007, p. 542-548.

Zheng, Z.; Lyu, M. R. A qos-aware middleware for fault tolerant web services. 2008 19th International Symposium on Software Reliability Engineering (ISSRE), p. 97-106, 2008.

Disponível em http://ieeexplore.ieee.org/lpdocs/epic03/wrapper.htm? arnumber $=4700314$

Zhou, W.; Wang, L. A byzantine fault tolerant protocol for composite web services. In: Computational Intelligence and Software Engineering (CiSE), 2010 International Conference on, 2010, p. 1-4.

Zhu, X.; Wang, B.; Wang, S. Reputation-driven web service selection based on collaboration network. In: Web Services (ICWS), 2011 IEEE International Conference on, 2011, p. $704-705$.

Zibi, Z.; Lyu, M. A qos-aware fault tolerant middleware for dependable service composition. 2009 .

Zuquim, D.; Garcia, G. Incorporação de qualidade de serviço no modelo de serviços web. 2007. 